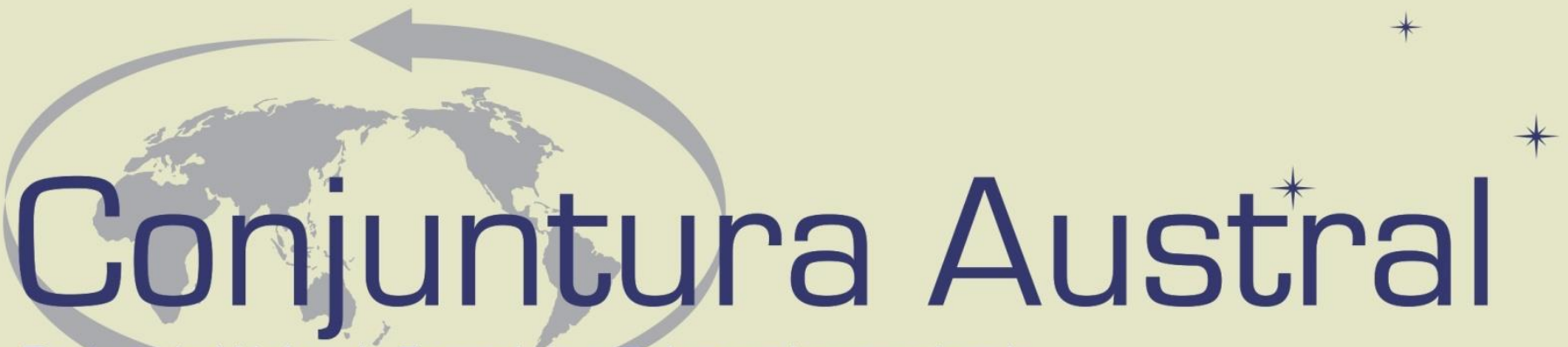

Revista do Núcleo de Estratégia e Relações Internacionais

Programa de Pós-Graduação em Estudos Estratégicos Internacionais/UFRGS

\title{
ALGUNAS CLA VES PARA EXPLICAR LA POLÍTICA EXTERIOR ARGENTINA POSTERIOR A LA CRISIS DE 2001
}

LA BILATERALIDAD URUGUAY-BRASIL EN LAS PRESIDENCIAS DE JOSÉ MUJICA Y DILMA ROUSSEFF: APUNTES DESDE LA POLÍTICA EXTERIOR

URUGUAYA

O PAPEL DAS CIDADES-GÊMEAS DE FRONTEIRA NA INTEGRAÇÃO REGIONAL SUL-AMERICANA

CHILE E BOLIVIA E O CONFLITO PARA ALCANÇAR O OCEANO: GUERRA DO PACIFICO E MUDANÇAS NAS RELAÇÕES ENTRE OS DOIS PAÍSES

O PAPEL DA COORDENÇÃO DE APERFEIÇOAMENTO DE PESSOAL DE NÍVEL SUPERIOR (CAPES) NA COOPERAÇÃO BRASILEIRA PARA O DESENVOLVIMENTO INTERNACIONAL (COBRADI)

OS (DES)ENCONTROS NAS RELAÇÕES ENTRE O BRASIL E O MÉXICO DE 2003 À 2013: UM BALANÇO PRELIMINAR

RESENHA DO LIVRO "TRANSFORMING MILITARY POWER SINCE THE COLD WAR: BRITAIN, FRANCE, AND THE UNITED STATES, 1991-2012"
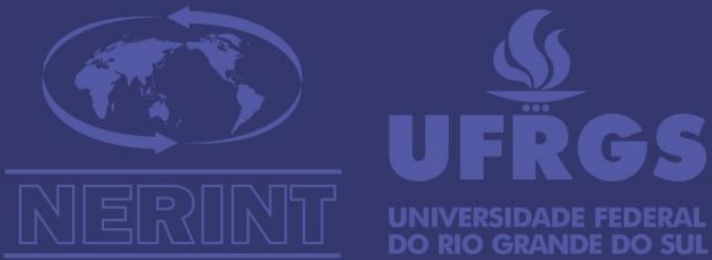


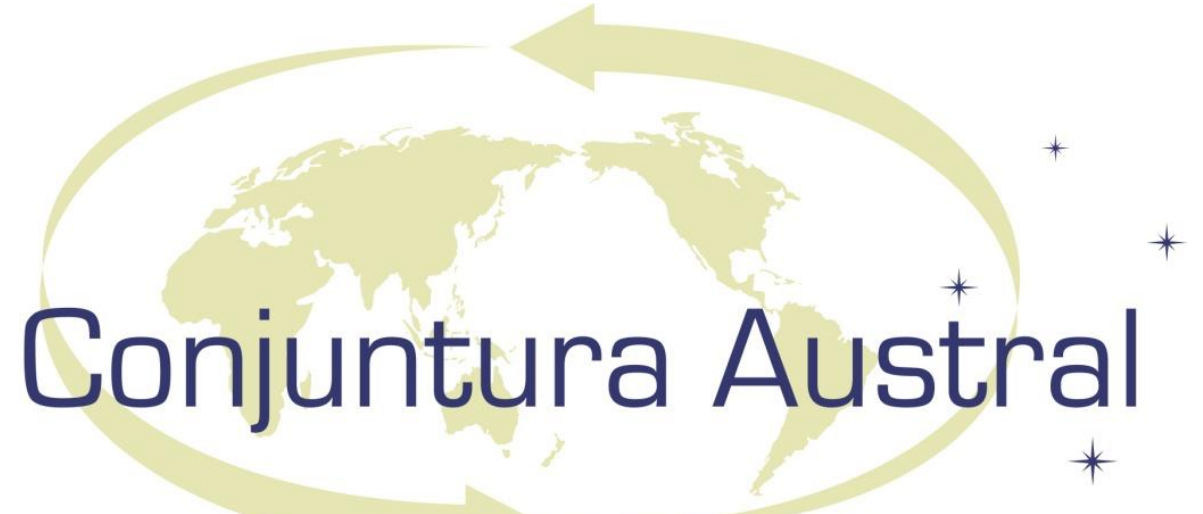




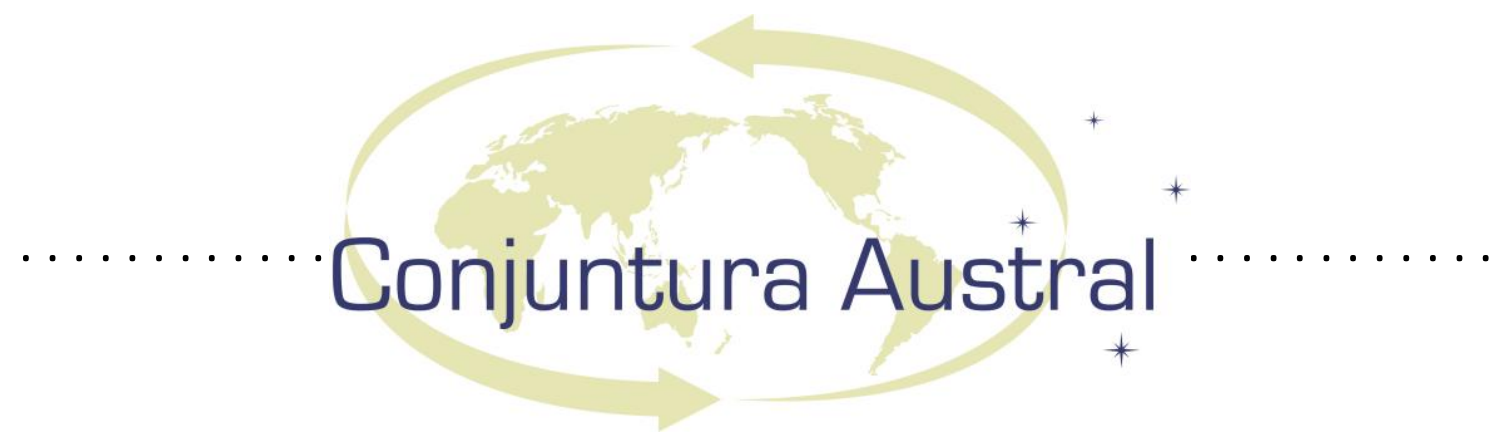

\section{FOCO E ESCOPO}

CONJUNTURA AUSTRAL é uma publicação Bimestral, em formato digital, do Núcleo de Estratégia e Relações Internacionais da UFRGS (NERINT), que publica trabalhos de relações internacionais com foco nos países que integram o Hemisfério Sul. Nesse sentido, tem como área geográfica de abrangência as relações internacionais da África, Ásia e América Latina, na perspectiva dos grandes temas da agenda de segurança, diplomacia e desenvolvimento.

A revista publica contribuições na forma de análises de conjuntura, artigos científicos e resenhas bibliográficas, cuja temática se situe na grande área de Estratégia e Relações Internacionais, com especial interesse nos temas relacionados aos países do hemisfério Sul político e suas estratégias de segurança e desenvolvimento.

Missão

Promover o debate e a reflexão sobre a conjuntura internacional, com ênfase nos processos de interesse imediato dos países em desenvolvimento.

\section{FOCUS AND SCOPE}

CONJUNTURA AUSTRAL is a bimonthly publication of NERINT (Center for International Relations and Strategic Studies), in digital format, that publishes international relations papers focusing on the countries that integrate the Southern Hemisphere. In that sense, its geographic coverage area comprises Africa, Asia and Latin America, in the perspective of great subjects of the security, diplomacy and development agendas.

The journal publishes contributions in the form of conjuncture analyses, articles and book reviews, about themes that lie in the vast area of Strategy and International Relations, with special interest in issues related to countries situated in the political South and their security and development strategies.

\section{Mission}

Promoting consideration and academic debate on the international conjuncture, with emphasis on processes of immediate interest in the developing countries.

Editor

André Luiz Reis da Silva (Universidade Federal do Rio Grande do Sul, Brasil)

Editor Assistente/ Assitant Editor

Guilherme Ziebell de Oliveira (Universidade Federal do Rio Grande do Sul, Brasil)

Comitê Editorial/ Editorial Committee

André Luiz Reis da Silva (Universidade Federal do Rio Grande do Sul, Brasil) - Editor

André Moreira Cunha (Universidade Federal do Rio Grande do Sul, Brasil) - Membro do Conselho

Eduardo Ernesto Filippi (Universidade Federal do Rio Grande do Sul, Brasil) - Membro do Conselho

José Miguel Quedi Martins (Universidade Federal do Rio Grande do Sul, Brasil) - Membro do Conselho

Luiz Augusto Faria (Universidade Federal do Rio Grande do Sul, Brasil) - Membro do Conselho

Marco Aurélio Chaves Cepik (Universidade Federal do Rio Grande do Sul, Brasil) - Membro do Conselho

Conselho Editorial/ Editorial Board

Adam Habib (University of Johannesburg, África do Sul)

Amado Luiz Cervo (Universidade de Brasília, Brasil)

Antonio Jorge Ramalho (Universidade de Brasília, Brasil)

Bertrand Badie (Sciences Po, França)

Boris F. Martynov (Academia de Ciências da Rússia/ Russian Academy of Sciences)

Carlos Arturi (Universidade Federal do Rio Grande do Sul, Brasil)

Flávio Sombra Saraiva (Universidade de Brasília, Brasil)

Gladys Lechini (Universidad Nacional de Rosário, Argentina)

Immanuel Wallerstein (Yale University, Estados Unidos)

Marcos Costa Lima (Universidade Federal de Pernambuco, Brasil)

Mehdi Parvizi Amineh (University of Amsterdam, Holanda)

Paulo Gilberto Fagundes Vizentini (Universidade Federal do Rio Grande do Sul, Brasil)

Samuel Pinheiro Guimarães (Alto Representante-Geral do Mercosul/ High General Representative of the Mercosur)

Shiguenoli Miyamoto (Universidade Estadual de Campinas, Brasil)

Willians Gonçalves (Universidade Federal Fluminense / Universidade do Estado do Rio de Janeiro, Brasil)

Sean W. Burges (Australian National Centre for Latin American Studies)

Equipe de Edição / Edition assistant

Thiago Silveira da Silva (Universidade Federal do Rio Grande do Sul, Brasil)

\section{CONTATO / Contact:}

Universidade Federal do Rio Grande do Sul - Faculdade de Ciências Econômicas

Programa de Pós-Graduação em Estudos Estratégicos Internacionais

Av. João Pessoa, 52 sala 33A - $3^{\circ}$ andar - CEP 90040-000 - Centro - Porto Alegre/RS - Brasil

Tel: +55 $513308-3963$ ou +55 $513308-7150$ Fax: +55 $513308-3963$

e-mails: reisdasilva@hotmail.com, nerint@ufrgs.br ou thiagosilveira1810@gmail.com 


\section{Conjuntura Austral …........}

Volume 6, Número 27 - 28 (Dez.2014 - Mar. 2015)

\section{ANÁLISE DE CONJUNTURA}

Algunas claves para explicar la política exterior argentina posterior a la crisis de 2001

Alejandro Simonoff

\section{ARTIGOS}

La bilateralidad Uruguay-Brasil en las presidencias de José Mujica y Dilma Rousseff: apuntes desde la política exterior uruguaya.

Rafael Alvariza Allende

O papel das cidades-gêmeas de fronteira na integração regional sul-americana.

Fábio Régio Bento

Chile e Bolívia e o conflito para alcançar o oceano: guerra do pacifico e mudanças nas relações entre os dois países

Eduardo Ernesto Filippi, Carla Carpim Charão

O papel da coordenção de aperfeiçoamento de pessoal de nível superior (CAPES) na cooperação brasileira para o desenvolvimento internacional (COBRADI).

Thais Mere Marques Aveiro

Os (des)encontros nas relações entre o Brasil e o México de 2003 à 2013: um balanço preliminar.

Tomaz Espósito Neto, Nicole Figueiredo

\section{LEITURA}

Resenha do livro "Transforming Military Power Since the Cold War: Britain, France, and the United States, 1991-2012", 


\title{
Conjuntura Austral
}

\section{ALGUNAS CLAVES PARA EXPLICAR LA POLÍTICA EXTERIOR ARGENTINA POSTERIOR A LA CRISIS DE 2001}

\section{Some clues to explain the Argentina's foreign policy post 2001 crisis}

\author{
Alejandro Simonoff ${ }^{1}$
}

\section{Introdución}

La llegada del mundo bipolar moldeó los diseños de inserción internacional del país entre la opción de alinearse con la potencia del bloque, Estados Unidos, o reclamar su pertenencia al bloque occidental pero priorizando a la Región - fundamentalmente con un acercamiento a Brasil. Estas opciones constituyeron el marco donde la oposición y la cooperación, se alternaban, causando cierto erratismo.

Esta situación comenzó a cambiar cuando desde 1983 se delineó una estructura triangular que involucró a la Argentina con estos dos países ${ }^{2}$. Pero las pretensiones latinoamericanistas impulsadas por Raúl Alfonsín encontraron ciertos límites, como lo señalamos oportunamente: "Existieron fuertes condicionantes, como el endeudamiento que generó la necesidad de acercarse a Washington para conseguir apoyo financiero, ya sea unilateral o de los organismos multilaterales que controla, lo que ocasionó una tensión en la búsqueda de un mayor marco autonómico" (SIMONOFF, 2010: 329).

En los años noventa, con las autodenominadas relaciones "carnales" con Estados Unidos, inspiradas en el realismo periférico escudeano, se buscó el alineamiento con Washington y la correspondencia con la política de convertibilidad inaugurada por la

\footnotetext{
1 Doctor en Relaciones Internacionales de la Universidad Nacional de La Plata. Profesor de Política Exterior Argentina en los posgrados de la UNLP e Investigador de los Institutos de Relaciones Internacionales y de Ciencias Sociales y Humanas de la UNLP. Email: asimonoff2010@gmail.com

${ }^{2}$ El debate por cuáles deben ser sus prioridades, encierra no solo una cuestión de opciones políticas sino la imagen que su clase dirigente tiene sobre el país.
} 


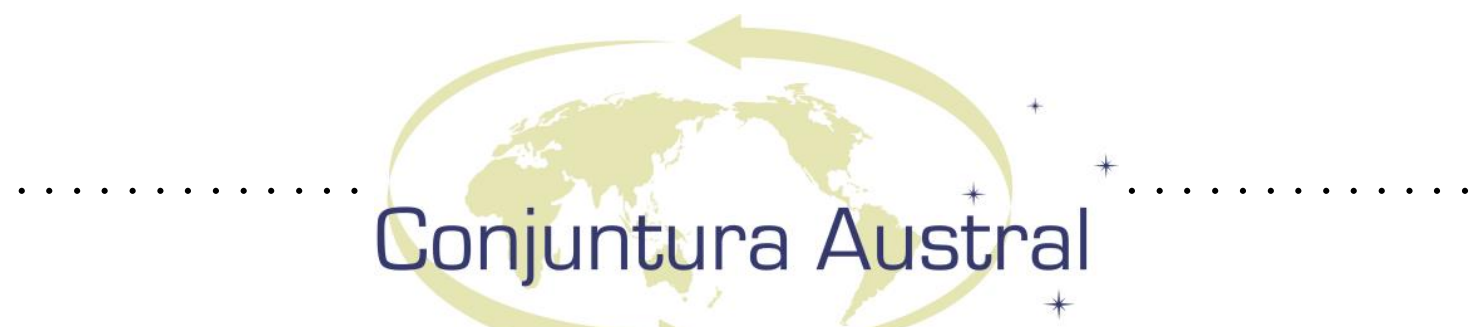

administración de Menem, como lo ha señalado Mario Rapoport (2009)³.

Para este autor, la gestión de la Alianza “... no modificó en lo sustancial la política exterior... aunque pareció orientarse en forma más definida hacia Brasil". Es decir, Rapoport, como otros autores, ubicó a esa administración dentro de una continuidad con la anterior, a pesar que se vislumbraron algunos cambios, como los alejamientos de la estrategia de seducción a los Kelpers, del apoyo al Plan Colombia y la negociación en torno al ALCA (RAPOPORT, 2006: 903).

El colapso de la convertibilidad en diciembre de 2001 tuvo también un impacto en la política exterior de los gobiernos posteriores a la crisis, del mismo modo que su sostenimiento condicionó la estrategia hacia Washington y Brasilia del gobierno de Fernando De la Rúa ${ }^{4}$.

Los cambios de la administración Bush en materia de las Organizaciones Multilaterales de Crédito - donde abandonó el rol de "bombero" del sistema internacional que había tenido en los años de Clinton - resultaron clave para comprender el fin de la convertibilidad en 2001. Pero también existieron ciertos desplazamientos de Brasil que pasó de una estrategia regional en torno al MERCOSUR hacia otra más sudamericana.

Desde el inicio del nuevo milenio, este triángulo ha mostrado tensiones, con respecto a Washington - por el impacto de su agenda de seguridad, tras el 11 de Septiembre - y con Brasilia, debido a su reposicionamiento internacional.

Otro factor inescrutable fue la crisis de 2001 que alteró sensiblemente los márgenes internos de maniobra internacional del Estado, en un escenario más flexible, por lo menos en términos regionales. Así lo entendió Carlos Escudé, quien señaló en los primeros años del nuevo siglo: "La pérdida de la capacidad de sanción por parte de los Estados Unidos y de las instituciones como el FMI es un dato nuevo, que modifica dramáticamente las recetas normativas para los Estados periféricos que sufren la crisis más agudamente" (ESCUDÉ, 2004:19).

\footnotetext{
${ }^{3}$ Pero no fue menos cierto que durante esa administración se creó el MERCOSUR.

${ }^{4}$ La crisis de 2001 profundizó el quiebre del modelo de relación privilegiada con Estados Unidos inaugurada en la década anterior; a los ya señalados por Mario Rapoport se le sumaron las lecturas de Escudé en torno a la llegada del Estado Parasitario (Escude, 2005:117 y ss.) y la flexibilización del realismo periférico (Escude, 2009), y las de Russell \& Tokatliàn con el supuesto reemplazo del modelo de aquiescencia pragmática por el de autonomía relacional (Russell \& Tokatlian, 2002:414-419).
} 


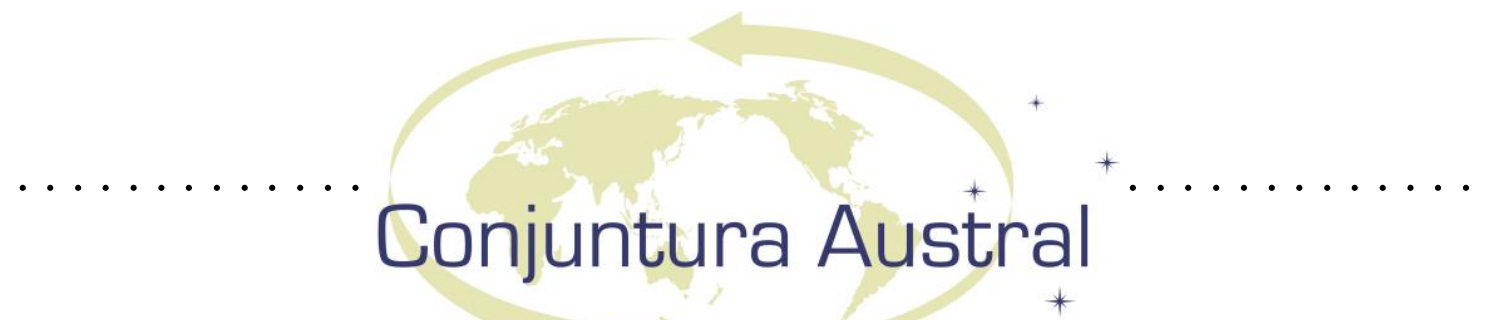

Esta "pérdida de la capacidad de sanción”, sumada a la declaración de cesación de pagos de la deuda externa a fines de diciembre de 2001 y un escenario mundial menos unipolar fueron los elementos que plantearon un nuevo marco para la política exterior argentina.

En función de este cuadro inicial, creemos poder leer la estrategia de inserción seguida por las distintas administraciones de acuerdo a las exigencias externas, tales como la securitización de la agenda internacional y las cuestiones referidas a la deuda externa, y una serie de cuestiones de interés propio, como son la prioridad regional y la inserción económica internacional.

\section{La política exterior Pos Crisis de $2001^{5}$}

Las estrategias adoptadas por los sucesivos gobiernos desde 2001 frente a los desafíos que implicaron las principales cuestiones nacionales e internacionales no podríamos suponer la existencia de una continuidad ante el cambio de modelo económico y de inserción que obedeció a la propia supervivencia del Estado-Nación y la sociedad argentina. ${ }^{6}$

En función de la importancia que para Argentina tienen Brasil y Estados Unidos, se fueron constituyendo ejes como la securitización de la agenda internacional, los vínculos con la región y el MERCOSUR, la negociación de la deuda externa, la reinserción internacional del país y la cuestión Malvinas.

La securitización de la agenda internacional llevó a los gobiernos argentinos en medio de la crisis a evitar compromisos directos con la política de Washington, aspirando a mecanismos de carácter multilateral, como mantener y reforzar las misiones de paz, buscar ciertos linkages con la lucha contra el terrorismo, como el avance judicial sobre ciudadanos iraníes en la causa de los atentados en los años noventa, pero fijando distancia

\footnotetext{
${ }^{5}$ Para un análisis más detallado véase nuestro: Cinco claves explicativas para la política exterior argentina posterior a la crisis de 2001" (2012)

${ }^{6}$ Fue paradójico que mientras la crisis de 2001 pulverizaba las potencialidades autonómicas de la Argentina, un marco favorable para esas políticas permitió desarrollarlas en un alto grado.
} 


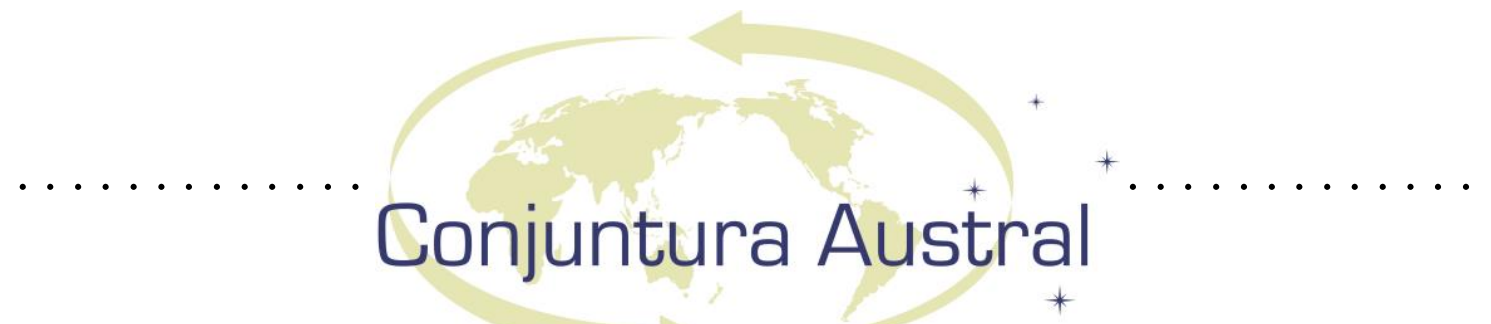

del unipolarismo. ${ }^{7}$

La defensa del gobierno, a partir de 2004, de la llamada pista iraní en la Causa AMIA - sostenida desde los tiempos del Juez Galeano-, incluso fue útil para establecer una vinculación con la estrategia de lucha contra el terrorismo, patrocinada por Washington desde que George Bush hijo era presidente, y a su vez no adherir al unilateralismo con que era llevado adelante. La reciente preocupación por establecer la Verdad, dejó lugar a cierta suspicacia de lo actuado por la Justicia Argentina, relativizando los reclamos realizados en diversos foros internacionales, como la propia Asamblea de Naciones Unidas, y virar hacia la siempre latente e incómoda pista siria, con lo cual se estarían demoliendo los cimientos de una estrategia cooperativa con Washington.

Una muestra de este viraje surge de la denuncia por encubrimiento contra la Presidente y el Canciller, entre otros, por parte del Fiscal de la Unidad Especial para el Atentado de la AMIA, Alberto Nissman y su posterior muerte antes que hiciera su presentación ante una Comisión de la Cámara de Diputados de la Nación. La misma se fundamentó en la existencia de negociaciones paralelas entre dirigentes cercanos al gobierno y de la comunidad iraní local que derivaron en el Memorándum de Entendimiento firmado hace dos años. Este documento internacional, según el denunciante, fue el instrumento para consumar el encubrimiento de los ciudadanos persas que la justicia argentina relaciona con aquel atentado terrorista. ${ }^{8}$

Aunque también hay que reconocer que el tema de vinculación con Washington en referencia al régimen iraní fue mudando hacia la no proliferación, donde Argentina ha sido reconocida por la administración demócrata como un socio importante.

El impacto de las estrategias de Washington produjo una mayor autonomía en

\footnotetext{
${ }^{7}$ Este punto resulta crucial para una política carácter autonomista heterodoxa, ya que por un lado la Argentina no entró en contradicción con un lineamiento estratégico de Washington, sino que lo acompaña estableciendo límites al diferenciar un interés general del propio de la potencia, con ello se estarían danto dos de las tres condiciones de la elaboración puigiana (no enfrentar los lineamientos estratégicos de las grandes potencias y diferenciar cuando están en juego sus propios intereses o los de bloque) (Puig. 1984: I: 68)

${ }^{8}$ No fue la primera vez que un presidente fuera acusado de encubrimiento por este caso, Carlos Menem lo fue hace más de una década, pero por la llamada pista siria.
} 


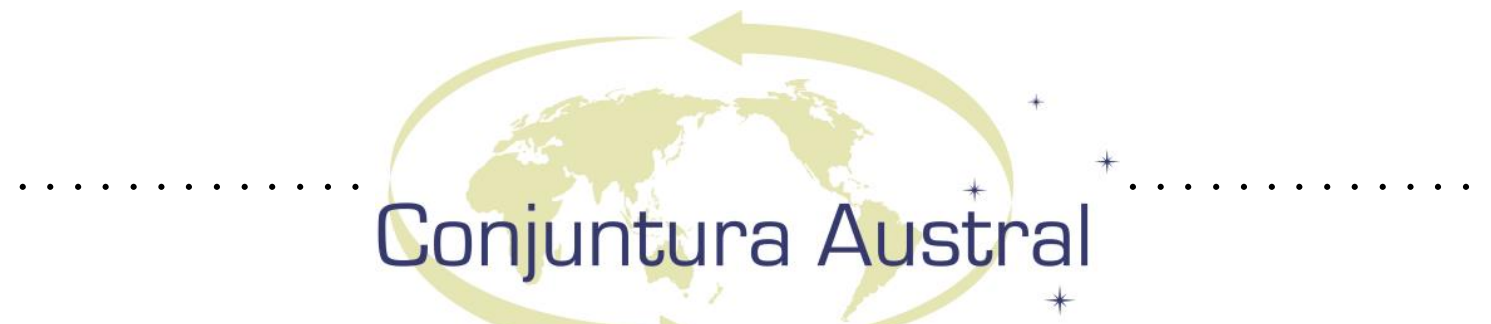

muchos aspectos, pero también trajo aparejadas nuevas responsabilidades, como lo demostró la intervención en la MINUSTAH en Haití y en las diversas crisis que tuvieron lugar principalmente en el Cono Sur.

En este plano y dentro del marco de la regionalización de las Misiones de Paz de Naciones Unidas fueron, tras Afganistán e Irak, llevadas adelante o como formas de compensación en contra de la legalización de la segunda, como podría ser el caso de Chile, o como la forma de aporte indirecto de tropas, como puede ser el de Argentina, lo cierto que fue un ámbito de convergencia y que puede convertirse en una oportunidad para un comportamiento autonómico. ${ }^{9}$

En este esquema debemos sumar a Brasil, y no quedo reducido al envío de tropas sino que también a la articulación de políticas para cumplimentar el tipo de mandato de la operación entre los tres países en el "ABC sobre Haití" fue un dato por demás auspicioso.

Además, la función de estabilizador regional, que había sido desempeñada conjuntamente con Brasilia - como por ejemplo en los casos de las crisis políticas en Bolivia (2003) y Ecuador (2005), tras la creación de la Unión de Naciones Sudamericanas (UNASUR) se desplazaron hacia ésta, en un marco más institucionalizado y también más limitado al espacio sudamericano que al latinoamericano

El marco externo trajo aparejados desafíos que sumados a la crisis de 2001, hicieron que la Argentina profundizase su rol regional. Tras ciertos titubeos iniciales, la estrategia de inserción internacional tuvo un vuelco hacia la opción de Brasil. ${ }^{10}$

El eje de la integración regional tuvo al Mercosur como actor central. ${ }^{11}$ Éste profundizó su perfil como instrumento de inserción económica internacional para sus miembros - missiones comerciales conjuntas, participación en le G22 de la Organización

\footnotetext{
${ }^{9} \mathrm{Si}$ bien los motivos que llevaron a la instrumentación de la intervención pueden ser discutibles, lo cierto fue que los estados participantes hicieron uso de ese espacio para generar instancias de coordinación políticas.

${ }^{10}$ La prioridad regional es una de las condiciones para desarrollar una política autonómica en sentido puigiano. (Puig, 1980: 198)

${ }^{11}$ Para Puig la integración no es de por si autonomizante, sino que dependen del contexto y desde sus escritos de los ochenta sostuvo que la asociación solidarista se hacía ineludible para un proyecto que buscase incrementar los márgenes de maniobra del país. (Puig, 1986)
} 


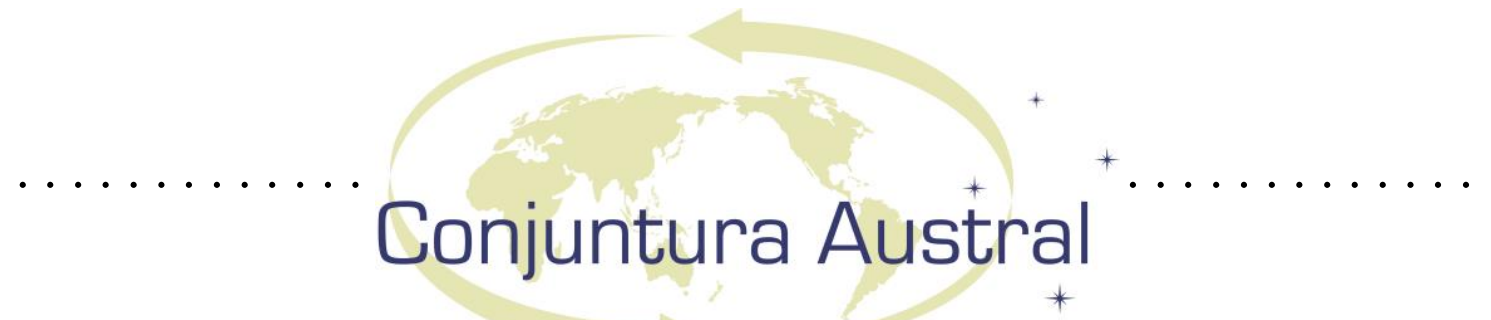

Mundial de Comercio (OMC), rechazo al Área de Libre Comercio de las Américas (ALCA) entre otros.

Pero obviamente que no podemos desatender en el marco de la estrategia de integración las relaciones con Brasil. Éstas pasaron de un buen momento, marcado por la solidaridad de ese país en la crisis de 2001, y reforzado con la llegada de Lula Da Silva al Planalto hasta fines del año 2004, cuando empezaron ciertas tensiones: las discusiones en torno al rediseño del Consejo de Seguridad y el rechazo inicial a la Comunidad Sudamericana de Naciones. Sin embargo, sobre el final de la gestión de Néstor Kirchner estas rispideces aparecían olvidadas.

En el caso específico del primer mandato de Cristina Fernández en relación con Brasil, a diferencia de lo ocurrido en la gestión de Néstor Kirchner, estuvo marcada principalmente por los efectos de la crisis mundial de 2008, y no tanto por las discusiones anteriormente citadas. La acumulación de tensiones en el ámbito comercial y de inversiones con Brasil, podría indicar un indicativo del fin de la "paciencia estratégica" llevada desde los tiempos de Lula Da Silva por nuestro principal socio internacional.

Por otra parte, la ampliación del Mercosur, con la llegada de Venezuela como quinto país miembro, resulta central para la evolución del bloque comercial en un instrumento de inserción económica internacional para los socios.

Esta relación fue menos efectiva con los organismos multilaterales de crédito. Allí, la Argentina dependió primero de la ayuda de Washington desde la segunda fase de la administración de Duhalde en mayo de 2002, (en la consecución de este apoyo resultaron centrales los gobiernos de Ricardo Lagos y Vicente Fox) y a pesar del compromiso a establecer una estrategia conjunta en la Declaración de Copacabana (2004) y luego, entre 2005 y 2007, dependió del aporte venezolano.

Precisamente la estrategia de desendeudamiento ha sido exitosa, ya que virtualmente la Argentina salió del default declarado a fines de 2001. ${ }^{12}$ Se sustentó en dividir a los deudores en dos tipos: los tenedores privados, quienes tras dos fases de reestructuración con una importante reducción en 2005 y 2010, sumaron un $92 \%$ del

\footnotetext{
12 Resultaba imprescindible disminuir el grado de injerencia de los organismos multilaterales de crédito para poder establecer una política autonomista.
} 


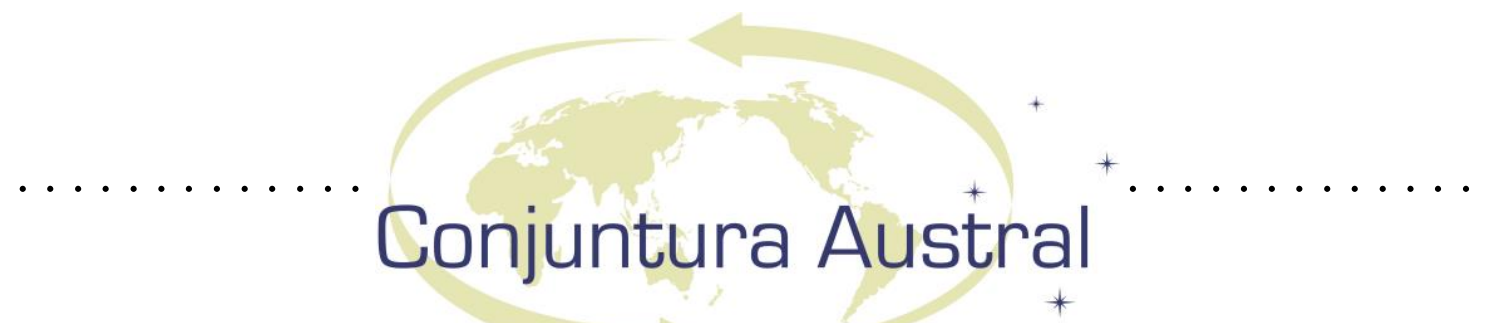

total, y los institucionales, donde a partir de mayo de 2002 se avanzó en una esquema de negociación de costos recíprocos y que en 2005 terminó con la cancelación de las acreencias con el FMI.

La segunda fase del canje de deuda en 2010 resultó un dato positivo para la estrategia de desendeudamiento, pero el frente con el Club de París dilató la esperanza del gobierno de mejorar las notas de las calificadoras de riesgo y el retorno de la inversión.

Por ello, años más tarde, estamos asistiendo al cierre del ciclo de Desendeudamiento iniciado en 2002, ya que tanto como en su monto total, en su participación en el PBI, o su participación per cápita se han incrementado en los años posteriores a la crisis de 2008. ${ }^{13}$ Pero además existe un viraje en aspectos que hasta aquí se criticaban como la intervención del FMI, el pago al Club de París, los pagos al CIADI, entre otros.

Toda estas acciones inmersas en una retórica por parte del Gobierno Nacional, claramente dirigida para el consumo interno, de "no vamos a pagar a los buitres", que determinó un fallo adverso en Nueva York, y donde la aplicación del principio pari passu podría poner en riesgo toda la estrategia de desendeudamiento.

Desde el fin de la convertibilidad, la Argentina se fue alejando del paradigma económico neoliberal por otro más heterodoxo, que algunos lo denominan neodesarrollista. ${ }^{14}$ Gracias a un tipo de cambio competitivo, la utilización de la capacidad ociosa y los precios de los commodities se pudo entrar en una fase de crecimiento económico.

La falta de acceso a los mercados internacionales, producto del default, fue suplida tanto por la recuperación de las instalaciones industriales, como por el doble superávit en materia fiscal y en los intercambios comerciales con el mundo. ${ }^{15}$

\footnotetext{
${ }^{13}$ El Día. Económico, 23 de marzo de 2014: 1.

${ }^{14}$ Este modelo se apartó del promocionado desde los centros de poder mundial, precisamente esta cuestión hace al tercer elemento de la caracterización de la Autonomía Heterodoxa. (Puig, 1984, I: 68).

15 Al momento del inicio de la crisis de 2008, la capacidad ociosa se había agotado que había evitado la necesidad de capitales para el crecimiento y el doble superávit, a medida que el crash global avanzó se fue reduciendo dramáticamente.
} 


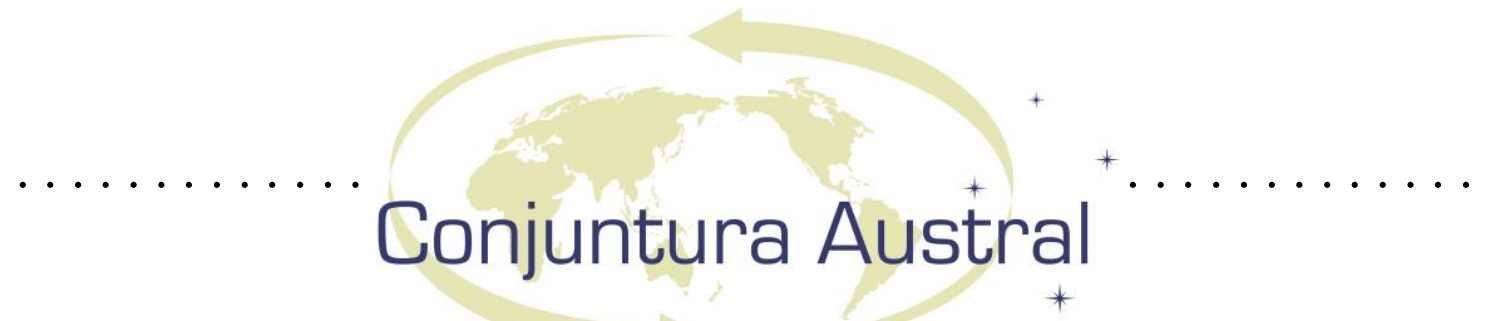

En este último plano se produjo un crecimiento asombroso ya que se pasó de 34.600 millones de dólares en 2002 a 157.000 en 2011, con un saldo ampliamente positivo que supera holgadamente los 10.000 millones anuales. La única retracción de este crecimiento se observó en 2009 y 2010 donde los intercambios cayeron levemente pero ampliando el saldo a unos 16.000 en el año 2009, por ejemplo. ${ }^{16}$

Fue evidente la profundización y diversificación de destinos de nuestras exportaciones. ${ }^{17}$ Las principales áreas de comercialización fueron el MERCOSUR, que osciló entre un 20 y un $25 \%$, mientras que las otras zonas importantes (Sudeste Asiático, Nafta y Unión Europea) rondaron entre un 12 y un 20 \%, nuestras importaciones están menos equilibradas, con una preeminencia del MERCOSUR, aproximadamente un tercio del total, y el creciente aumento de llegada de productos de origen chino. Más recientemente, existe una caída de las exportaciones, mientras que las importaciones se mantuvieron estables gracias a la política de administración del comercio exterior llevadas adelante desde 2010, reduciendo su superávit. ${ }^{18}$

La otra cuestión es la referida a la nacionalización de YPF, al respecto señalamos: que la andanada de sanciones que se anunciaron, tanto desde España y Repsol, como de la oposición a esta política exterior, resultó por lo menos magra, ya que solo se realizó una presentación en el CIADI, algunas medidas unilaterales fueron abandonadas y las multilaterales fueron rechazadas por considerar este asunto un problema bilateral. ${ }^{19}$

Los efectos en la región de la crisis de 2008 fueron más reducidos que en los países desarrollados, pero las esperanzas iniciales del gobierno del alejamiento del paradigma neoliberal parecen esfumarse lentamente. ${ }^{20}$

El gobierno en un principio subestimó sus efectos, debido tanto al doble superávit

\footnotetext{
${ }^{16}$ Para los montos y composición del Comercio Exterior véase: www.indec.gov.ar

${ }^{17}$ La diversificación es otra estrategia importante para el sustento de políticas puigianas. (Puig, 1984, I, 68)

${ }^{18} \mathrm{El}$ otro dato significativo fue que a pesar de los promocionados viajes a marcados no tradicionales, no se registró cambios favorables en ellos.

19 Una cuestión no menor es el paso de la argentinización de las empresas públicas privatizadas a su nacionalización, esto seguro devendrá en cambios en el modelo económico implementado por esta administración.

${ }^{20}$ Las estrategias seguidas en este tema, principalmente en torno del G 20, buscaron la coordinación con otros países emergentes, aunque no siempre se logró. Siendo también una acción recomendada por Puig para la consecución de márgenes de maniobra. (Puig, 1980: 44)
} 


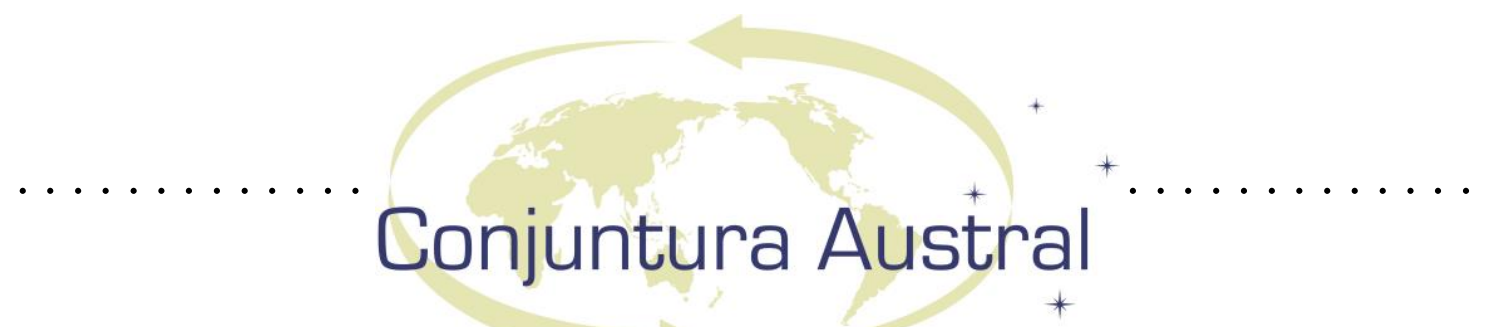

existente presupuestario y del comercio internacional, como a la escasa influencia de las inversiones extranjeras en el crecimiento argentino. Pero su avance demostró que ningún sector del planeta, ni ninguna actividad iban a quedar exentas, aunque sus efectos fueran variables. Si bien fue cierto que la disminución de los flujos de inversiones no afectarían inmediatamente a la economía argentina, existieron otros puntos del modelo de acumulación diversificado que podrían estar en peligro como los superávit gemelos, tanto por la caída del precio de los commodities, que impactaron directamente en las actividades agrícolas, como por la baja de la demanda de vehículos exportables, sobre todo desde Brasil, que redujeron tanto las arcas fiscales como el saldo favorable de la balanza comercial $^{21}$.

El gobierno argentino depositó muchas expectativas en los resultados que las Cumbres del G 20 lograrían en el nuevo diseño internacional. Por ello, la presidente sostuvo en la Asamblea General: "Sinceramente estamos convencidos que es necesario construir una nueva multilateralidad en la que realmente todos estemos en igualdad de condiciones, donde el manual del curso a seguir y de las obligaciones y de los derechos, sea igual para los países ricos que para los países pobres, que también sean iguales los derechos y responsabilidades que tienen las naciones en desarrollo y las que también tienen las que están en vías de desarrollo” (FERNÁNDEZ DE KIRCHNER, 2009).

A pesar de esta declaración de buena fe, además de las cuestiones ya señaladas, en Pittsburgh se evidenciaron otro tipo de tensiones entre las naciones desarrolladas y las emergentes, como las referidas al aumento de la participación de éstos últimos en los Organismos Multilaterales de Crédito, o sobre los efectos que los paquetes de estímulo implementados por los países más ricos tienen sobre los precios de la economía mundial, transfiriendo los efectos de la crisis a otros de menores recursos, ya no por ella misma sino por estas medidas ${ }^{22}$.

\footnotetext{
${ }^{21}$ No debemos obviar cierto desplazamiento entre la percepción inicial de la crisis, cuando la mandataria señaló en el mes de septiembre de 2008 en Nueva York "no necesitamos un Plan B", expresando la creencia de cierta inmunidad a los efectos de ella (Fernández de Kirchner, 2008b), a los planteos que encontramos en su mensaje de apertura del Congreso Nacional en 2009, donde se apreciaron y se señalaron las medidas adoptadas tendientes a dinamizar el mercado interno a partir de la promoción de ventas de diversos productos y la creación de ciertas medidas proteccionistas (Fernández de Kirchner, 2009).

${ }^{22}$ Sobre éste último punto véase Torres (2010).
} 


\section{Conjuntura Austral}

Tras esos sucesos iniciales, la preocupación argentina en ese foro multilateral estuvo concentrada en un punto particular, el tope a los precio de los commodities impulsado inicialmente por Francia, ante lo cual la Presidente argentina manifestó que "el verdadero problema es la falta de regulación de los mercados financieros en el mundo”, (FERNÁNDEZ DE KIRCHNER, 2011)

En la búsqueda de la regulación está la clave según la mandataria, para la proposición del empleo y la salida de la crisis global iniciada en 2008, en donde encontramos una señal de continuidad.

\section{Conclusiones}

De la breve descripción de nuestra política exterior desde el año 2002, observamos que existió una orientación estructural de carácter autonomista en sus principales aspectos, en donde la agenda de seguridad internacional por ejemplo, busca no confrontar con la propuesta de Washington, estableciendo una vinculación temática con los atentados de los años noventa y la Guerra contra el Terrorismo, pero a su vez establece distancia con el carácter unilateral que la administración republicana intentó darle. Pero además trató de establecer ciertas compensaciones a través de la participación en Misiones de Paz, y/o un rol de equilibrador de las tensiones en el ámbito regional. Esta estrategia permitió que Washington oficiara en contrapartida como moderador en las negociaciones del proceso de desendeudamiento hasta el 2005. El tercer elemento fue su clara prioridad regional, en donde el eje con Brasil resultó central.

Pero desde 2008 con la crisis internacional, la llegada de Barak Obama y los primeros tiempos de Cristina Fernández de Kirchner comenzaron a aparecer algunos ajustes y cambios (firma del Memorándum con Irán, el fallo que beneficia a los holdout, las estrategias de administración del comercio exterior, entre otros) que podrían estar ante un cambio de rumbo, que nos lleva a formular una pregunta: ¿estaremos frente a un cambio de estructura de nuestro relacionamiento externo, o sólo ante un nuevo sentido? 


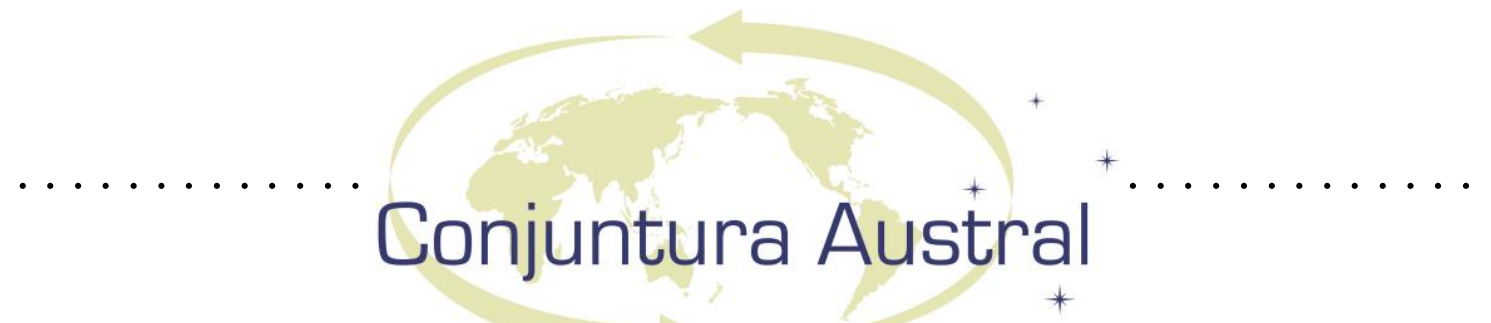

Referências

ESCUDÉ, C., 2004, “A río revuelto. Autonomía periférica en un contexto de desorden global”, en Agenda Internacional. Visión desde el sur, Buenos Aires, Año I, N ${ }^{\circ} 1$.

ESCUDÉ, C., 2005, El Estado Parasitario. Argentina, ciclos de vaciamiento, clase política delictiva y colapso de la política exterior, Buenos Aires, Lumiere.

ESCUDÉ, C., 2007, “Tiempo de autocrítica”, en La Nación, Buenos Aires, 8 de julio.

ESCUDÉ, C., 2009, Realismo periférico: una filosofía de política exterior para estados débiles, Buenos Aires, Universidad del CEMA.

FERNANDEZ DE KIRCHNER, C., 2009, "Palabras de la Presidenta de la nación, Cristina Fernández, en el acto de apertura del $127^{\circ}$ período ordinario de sesiones realizado ante la Asamblea Legislativa en el Honorable Congreso de la Nación". Disponible en: www.presidencia.gov.ar

FERNANDEZ DE KIRCHNER, C. 2011, "Palabras de la Presidenta de la Nación Cristina Fernández, ante empresarios del b20 en Cannes" en: http://www.presidencia.gov.ar/discursos/25494-la-presidenta-ante-empresarios-del-b20en-cannes, consultado 21/11/2011

PUIG, J.C. 1980. Doctrinas Internacionales y Autonomía Latinoamericana, Caracas, Instituto de Altos Estudios de América Latina - Universidad Simón Bolívar.

PUIG, J. C. (Comp.) 1984. América Latina: políticas exteriores comparadas. Buenos Aires, Grupo Editor Latinoamericano.

PUIG, J'.C. 1986. "Integración y autonomía en América Latina en las postrimerías siglo XX”, Integración Latinoamericana, año 11, N 109, 40-62.

RAPPOPORT, M., 2006, Historia económica, política y social de la Argentina (18802003), Buenos Aires, Ariel.

RAPPOPORT, M., 2009, “Argentina: economía y política internacional. Los procesos históricos", en Diplomacia, Estrategia, Política, Brasilia, Nº 10, Proyecto Raúl Prebisch.

RUSSELL, R. \& TOKATLIAN, J. G., 2002, "El lugar del Brasil en la política exterior de la Argentina: La visión del otro", en Desarrollo Económico - Revista De Ciencias Sociales, Buenos Aires, IDES, Vol. 42, Nº 167.

SIMONOFF, A., 2010, La Argentina y el Mundo frente al bicentenario de la Revolución de Mayo. Las relaciones exteriores argentinas desde la secesión de 


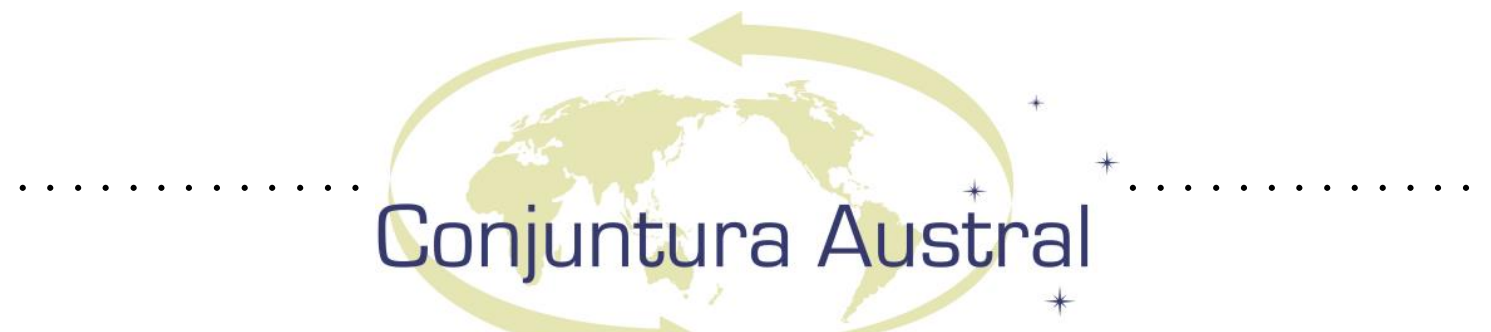

España hasta la actualidad, La Plata, Editorial de la Universidad Nacional de La Plata.

SIMONOFF, A. 2012, "Cinco claves explicativas para la política exterior argentina posterior a la crisis de 2001" en: MORASSO, C. y PEREYRA DOVAL, G. (Comp.). Argentina y Brasil: proyecciones internacionales, Cooperación Sur-Sur e integración._Rosario: UNR Editora, pp. 105-131.

TORRES, J., TORRES, M. A. \& TORRES, M. C., 2010, La política exterior argentina en los tiempos del default, Buenos Aires, Dunken.

\title{
Resumen
}

El presente trabajo se ocupa brevemente del desarrollo de la política exterior argentina durante la primera década y media del siglo XXI. Se analizan las estrategias adoptadas por los sucesivos gobiernos frente a los desafíos que implicaron las principales cuestiones nacionales e internacionales en cada período de gobierno. En función de la importancia que para Argentina tienen Brasil y Estados Unidos, se abordan las interacciones con estos actores, señalando los momentos de acercamiento y alejamiento en ambas relaciones. La securitización de la agenda mundial y la guerra en Irak, los vínculos con la región y el MERCOSUR, la negociación de la deuda externa, la reinserción internacional del país y la crisis financiera internacional, son los ejes que se plantean para comprender los lineamientos de la política externa descripta.

\section{Palavras Claves}

Política Exterior; Argentina; Brasil; Estados Unidos

\begin{abstract}
This paper biefly deals with the development of Argentina's foreign policy during the first decade and a half of the 21 st century. We analyze the strategies adopted by successive administrations when facing the challenges posed by the main national and international issues in each government. Due to the importance of Brazil and the United States to Argentina, interactions with these actors are discussed, highlighting moments of rapprochement and distance in both relations. Securitization of the global agenda and the war in Iraq, the ties with the region and MERCOSUR, the negotiation of the external debt, Argentina's international reintegration and the international financial crisis are the axes we present in order to understand the guidelines of the described foreign policy.
\end{abstract}

Keywords

Foreign Policy; Argentina; Brazil; United States

Artigo recebido em 07 de janeiro de 2014. Aprovado em $1^{\circ}$ de Março de 2014. 


\title{
Conjuntura Austral
}

\section{LA BILATERALIDAD URUGUAY-BRASIL EN LAS PRESIDENCIAS DE JOSÉ MUJICA Y DILMA ROUSSEFF: APUNTES DESDE LA POLÍTICA EXTERIOR URUGUAYA}

\section{The Uruguay-Brasil bilateral chairs in José Mujica and Dilma Rousseff: notes from Uruguay's foreign policy}

\author{
Rafael Alvariza Allende ${ }^{l}$
}

\section{Introdución}

El $1^{\circ}$ de marzo de 2005 , la coalición de partidos políticos progresistas Frente Amplio asumió el Poder Ejecutivo luego de haber ganado las elecciones presidenciales de 2004, acontecimiento electoral y político sin precedentes en Uruguay. Representada bajo el lema "Frente Amplio-Encuentro Progresista-Nueva Mayoría" y con el 50,3\% de los votos de la ciudadanía, la victoria de la izquierda determinó que Tabaré Vázquez asumiera la Presidencia del país con el respaldo de una mayoría parlamentaria integrada por 17 de los 31 Senadores y de 52 de los 99 representantes (o diputados) de la República.

La conformación del primer gobierno de izquierda en Uruguay supuso cambios en su política exterior y un nuevo modelo de inserción internacional. Esta política exterior, fue una de las tantas políticas públicas que experimentaron cambios frente a las tradicionalmente desarrollas por el Partido Colorado y el Partido Nacional, partidos políticos estos que han gobernado la República durante la mayor parte de su historia.

\footnotetext{
${ }^{1}$ Licenciado en Relaciones Internacionales y estudiante de Maestría en Ciencias Humanas Opción Estudios Latinoamericanos por la Universidad de la República (UdelaR, Uruguay). Becario por el Convenio CAPESUdelaR con estancia en el Programa de Postgrado en Ciencias Sociales de la Pontifícia Universidade Católica do Rio Grande do Sul (PUC-RS, Brasil). Investigador colaborador en el Programa de Estudios Internacionales de la Facultad de Ciencias Sociales de la UdelaR y en el Núcleo de Estudos em Relações e Organizações Internacionais de la PUC-RS.
} 


\section{Conjuntura Austral}

La política exterior es un área particular de la acción política gubernamental que abarca tres dimensiones diferenciadas: la político-diplomática, la militar-estratégica y la económica, y que se proyectan al ámbito externo frente a un amplio abanico de actores e instituciones gubernamentales y no gubernamentales, ya sea en el plano bilateral como en el plano multilateral (RUSSELL, 1990:255). De esta manera, podemos concebir la política exterior de un Estado como la proyección de su interés nacional más allá de sus fronteras y limitada por el poder negociador de la contraparte. En este sentido, los análisis de política exterior se ocupan principalmente de aquellos comportamientos dentro de un cierto país que son dirigidos o pueden ser referidos a su medio externo, por lo que la política exterior puede ser vista como una especie de política pública (VAN KLAVEREN, 1992).

Hasta el advenimiento de la "era progresista" la política exterior uruguaya podría caracterizarse como pacifista, juridicista, pronorteamericana, panamericanista, proisraelí, y proclive a la integración regional (PÉREZ ANTÓN, 2010). De esta manera, se afirma también que esta política exterior ha cumplido con los principios rectores de defensa de la soberanía de los Estados; de no intervención; de solución pacífica de controversias; de defensa de los derechos humanos; de rechazo al terrorismo, a la violencia y a la discriminación; de cumplimiento de buena fe de los Tratados; de solidaridad internacional; y de multilateralismo que prioriza el sistema de Naciones Unidas como único medio de restablecer la vigencia del Derecho Internacional, de la paz y del fortalecimiento del sistema internacional (FERRO, et al., 2006).

Sin embargo, con la llegada al poder del Frente Amplio se percibe un cambio en la política exterior del país. En este sentido, un breve análisis del programa de gobierno del Frente Amplio y de las variaciones adaptativas de su contenido de acuerdo al escenario internacional imperante, resulta un insumo para comprender este cambio.

La dimensión internacional en los programas de los partidos políticos de izquierda uruguayos tuvo su origen en el internacionalismo de corte marxista; movimiento político con fuertes conexiones con las izquierdas europeas y presente en la base programática de dos de los partidos fundadores del Frente Amplio: el Partido Comunista y el Partido Socialista uruguayo. A su vez, el antiimperialismo, la Teología de la Liberación, el 


\section{Conjuntura Austral}

estudio del indigenismo y los movimientos agraristas, la subordinación de América Latina y la Revolución Cubana incidieron fuertemente en la identidad política de la izquierda en el país (CLEMENTE, 2004). A partir de la fundación de la coalición de partidos políticos Frente Amplio en 1971, la izquierda uruguaya comienza a incorporar nuevos temas y problemas propios al contexto regional y al sistema internacional. A partir del estudio de diversos documentos elaborados por el Frente Amplio, Isabel Clemente (CLEMENTE, 2004) identifica claras variaciones en el programa político de la coalición y que inciden directamente en la construcción de su política exterior.

A grandes rasgos, podremos subrayar que, para su fundación, está latente la necesidad de la construcción de un régimen nuevo parte de la lucha por la liberalización y desarrollo del Tercer Mundo y de América Latina en particular ("Declaración Constitutiva y Compromiso Político”, 05/02/1971). Luego, durante la transición de la dictadura a la democracia, el Frente Amplio abogaba por una política exterior independiente, por el mantenimiento de relaciones con todos los países, por la reestructura de Cancillería y por un nuevo concepto de integración latinoamericana ("Bases Programáticas”, 1984).

En los años siguientes, el principio de solidaridad activa con todos los pueblos que luchan contra el colonialismo y el rechazo a la Organización de Estados Americanos (OEA), a la Asociación Latinoamericana de Integración (ALADI) y al Fondo Monetario Internacional (FMI) como instrumentos del imperialismo y responsables de la dependencia regional, desaparecen como líneas programáticas. Ya en 1991, el Documento de los “24" presenta a la integración de América Latina - y en especial el Cono Sur - como "una respuesta válida y necesaria para enfrentar los nuevos desafíos del sistema internacional en transición"; también allí, surge la idea de consolidar las relaciones exteriores como una política de Estado.

Una década después, el Frente Amplio incorporó nuevas categorías analíticas para la fundamentación de su política exterior. En este sentido, se destaca la problemática de la globalización - concibiéndola como el resultado de la revolución científica y tecnológica que determina el desarrollo de las comunicaciones y la profundización de asimetrías entre dominados y dominadores - y se examina al neoliberalismo como una 


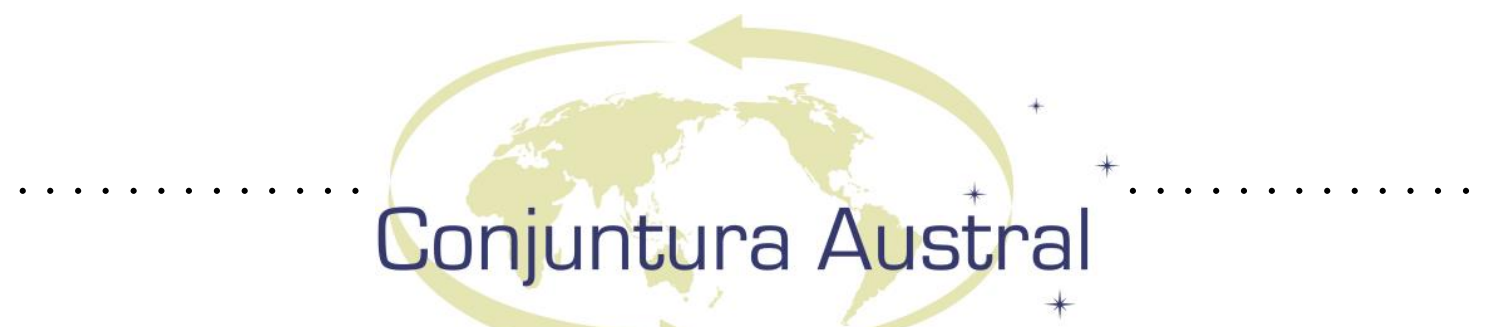

ideología que se presenta como inexorable y negadora de un pensamiento alternativo. Para ello, se proponen tres respuestas, a saber: la articulación de los movimientos progresistas del mundo; la democratización del conocimiento y de los medios de comunicación; y la promoción de la integración regional como estrategia para interactuar con los principales bloques económicos. Aquí, nace la necesidad de reconfigurar el MERCOSUR como instrumento de los movimientos progresistas y de los intereses nacionales ("Pautas para el desarrollo ideológico y la elaboración programática, 2001).

En palabras de Clemente:

Esta revisión de textos revela la persistencia de los temas y supuestos principales en el proyecto de política exterior de la izquierda desde 1971 a 2004 y permite establecer que los elementos de cambio están directamente condicionados por los factores externos que los propios documentos constatan parcialmente, en particular los que tienen que ver con el cambio en el orden internacional: el derrumbe del campo socialista, la desarticulación del Tercer Mundo y del movimiento de No Alineados, la restauración democrática en América Latina, la conversión de la mayoría de los movimientos insurgentes latinoamericanos en partidos políticos, la creación de nuevos espacios para el ejercicio de una política exterior autónoma de América Latina con la iniciativa de Contadora y el Grupo de Río, la emergencia de nuevas economías capitalistas en el Sudeste Asiático y la vertiginosa transformación de China e India en grandes potencias económicas. (CLEMENTE, 2004: 327).

Para las elecciones nacionales de 2004, el Frente Amplio presentó como programa de gobierno una "Recopilación de las propuestas, proyectos e ideas para el gobierno progresista formuladas por el Dr. Tabaré Vázquez en el ciclo 'la transición responsable'", destinando al capítulo "Uruguay Integrado. En el MERCOSUR y en el mundo" sus principales lineamientos en materia de política exterior (FERNÁNDEZ LUZURIAGA, 2005).

El programa de gobierno frenteamplista - que tenía a Tabaré Vazquez como candidato presidenciable - se inicia resaltando los principios y valores que hacen a la política exterior uruguaya, para continuar con su proyecto de inserción en el sistema internacional y el desarrollo de una política de comercio exterior, seguido de la importancia del MERCOSUR y de los procesos de integración regional, para finalizar con la necesidad de reforma del Ministerio de Relaciones Exteriores y otros temas de política exterior donde se destaca la defensa y promoción activa de los derechos humanos. 


\section{Conjuntura Austral}

El documento señala que los vínculos históricos, la estabilidad política y el desarrollo económico, así como la circulación de personas, determinan que la relación primera con el exterior sea con Argentina y Brasil, países "hermanos y vecinos", con quienes buscará fortalecer las relaciones bilaterales y la integración como un todo, sin contradecir una política de inserción internacional activa. Además de pilar para la integración regional, el MERCOSUR aparece como un bloque necesario para negociar frente al Área de Libre Comercio de las Américas (ALCA), a la Unión Europea y a otros ámbitos multilaterales. Pero también la OEA, las Cumbres Iberoamericanas y la cooperación sur-sur son destacados como instrumentos para la inserción internacional.

La victoria de Tabaré Vázquez y su asunción el $1^{\circ}$ de Marzo de 2005 implicó el desarrollo de una política exterior de pragmatismo divida entre el relanzamiento del MERCOSUR bajo el lema “más y mejor MERCOSUR” y la búsqueda de nuevos socios estratégicos como fue el caso de Estados Unidos. Su agenda exterior estuvo, en cierta medida, dominada por el conflicto con Argentina por la instalación de plantas procesadoras de celulosa en la frontera, así como también por la negociación de un Tratado de Libre Comercio con Estados Unidos en 2006.

Para Carlos Luján, la agenda internacional del primer gobierno progresista estuvo marcada por tres temas que construyeron el debate acerca de la política exterior del país. En primer lugar, ubica las relaciones con Argentina, Brasil y Estados Unidos, en segundo, la definición del espacio regional - MERCOSUR, Sudamérica o Latinoamérica prioritario para el país, y en tercer lugar, se refiere a los bloques económicos y políticos por los cuales el país debía inclinarse: Asia, Europa o Norteamérica (LUJÁN EN QUIROGA; França, 2010:136-176).

Con respecto al primer tema, cabe destacar que el diferendo con Argentina consumió importantes energías de la diplomacia uruguaya durante el gobierno de Vázquez. Alcanzando el punto más álgido en 2006, implicó la demanda argentina ante la Corte Internacional de Justicia de La Haya, donde se acusaba al país de violar el Estatuto del Río Uruguay al autorizar la instalación plantas procesadoras celulosa en Fray Bentos. El pedido de Argentina de reubicación de plantas ante la OEA y el Banco Mundial y posteriormente la solicitud de suspensión de estas obras, así como el bloqueo de dos 


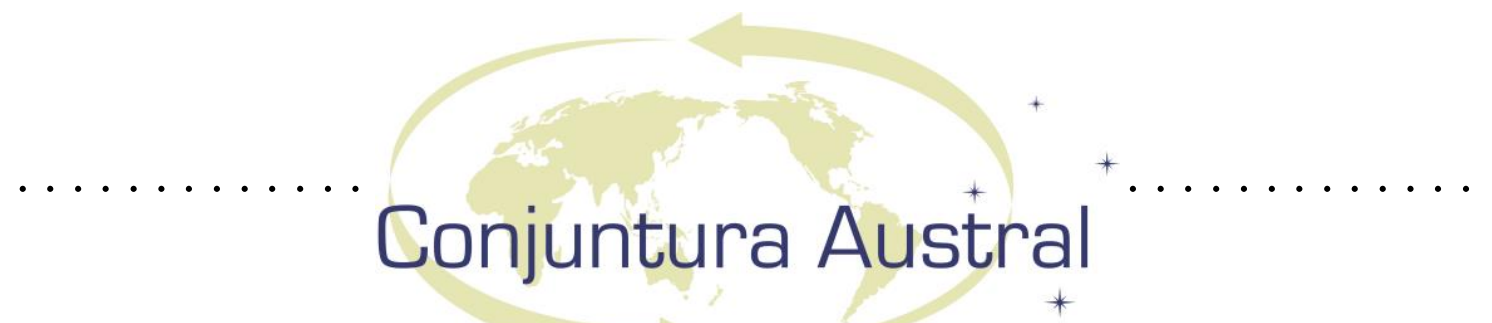

puentes binacionales por ambientalistas que causaron importantes pérdidas a la economía uruguaya, así como la la creación de un Tribunal Ad hoc en el MERCOSUR para tratar el tema - y su pronunciamiento ambiguo e incapaz de resolver el conflicto - se tradujo en el desarrollo de una tesitura de firmeza y reafirmación soberanista del gobierno frenteamplista.

Con el respaldo de los partidos políticos con representación parlamentaria, el gobierno uruguayo desarrolló una campaña ante diferentes organismos internacionales donde reafirmaba su estrategia internacional de promoción de inversiones, inclusive si ello implicara el asumir los costos del corte de los puentes.

Más allá de este diferendo, la diplomacia uruguaya encontró puntos fuertes con el éxito en la negociación de la deuda externa con el FMI tras la crisis económico-financiera del año 2002, y en la jerarquización del rol de Naciones Unidas mediante la intervención en operaciones de mantenimiento de paz en Congo y Haití y participando activamente en los diferentes espacios que promueven una reforma en el Sistema de Naciones Unidas. También cabe destacar el estrechamiento en las relaciones con Venezuela y el apoyo a su ingreso al MERCOSUR, el acercamiento a Palestina y a la República Saharaui, el restablecimiento de las relaciones con Cuba, y el acercamiento a los uruguayos residentes en el exterior del país.

Para Luján:

La idea central es que el gobierno de Uruguay ha adoptado como orientación de su política exterior la búsqueda de una inserción internacional en la diversidad, con proyección simultánea hacia el espacio regional y hacia el mundo, lo que ha sido denominado "regionalismo abierto". El balance entre continuidades, ajustes y cambios en lo que refiere a la política exterior del Uruguay durante la presidencia del Dr. Tabaré Vázquez surge del análisis de los puntos fuertes y las oportunidades de mejora que ha tenido el país en materia internacional (LUJÁN EN QUIROGA; França, 2010:141).

Para el investigador, este "regionalismo abierto" orientaría a las relaciones bilaterales y multilaterales en detrimento del acentuado pro-americanismo de los anteriores gobiernos. 


\section{Conjuntura Austral}

\section{La política exterior de José Mujica y su relacionamiento con Brasil}

La llegada al poder de los gobiernos progresistas determinó un nuevo escenario de regionalismo sudamericano que se plasmó en el relanzamiento y creación de nuevos espacios de integración regional. Colmado de expectativas en lo que a avances en la integración política y económica se refiere mediante el rechazo - más o menos explicito - al modelo neoliberal de la década de los noventa, estos gobiernos progresistas incorporaron también una nueva agenda social y cultural.

Para el caso de Uruguay, la política exterior del país se debatió entre un modo de inserción en la diversidad y la inclinación hacia un único polo, representado en el acercamiento a Estados Unidos, o en la elección de Sudamérica como espacio de relacionamiento fundamental y prioritario geoestratégicamente donde se potenciaría a Brasil como un actor global en un mundo multipolar (LUJÁN EN QUIROGA; França, 2010:150-153).

Con la reelección del Frente Amplio en las elecciones presidenciales de 2009 y la asunción de José Mujica como presidente de los uruguayos el $1^{\circ}$ de marzo de 2010, varios analistas coinciden con que se procuró dar continuidad a la política exterior desarrollada por su antecesor Vázquez.

La plataforma pre-electoral del gobierno de Mujica se encuentra condensada en el "V Congreso Extraordinario Zelmar Michelini" donde nuevamente - al igual que en las elecciones de 2004 - se presenta un capítulo "Uruguay Integrado". Estructurado de manera similar al programa presentado en 2004, este capítulo versa sobre los principios de la política internacional, seguida por aspectos políticos comerciales, los procesos de integración donde se destaca el rol de la UNASUR, la vinculación con los uruguayos en el exterior, la cooperación internacional y el papel del Ministerio de Relaciones Exteriores. Mientras que los principios rectores de la política exterior uruguaya se confunden en primer capítulo de la Carta de las Naciones Unidas, los pilares se refieren a los grandes valores de la izquierda uruguaya. (FERNÁNDEZ LUZURIAGA, 2010).

Esta plataforma planteaba una estrategia de inserción internacional que privilegiaba al MERCOSUR, pero también al bilateralismo múltiple. En este sentido, se resaltó la necesidad de levantar las barreras intrabloque, de establecer niveles de 


\section{Conjuntura Austral}

protección moderados extrabloque y de negociar acuerdos MERCOSUR con terceros países.

El gobierno de Mujica construyó una agenda comercial con metas a corto plazo y a mediano plazo en lo social, sobre una adecuación de estructura institucional y toma de decisiones. Su plataforma de gobierno, preveía también una política monetaria y cambiaria diferenciada, la intervención del sistema financiero público y la regulación de los flujos de capital internacional. Existieron firmes intensiones de evitar la competencia desleal de productos importados mediante el gravamen de impuestos. Bajo el lema "Uruguay abierto al mundo" se configuró una estrategia de desarrollo y de inserción internacional basada en la fórmula "agro+ inteligencia + turismo + logística regional".

En la región, se apoyaron los distintos procesos de integración latinoamericana. Se descartó el ingreso a la Alianza Bolivariana para los Pueblos de Nuestra América (ALBA), se fomentó la cooperación internacional con la creación de la Agencia Uruguaya de Cooperación Internacional (AUCI) y se consideró a la Unión de Naciones Sudamericanas (UNASUR) como la apuesta regional más decisiva junto con el Consejo Sudamericano de Defensa y el Banco del Sur, como espacios de negociación claves en energía, riquezas naturales y renegociación de la deuda externa.

Han sido también iniciativas características de su política exterior, el fortalecimiento del cuerpo diplomático, el reconocimiento de la responsabilidad del Estado ante crímenes de lesa Humanidad - él de mayor repercusión fue el llevado a cabo a partir de la conocida sentencia de la Corte Interamericana de Derechos Humanos por el "Caso Gelman vs. Uruguay" en 2010 - y el discurso en foros internacionales sobre capitalismo, consumo, medioambiente, el papel del hombre y la felicidad. Esto determinó una proyección de la imagen del presidente Mujica a escala global; proyección esta que se ha fortalecido con la adopción de reformas liberales como la despenalización del aborto, el matrimonio igualitario y la regulación del consumo de marihuana en el país.

Con relación a Argentina, el gobierno de José Mujica fortaleció el diálogo teniendo como consecuencia la reafirmación del papel de la Comisión Administradora del Río Uruguay (CARU) y de la Comisión Administradora del Río de la Plata (CARP) y el relanzamiento de comités binacionales de frontera. Asimismo, se mantuvieron 


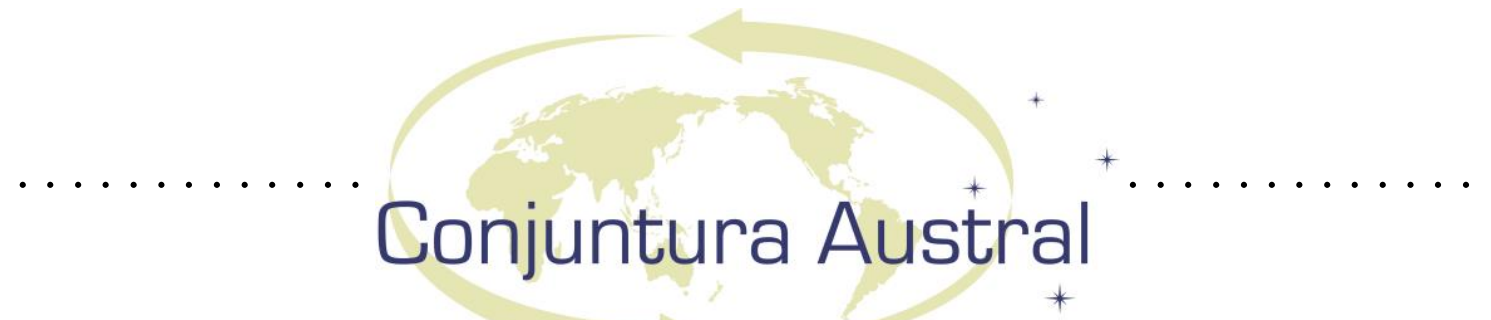

reuniones con ambientalistas argentinos y no se autorizó a la empresa Montes del Plata a establecerse en Fray Bentos. Se sucedieron entrevistas con la presidenta Cristina Fernández de Kirchner y se dieron muestras de colaboración internacional, como por ejemplo, con el apoyo de la candidatura del ex Presidente Néstor Kirchner a la Secretaria de UNASUR y la reafirmación de la soberanía de Argentina sobre las Islas Malvinas, Georgias del Sur y Sandwich del Sur.

Por su parte, Argentina, entre otras iniciativas, eliminó las trabas impuestas en el Fondo de Convergencia Estructural del MERCOSUR (FOCEM) al proyecto de interconexión eléctrica con Brasil. A su vez, los ambientalistas levantaron los cortes de puentes binacionales. Sin embargo, la discordia respecto de un aumento en la producción de las plantas procesadoras de celulosa y las dificultades en el diálogo comercial continúan tensionando, por momentos, el relacionamiento bilateral.

Podremos señalar también como otras particularidades de su política exterior, una la presencia marcada en la Organización Mundial del Comercio (OMC), el relacionamiento con disidentes cubanos, la colaboración con la Organización para la Cooperación y el Desarrollo Económico (OCDE) para la transparencia fiscal, el intento de relanzar el URUPABOL, la diversificación de sus mercados con Asia y el rechazo a la firma de un Tratado de Libre Comercio con Estados Unidos.

En lo que a la relación bilateral con Brasil se refiere, podremos afirmar que están especialmente signadas por la vecindad. En el caso uruguayo esto representa un permanente desafío teniendo en cuenta la extensión, población y poder desproporcional con el que cuenta Brasil. Desde principios de siglo XX, las relaciones entre ambos países han sido de cordialidad y cooperación. Esta "buena vecindad" ha sido clara durante el "período batllista" (1904-1933), el retorno a la democracia (1973-1958/1964-1985), y en la década del noventa con la firma del Tratado de Asunción (1991) que dio origen al MERCOSUR. Sin embargo, con los gobiernos progresistas de Luis Inácio Lula da Silva (2003-2010) y Dilma Rousseff en Brasil (2011-2014), y Tabaré Vázquez (2005-2010) y José Mujica (2010-2015) en Uruguay, las relaciones bilaterales han experimentado una renovación en la cooperación y una diversificación de agenda. 


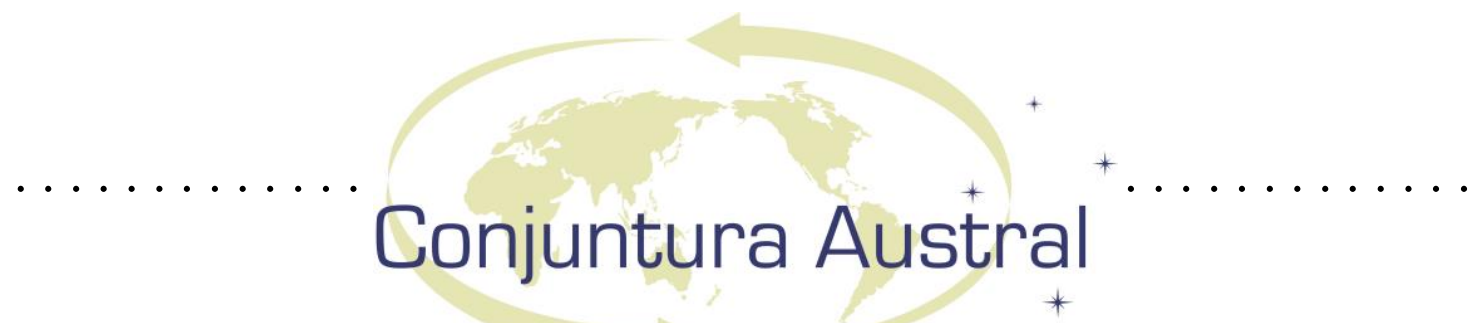

En este contexto, podremos afirmar que Brasil ha desenvuelto una política exterior con el claro objetivo de alcanzar el desarrollo nacional y de convertirlo en recurso de poder económico, industrial y militar - poniendo al servicio del interés nacional el progreso tecnológico, la cooperación internacional, las inversiones, la ampliación de los mercados - así como también la obtención del reconocimiento internacional como "potencia regional" y el establecimiento de "alianzas estratégicas" con el resto del mundo.

La elección de Lula da Silva (2003-2010) del Partido dos Trabalhadores (PT) promovió una inserción internacional interdependiente (CERVO; BUENO, 2012). Su gobierno incentivó la internacionalización de las empresas brasileñas, promovió la integración regional en América del Sur - siendo la UNASUR su apuesta más importante en 2011 -, diversificó las relaciones con árabes y africanos, fortaleció la imagen de Brasil como actor internacional teniendo como objetivo principal la obtención de un asiento permanente en el Consejo de Seguridad de Naciones Unidas. Con la asunción de los gobiernos progresistas en Brasil y Uruguay, fue iniciado un notorio estrechamiento de las relaciones bilaterales. Un mes después de asumir la Presidencia de la República, en abril de 2005 Tabaré Vázquez eligió a Brasilia como su primera visita oficial al exterior. Ese fue el puntapié inicial para una serie de visitas recíprocas entre gobernantes progresistas.

En marzo de 2006, cuando Lula da Silva recibió nuevamente al Presidente uruguayo en Brasilia, el mandatario brasileño expresó:

\begin{abstract}
As profundas afinidades entre nossos dois países e governos exigem que avancemos nos grandes projetos de integração física e produtiva de modo a garantir o desenvolvimento solidário de nossos povos. Para cumprir esse objetivo determinei a realização de reuniões em nível ministerial, para tratar de todos os aspectos das relações com o Uruguai [...] No Brasil, temos acompanhado com grande interesse e entusiasmo as realizações de seu governo. A retomada vigorosa do crescimento econômico com justiça social é também o alvo maior de meu governo [...] A franqueza e o espírito construtivo com que conversamos, os entendimentos a que chegamos, me dão uma certeza. Esta sua visita ao Brasil marcará uma nova fase no diálogo entre nossos países e na realização do potencial de cooperação entre nossos dois povos. (Brasil, 2006).
\end{abstract}

De esta manera, el relacionamiento con el Brasil fue uno de los temas que formaron parte del debate acerca de la agenda internacional del primer gobierno progresista. En este sentido, Luján expresa: 


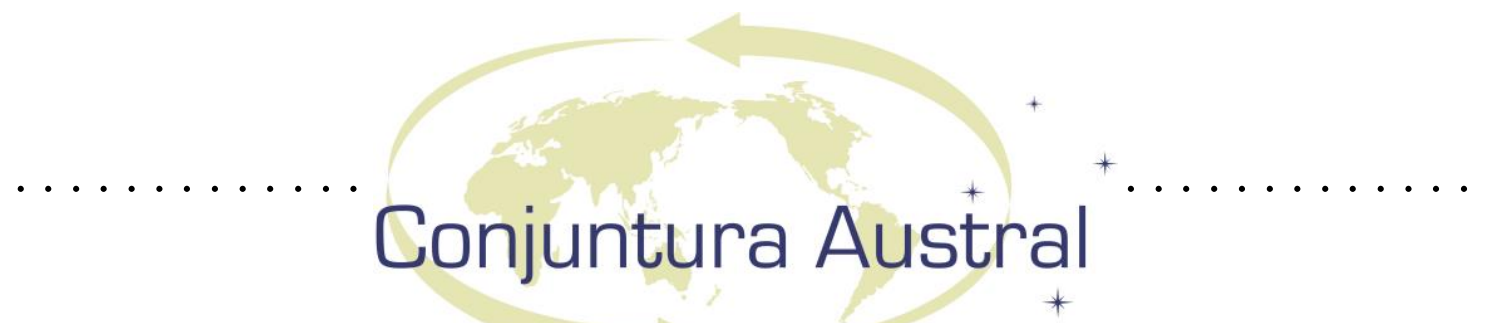

Las relaciones con el Brasil de Lula han sido excelentes, más allá de inconvenientes comerciales en nuestras fronteras, todos ellos subsanables. Las frecuentes visitas del asesor personal del Presidente brasileño en materia internacional, el Dr. Marco Aurelio García al Uruguay son un indicador de la muy buena relación existente entre dos gobiernos afines, afinidad inexistente con el anterior gobierno colorado. Sin embargo, tan buen relacionamiento no se ha traducido en una acción de liderazgo regional brasileño que permitiera mejorar las debilitadas relaciones con Argentina. (LUJÁN EN QUIROGA; França, 2010:138).

En el gobierno de José Mujica las relaciones bilaterales continuaron el curso de la "buena vecindad" y la cooperación establecida a partir de los gobiernos Da SilvaVázquez. En este sentido, la elección de Montevideo en mayo de 2011 por la presidenta Dilma Rousseff como destino de uno de sus primeros viajes oficiales al exterior desde su asunción y la posterior definición de las relaciones con Uruguay como "estratégicas", fue una clara señal que la diplomacia uruguaya supo aprovechar.

La política exterior de Dilma Rousseff se podría definir a partir de la continuidad de los principales objetivos en la esfera internacional postulados en esta área por la gestión Lula da Silva. Sin embargo, la diplomacia de Rousseff procura estos objetivos con menor activismo y mayores limitaciones externas, caracterizándose por un ajuste en medio de la continuidad; mientras que Lula se consolidó como líder político a partir de sus dotes carismáticos, Rousseff se destacó en la administración pública por su capacidad técnica y gestora (CONTE CORNETET, 2014).

En una reunión con empresarios y altas autoridades del gobierno uruguayo, el presidente Mujica destacó la importancia de un estrecho relacionamiento con el Brasil al expresar:

Estamos al lado de una potencia excelente que se llama Brasil, y está viviendo un momento histórico, que tiene un gobierno afín. Que torpes nosotros si no sabemos aprovechar esa posibilidad con los de arriba, porque aparte de todo este Brasil de hoy tiene voluntad política. Y antes, no [...] Brasil tiene necesidad de jugar como potencia y como tal necesita influencia de carácter político, es la potencia emergente del Atlántico Sur. Brasil es un país de casi 200 millones de habitantes, con una reserva petrolífera enorme pero sobre todo, tiene la mayor reserva de energía hidroeléctrica disponible en el mundo [...] es hora de hablar en portugués despacio y en español despacio, a partir de ahí nos entendemos. Y no entrar en los nacionalismos pequeños de cotorro que nos estropean el otro verdadero nacionalismo que es la construcción de la posibilidad de esta América (ALVARIZA, 7 de mayo de 2012). 


\section{Conjuntura Austral}

\section{Uruguay-Brasil: La dimensión global, regional y bilateral de las actuales agendas de cooperación}

En su Teoría de la Interdependencia y de los Regímenes Internacionales, Robert O. Keohane y Josep S. Nye (1989) sostienen que los Estados son interdependientes. Donde existe intercambio, hay necesariamente interdependencia. En los sistemas políticos internacionales, los Estados son las unidades de mayor importancia que "buscan maximizar sus intereses y poder". La interdependencia puede ser fuente de poder, entendida como la habilidad de un actor para lograr que sus pares tomen determinadas acciones que de otra forma no lo harían, controlando potencialmente sus recursos y resultados. La interdependencia simple indica que los Estados a través de su acción nacional unilateral, no reúnen la capacidad suficiente para alcanzar óptimos resultados. En cambio, la interdependencia compleja se caracteriza por la existencia de múltiples canales que conectan las sociedades en sus relaciones interestatales, transgubernamentales $\mathrm{y}$ transnacionales; por una agenda de variados temas no jerarquizados (económicos, energéticos, ecológicos, culturales, etc.) y no supeditados a la seguridad miliar; y por la ausencia del uso de la fuerza. En la construcción de una agenda de integración y cooperación hacia el Brasil, la interdependencia compleja parece jugar un papel de relevancia.

En materia de política exterior se perciben cuatro dimensiones claramente identificables. En una primera dimensión se identifica a la agenda global; en una segunda dimensión los temas referidos a los espacios regionales de integración conforman la agenda regional; finalmente, en la tercera dimensión se analizan las relaciones bilaterales con énfasis en el nuevo paradigma de cooperación e integración de estos Estados proponen.

La dimensión multilateral del relacionamiento ambos países responde claramente a dos iniciativas: la disposición de Brasil de proyectarse regionalmente y de asumir los costos, y el reconocimiento uruguayo al liderazgo de Brasil.

El papel privilegiado de Brasil en el escenario internacional reforzó su liderazgo en la región, concomitantemente con el desarrollo de una política exterior que mostró la clara intención de asumir los costos por este liderazgo. Ello se debe al cambio en el 


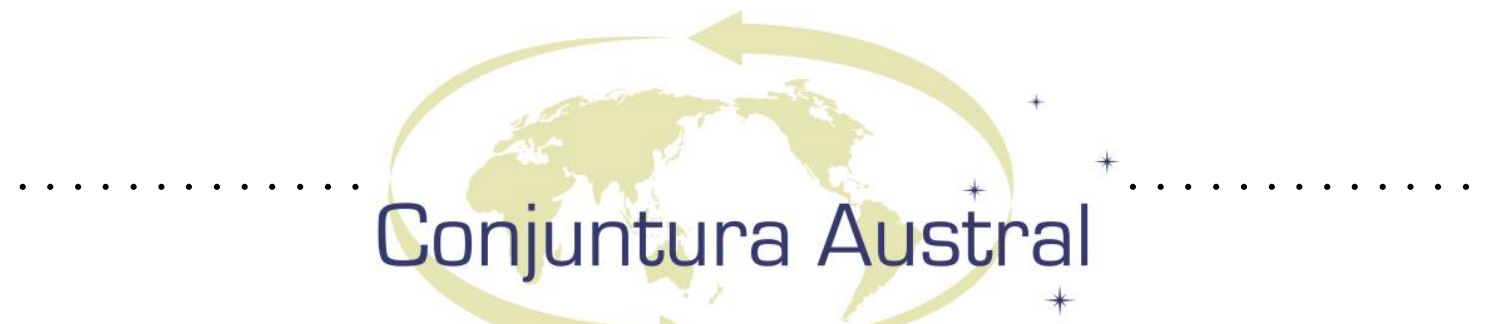

modelo de desarrollo que Brasil inició a partir del gobierno de Lula Da Silva, donde se prioriza el desarrollo mediante la internacionalización de la economía. Aquí las iniciativas bilaterales de integración aparecen como una oportunidad de esta internacionalización (MALLMANN; MARQUES, 2013: 11). En este contexto cabe recordar las claras asimetrías existentes entre Uruguay y Brasil - y de este gigante con el resto de América Latina - y que se han agudizado en la última década. Estas profundas asimetrías, también evidentes en el MERCOSUR y otros espacios de integración, fortalecieron una orientación de Brasil hacia una política exterior que privilegie también el bilateralismo con sus vecinos sudamericanos.

A su vez, cabe destacar que con relación a Brasil, Uruguay viene desarrollando una política de reconocimiento de su liderazgo. Prueba de ello, es el apoyo uruguayo a los posicionamientos de Brasil en diversos foros internacionales. Un ejemplo es la necesidad de reforma de las Naciones Unidas y el nombramiento de Brasil como Miembro Permanente del Consejo de Seguridad. En el seno de la ONU, ambos países han colaborado estrechamente en la Misión de Naciones Unidas para la Estabilidad en Haití (MINUSTAH).

En comunicado de prensa del 21 octubre de 2013, en ocasión de la primera visita oficial del Canciller brasileño Luiz Alberto Figueiredo a Uruguay, se remarcó que:

Uruguay y Brasil coincidieron en "seguir los compromisos con el
multilateralismo y con Haití, pero también cumplir con los
compromisos asumidos en el marco de la UNASUR y del propio
mandato de ONU, de reducción progresiva de efectivos". Allí, el
Canciller uruguayo, Luis Almagro señaló que se trataron otros temas de
interés global: "las Naciones Unidas, la situación en Medio Oriente,
asuntos de cooperación y temas comerciales en general, así como en el
avance para lograr consensos regionales en torno a una candidatura en
el marco de la Unasur". (Uruguay, 21 de Octubre de 2013).

En la OMC ambos países abogan por el desarrollo de un sistema multilateral de comercio. También allí, existieron consensos en las negociaciones de la Ronda de Doha sobre la retirada de barreras proteccionistas a los productos agrícolas. Otros posicionamientos conjuntos se han demostrado, entre otros, con respecto al establecimiento de relaciones con Palestina y reconocimiento de autodeterminación de su pueblo, así como la condena a la violación de derechos humanos en varios países del 


\section{Conjuntura Austral}

mundo, como el caso de Irán. Recientemente la propuesta uruguayo-brasileña llevada a la OEA donde se respaldó al gobierno argentino en la contienda que mantiene con los fondos financieros especuladores acreedores de deuda pública, ha demostrado la solidez en la construcción de una agenda global con coincidencias.

También, Uruguay ha apoyado diversas candidaturas de funcionarios brasileños para la ocupar las direcciones de algunos foros internacionales. Tal es el caso de la candidatura de Jose Graziano da Silva al cargo de Director General de la Organización Mundial para la Agricultura (FAO) para el período 2012-2015 y la de Roberto Azevedo como Director General de la OMC. En contrapartida, Brasil apoyó la candidatura de Uruguay como Miembro No Permanente del Consejo para el período 2016-2017. En este sentido, los gobiernos de Rousseff y Mujica han demostrado mayor sintonía que los anteriores gobiernos de Lula da Silva y Vázquez, cuando estos lanzaron candidatos propios para la OMC y cuando Uruguay no apoyó al candidato brasileño a la presidencia del Banco Interamericano de Desarrollo (BID).

Con respecto a la dimensión regional presente en el relacionamiento de ambos países, interesa especialmente la referida al MERCOSUR como espacio privilegiado de integración regional.

En lo que hace respecto a la agenda regional, el apoyo al fortalecimiento de la Unión de Naciones Latinoamericanas (UNASUR), de las Comunidad de Estados Latinoamericanos y Caribeños (CELAC) así como la reactivación de la Zona de Paz y Cooperación del Atlántico Sur (ZOPACAS), son claras demostraciones de cooperación. Sin embargo, es el MERCOSUR la iniciativa regional más importante que han impulsado ambos Estados y espacio privilegiado de integración.

A su vez, fue marcada por la suspensión de Paraguay y por el ingreso de Venezuela al bloque. El juicio político que depuso al entonces presidente Fernando Lugo en junio de 2012 representó uno de los desafíos políticos de mayor trascendencia para la región. Considerado un acto de ruptura democrática en aquel país, Paraguay fue suspendido del MERCOSUR y de la UNASUR. Además de las medidas institucionales, los presidentes de Uruguay y de Brasil hicieron fuertes declaraciones al respecto; mientras que Mujica clasificó el episodio de un "golpe de Estado parlamentario" (Uruguay, 25 de 


\title{
Conjuntura Austral
}

Junio de 2012), Itamaraty condenó la destitución de Lugo afirmando que no se contempló el derecho de defensa, comprometiendo a la democracia, condición esencial para la integración regional (Brasil, 23 de junio de 2012). Paralelamente, en julio de 2012 se produjo el ingreso de Venezuela como miembro pleno del bloque, ocasión donde nuevamente los presidentes coincidieron en defender la importancia geopolítica y económica del país caribeño. Ambos países han saludado también el ingreso de Bolivia - ya ratificado por Uruguay y Venezuela - al bloque y que estiman se consolidará próximamente.

En un comunicado conjunto del 30 de mayo de 2011, los presidentes Mujica y Rousseff reafirmaron que el proyecto integracionista es:

\begin{abstract}
Essencial como instrumento na melhora da qualidade de vida de seus povos e para a inserção internacional do bloco, destacando seu papel estratégico na integração política, social, econômica e comercial, e identificando a necessidade da plena implementação da união aduaneira em curto prazo (Brasil, 30 de maio de 2011).
\end{abstract}

A pesar de estas coincidencias a nivel regional, cabe resaltar algunas diferencias a entre ambas diplomacias. En 2006, el gobierno brasileño rechazó las negociaciones emprendidas por el gobierno de Tabaré Vázquez para la concreción de un Tratado de Libre Comercio (TLC) con Estados Unidos y en claro debilitamiento del MERCOSUR. Aunque la firma de este TLC con la potencia norteamericana no se llegó a concretizar, este acercamiento fue interpretado por varios analistas como una respuesta de Uruguay ante la neutralidad de Brasil - en el diferendo que lo enfrentaba con Argentina por la instalación de plantas de celulosa - y su incapacidad de actuar como mediador.

En julio de 2012, el gobierno de Rousseff criticó severamente la aceptación de Uruguay de ingresar como observador a la Alianza del Pacífico (Uruguay, 25 de Julio de 2012), entendiendo que ha dado fuertes señales a Uruguay con la construcción de una solida agenda bilateral (La Diaria, $1^{\circ}$ de octubre de 2012).

En este sentido, la debilidad del MERCOSUR se manifestó en un padrón de relacionamiento regional adepto al bilateralismo y poco simpatizante a los acuerdos institucionales multilaterales profundos. La reducida institucionalización del MERCSOUR y de otras instancias intergubernamentales tales como la UNASUR 


\section{Conjuntura Austral}

confirma en cierta medida esta premisa. A pesar de que Brasil en política exterior desarrolle un discurso que apunta al comportamiento multilateral como prioridad, delante de los costos reducidos de las negociaciones bilaterales con sus vecinos, esta vía parece haber sido la privilegiada por Itamaraty (ALVARIZA, et al., 2014). A pesar de ello, cabe destacar que diferentemente de otras experiencias de integración que sucumbieron de cara al colapso económico y comercial, el MERCOSUR - y en términos más amplios, la integración sudamericana - continúa agregando temas nuevos en sus agendas correspondientes.

Como se ha dicho, en el caso de las relaciones uruguayo-brasileñas, es notorio el fortalecimiento de las agendas bilaterales a partir de la llegada al poder de los gobiernos progresistas. Sin embargo, fue quizás el 31 de Julio de 2012 que estas relaciones se estrecharon aún más con el inicio de las negociaciones bilaterales que tuvieron como resultado el establecimiento de una asociación estratégica con base en un "nuevo paradigma" de integración bilateral, materializado en la creación del "Grupo de Alto Nivel Brasil-Uruguay (GAN). El GAN fue creado para ejecutar el "Plan de Acción para el Desarrollo Sustentable y la Integración" cuyo objetivo es la intensificación de diversos proyectos de integración así como la complementación productiva y la cooperación. Este plano abrió espació también para la asociación entre actores públicos y privados que manifiesten su interés en la cooperación bilateral (Brasil, 31 de Julio de 2012).

Desde el punto de vista uruguayo, este nuevo paradigma se inserta en la estrategia del gobierno frenteamplista que continúa privilegiando el MERCOSUR como plataforma de inserción internacional (ALVARIZA, 2013), aunque también privilegie el bilateralismo múltiple. Bajo el lema "Uruguay abierto al mundo" reciben especial atención las áreas vinculadas a la logística regional, a la agropecuaria y al turismo, así como la apertura y diversificación de mercados.

Un año luego de la consolidación de un "nuevo paradigma de integración bilateral" entre Brasil y Uruguay, los Ministros de Relaciones Exteriores, Antonio Patriota y Luis Almagro, celebraron el 9 de julio de 2013 en Brasilia la $1^{\circ}$ Reunión Plenaria del Grupo de Alto Nivel Brasil-Uruguay (GAN). Este encuentro entre altas autoridades tuvo como consecuencia la aprobación del "Plan de Acción para el Desarrollo 


\section{Conjuntura Austral}

Sustentable y la Integración Uruguay-Brasil”.

El "Plano de Acción" bilateral establece objetivos generales y específicos, la división de tareas y responsabilidades, la identificación de puntos focales en ambos gobiernos, así como plazos para la consolidación de la integración bilateral. Con este propósito, se conformaran seis "subgrupos de trabajo" o "áreas" donde se trabajarán iniciativas consideradas prioritarias. Integración productiva; Ciencia, tecnología e innovación; Comunicación e información; Integración de infraestructura de transportes; Libre circulación de bienes y servicios; y Libre circulación de personas; conforman los subgrupos que deberán proseguir sus actividades y reuniones de forma independiente. El GAN es el responsable por el acompañamiento de estos subgrupos y por la evaluación de los avances registrados, con la clara intensión de dar cumplimiento a los objetivos establecidos en el "Plano de Acción”, el cual también podrá ser modificado y actualizado con nuevos proyectos (Uruguay, 21 de octubre de 2013). En este contexto, cabe destacar las numerosas reuniones entre ministros y demás representantes gubernamentales en ambos países.

En integración productiva, se viene desarrollando proyectos de cooperación energética, principalmente en energía eólica. El intercambio de energía eléctrica a través de la conversora instalada en Rivera (72 MW), la inversión conjunta de UTE y ELECTROBRAS en la creación de un parque de energía eólica y la construcción de una línea de transmisión eléctrica de 500KW entre las ciudades de San Carlos (Uruguay) y Candiota (Brasil), están entre las negociaciones destacadas. En lo referido a ciencia, tecnología e innovación se registra un mecanismo de cooperación bilateral que agrupa los temas de biotecnología, nanotecnología, medio ambiente, biomedicina y teconologías de la información y comunicación (TIC's). En este sentido, se proyecta la creación de una plataforma digital para la formación de recursos humanos en TIC's y la creación del Centro Binacional de Tecnologías de la Información y de la Comunicación. Fue previsto también el ingreso de Uruguay al Centro Brasil-Argentina de Biotecnología (CBAB) (ALVARIZA, 2013). 


\section{Conjuntura Austral}

Sobre la cooperación en ciencia y tecnología, la presidenta Dilma afirmó:

El presidente Mujica y yo decidimos también expandir los horizontes temáticos de nuestra agenda bilateral, creamos en un mecanismo nuevo para coordinar los esfuerzos de cooperación en el campo de la ciencia y tecnología. Vamos apoyar proyectos de desarrollo conjunto en el campos de biotecnología, la nanotecnología, de tecnología de la información (Brasil, 30 de mayo de 2011).

Con la decisión de Uruguay de adoptar la norma nipo-brasileña de TV digital (ISDB-T) se ha registrado importantes esfuerzos en comunicación e información, donde se está trabajando temas vinculados a contenidos digitales creativos, aplicaciones interactivas, democratización del acceso a internet y telecomunicaciones en general. También se están desarrollando proyectos para la interconexión de redes y la atención en las áreas de frontera entre las empresas estatales ANTEL y TELEBRAS (Brasil, 31 de julio de 2012).

Otro tema donde se registra avances es en la cooperación en defensa, asuntos espaciales y estadísticas a partir del interés de incluir a la industria naval en iniciativas binacionales, así como en el intercambio de experiencias, en las operaciones conjuntas de defensa, en la ejecución de proyectos conjuntos entre el Instituto Nacional de Investigaciones Espaciales (INPE) y la Dirección Nacional de Meteorología (DNM), además de la cooperación ente el Instituto Brasilero de Geografía y Estadística (IBGE) y el Instituto Nacional de Estadística (INE) (ALVARIZA, 2013).

Entre los principales avances en Integración de infraestructura de transportes se identifican el establecimiento de un cronograma preliminar que establece para 2017 la finalización de la construcción de un nuevo puente sobre el río Yaguarón dedicado al tránsito de cargas pesadas y la restauración del Puente Internacional Barón de Maua que une a las ciudades de Jaguarón (Brasil) y Rio Branco (Uruguay), buscando beneficiar al turismo y el transito local. Reciben atención también la interconexión ferroviaria entre las ciudades de Montevideo, Rivera, Santana do Livramento y Cacequi como vía para facilitar el comercio terrestre, y cuyo proyecto recibirá en parte financiamiento del FOCEM. Vale destacar también la Hidrovía Brasil-Uruguay, que posibilitará un sistema 


\section{Conjuntura Austral}

de transporte fluvial moderno de cargas y pasajeros, ofreciendo una alternativa de bajo costo para el transporte multimodal; este tema viene siendo trabajado también por las Comisiones Mixtas de la Cuenca de la Laguna Merín y del Rio Cuareim. También está presente en la agenda la construcción de un puerto de aguas profundas en el departamento uruguayo de Rocha así como la internacionalización del Aeropuerto de Rivera, donde Uruguay esta previendo incorporar otros países socios (Uruguay, 21 de octubre de 2013).

En lo que se refiere a la libre circulación de bienes y servicios, se destacan la negociación de la aplicabilidad del "Acuerdo de Complementación Económica" (ACE $\mathrm{n}^{\circ} 2$ ) suscrito por ambos países (ALADI, 2013). En este sentido, se prevén mecanismos bilaterales para medidas sanitarias y fitosanitarias, reglamentación técnica y procedimientos de evaluación de conformidad, así como también el compromiso de armonizar trámites aduaneros y mecanismos para dirimir divergencias comerciales. Para alcanzar estos objetivos, se creó la Comisión de Comercio Bilateral (CCB) y se ha tenido la colaboración del Instituto de Investigación Económica Aplicada (IPEA) de Brasil. Recientemente, Uruguay ha manifestado la intensión de liberalizar el tránsito de algunos bienes y servicios con Brasil en un futuro próximo (Uruguay, 10 de mayo de 2013).

A su vez, en lo que se refiere a la libre circulación de personas, se destacan los acuerdos obtenidos en materia de residencia, derechos laborales y políticas educativas y culturales, con claras ganancias para la población en general, principalmente la localizada en áreas de frontera. La implementación de la Agenda Binacional de Cooperación y Desarrollo Fronterizo ocurre en una región cuyas características han sido construidas históricamente desde la formación de las poblaciones en los dos países. Los intercambios económicos, los movimientos migratorios, los conflictos políticos y las influencias culturales de ambos lados de la línea fronteriza contribuyeron a la génesis de una sociedad con perfil propio. La demarcación territorial entre los dos Estados no fue obstáculo para la formación de una "frontera abierta" entendida como un espacio de múltiples interacciones entre sus habitantes. Con la aprobación, en 2002, de la Nueva Agenda de Cooperación y Desarrollo Fronterizo, fue puesto en práctica un plan de acción para el desarrollo integrado de la región.

Responsable por la articulación de políticas integradas y por las negociaciones de 


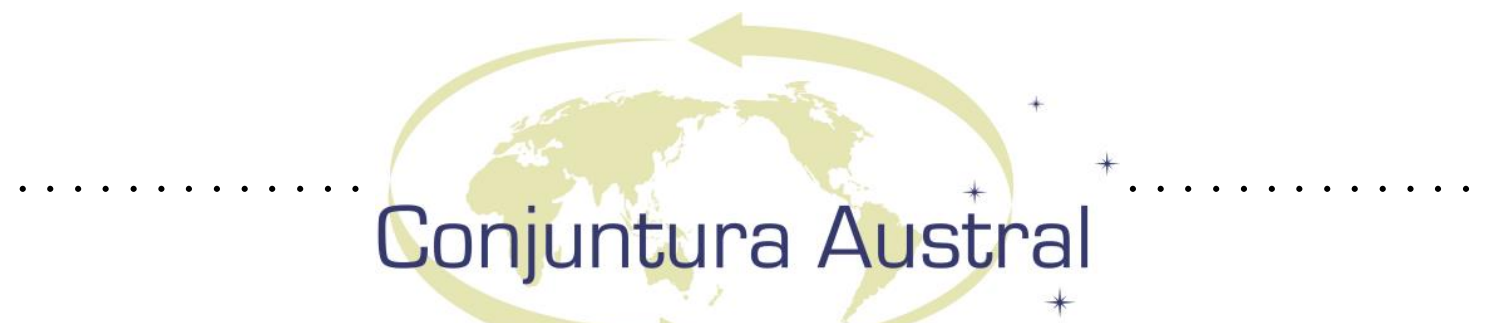

instrumentos jurídicos innovadores, esta agenda beneficiará a aproximadamente 800 mil personas a lo largo de $1.069 \mathrm{~km}$ de frontera. Entre los principales acuerdos se destaca el "Acuerdo sobre permiso de residencia, estudio y trabajo para los nacionales fronterizos uruguayos y brasileños" (2010) a través del "Documento especial de fronterizo" expedido por el Departamento de Policía Federal de Brasil y por la Dirección Nacional de Migraciones de Uruguay. El presente acuerdo incluye también el "Ajuste complementario del Acuerdo sobre permiso de residencia, estudio y trabajo para los nacionales fronterizos uruguayos y brasileños para prestación de Servicios de Salud" en sistemas públicos o contrataos entre personas jurídicas y físicas, situadas en las localidades fronterizas (ALVARIZA, 2013). Otras iniciativas se refieren al "Proyecto de Saneamiento Integrado Acegua -Aceguá" con financiamiento del Fondo de Convergencia Estructural del MERCOSUR (FOCEM) aprobado en 2005 por el bloque con el objetivo de disminuir la asimetría entre los miembros, y una variada oferta de cursos binacionales impartida por centros educativos públicos de la región.

El objetivo central de esta estrategia es la promoción del desarrollo integral de la línea de frontera común, que reconoce a Rio Grande do Sul como sede alternativa de las reuniones entre representantes de los gobiernos centrales. En el encuentro de octubre de 2013 en Montevideo entre los Cancilleres Luiz Alberto Figueiredo y Luis Almagro, el Canciller brasilero enfatizó el objetivo de que esta integración bilateral tenga un carácter ejemplar en la región (Uruguay, 21 de octubre de 2013).

\section{Referências}

Asociación Latinoamericana de Integración (ALADI) (2013). Acuerdo de Complementación Económica $\mathbf{N}^{\circ} 2$ celebrado entre la República Federativa del Brasil y la República Oriental del Uruguay - Septuagésimo Primer Protocolo Adicional. Disponible en: http://www.aladi.org/nsfaladi/textacdos.nsf/b3198303bf8b318403256fc50052d176/367c 9d8d126de1d7032570e3004b1b78?OpenDocument

ALVARIZA ALLENDE, R. (7 de mayo de 2012). Positivas repercusiones de la visita de Mujica a Brasil. CEIRI Newspaper. Disponible en: Disponible en: http://www.jornal.ceiri.com.br/positivas-repercusiones-de-la-visita-de-mujica-a-brasil/ 


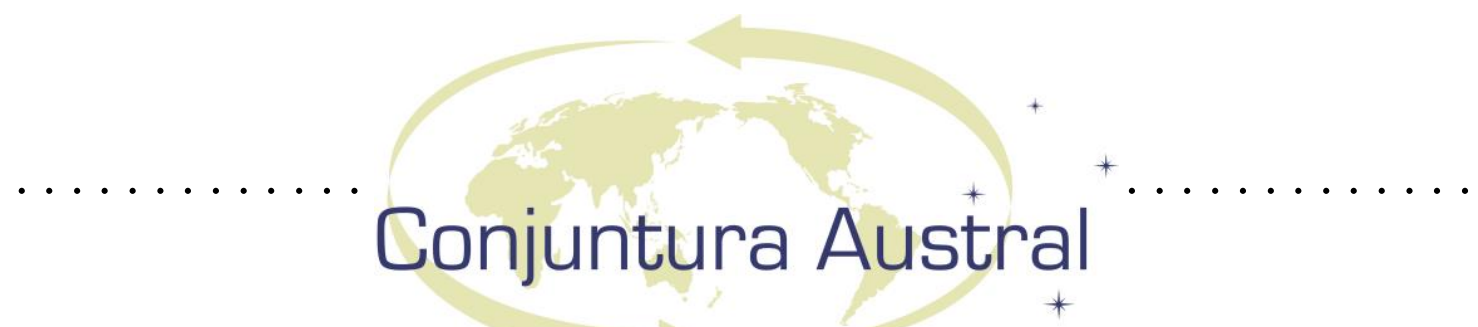

ALVARIZA ALLENDE, R. (2013). Uruguai-Brasil: cooperação e integração nos governos de Mujica e Rousseff. Mundorama: Divulgação Científica em Relações Internacionais do Instituto de Relações Internacionais da Universidade de Brasília iREL-UnB, 69, p. 1.

ALVARIZA ALLENDE, R.; MALLMANN, M. I.; Schneider Marques, T.C. (2014). Relações uruguaio-brasileiras: uma breve aproximação das atuais agendas de cooperação.

RÜCKERT, A. (Ed.) Integração regional, fronteiras e globalizacao no continente americano. Porto Alegre: Editora Compasso Lugar-Cultura \& Imprensa Livre. Manuscrito no publicado.

BRASIL, Ministério das Relações Exteriores do. (2006). Discurso do Presidente da República, Luiz Inácio Lula da Silva por ocasião da visita do Presidente do Uruguai,

VAZQUEZ, Tabaré. Disponible en: http://www.itamaraty.gov.br/sala-deimprensa/discursos-artigos-entrevistas-e-outras-comunicacoes/presidente-da-republicafederativa-do-brasil/15969536046-discurso-do-presidente-da-republica-luiz-inacio/

BRASIL, Ministério das Relações Exteriores do. (30 de mayo de 2011). Atos assinados por ocasião da visita da Presidenta Dilma Rousseff ao Uruguai. Disponible en: http://www.itamaraty.gov.br/index.php?option=com_content \&view=article\&id=2623\& catid=42: notas\&Itemid=280\&lang=pt-br

BRASIL, Presidência da Republica do. (30 de mayo de 2011). Declaração à imprensa da Presidenta da República, Dilma Rousseff, em conjunto com o Presidente da República do Uruguai, José Mujica. Montevidéu, Uruguai. 30 de maio de 2011. Disponible en: http://www2.planalto.gov.br/imprensa/discursos/declaracao-a-imprensada-presidenta-da-republica-dilma-rousseff-em-conjunto-com-o-presidente-da-republicaoriental-do-uruguai-jose-mujica

BRASIL, Ministério das Relações Exteriores do. (23 de junio de 2012). Situação no Paraguai, nota $\mathbf{n}^{\mathbf{0}}$ 155. Disponible en: http://www.itamaraty.gov.br/sala-deimprensa/notas-a-imprensa/situacao-no-paraguai/

CERVO, A. L.; Bueno, C. (2012). História da política exterior do Brasil ( $4^{a}$ ed.). Brasilia: Editora Universidade de Brasilia - UnB.

CLEMENTE BATALLA, I. (2004). La política exterior del primer gobierno de izquierda en Uruguay. Nordic journal of Latin American and Caribbean Studies, vol. 34 (1-2), pp. 323-351. 


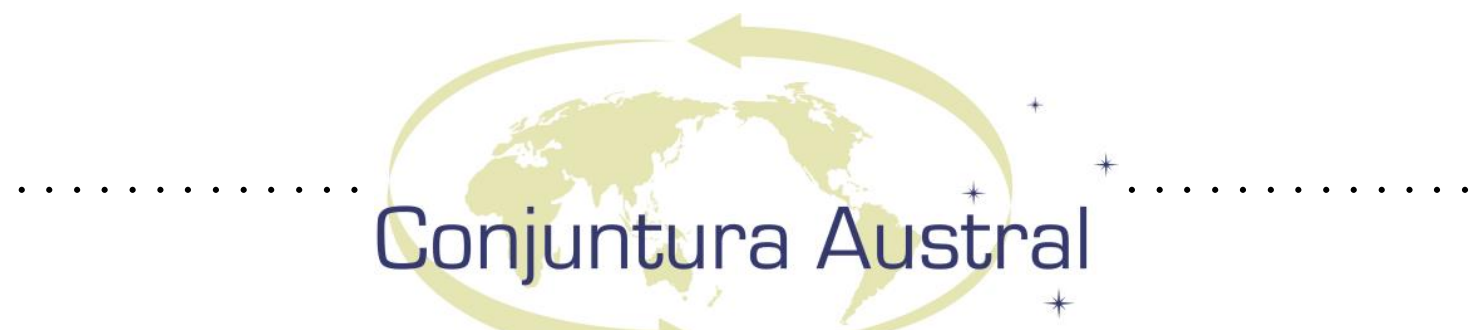

CONTE CORNETET, J. M. (2014). A política externa de Dilma Rousseff: contenção na continuidade. Revista Conjuntura Austral, vol. 5 (24), pp. 111-150.

FERRO CLÉRICO, L., FERNÁNDEZ LUZURIAGA, W. y HERNÁNDEZ NILSON, D. (2006). La estrategia de inserción internacional de Uruguay en el gobierno del Frente Amplio. Revista Uruguaya de Ciencia Política, vol. 15 (1), pp. 129-150.

FERNÁNDEZ LUZURIAGA, W. (2005). La Política Exterior del Uruguay en las Elecciones Nacionales de 2004. Serie Documentos de Trabajo $\mathbf{n}^{\circ}$ 66, Unidad Multidisciplinaria, Facultad de Ciencias Sociales, Universidad de la República.

FERNÁNDEZ LUZURIAGA, W. (2010b). El presidente electo en la transición, trazos de la política exterior del gobierno de José Mujica. Serie Documentos de Trabajo $\mathbf{n}^{\circ} \mathbf{7 8}$, Unidad Multidisciplinaria, Facultad de Ciencias Sociales, Universidad de la República.

KEOHANE, R. O. y NYE, J. S. (1989). Power and Independence. Nueva York: Harper Collins Publishers.

LA DIARIA $\left(1^{\circ}\right.$ de octubre de 2012). De primera mano. Disponible en: http://ladiaria.com.uy/articulo/2012/10/de-primera-mano/.

MALLMANN, M. I.; SCHNEIDER MARQUES, T. C. (2013a). A crise do multilateralismo e o Mercosul: uma lógica de integração? En Encontro Nacional da Associação Brasileira de Relações Internacionais: Multilateralismo, plurateralismo e a construção da ordem mundial (4: Belo Horizonte: 2013). Trabajos presentados. Belo Horizonte: ABRI.

Observatorio de Política Exterior Uruguaya. Montevideo: Programa de Estudios Internacionales, Facultad de Ciencias Sociales, Universidad de la República. Disponible en: http://observatoriopoliticaexterioruruguaya.wordpress.com/

PÉREZ ANTÓN, R. (2011). La política exterior uruguaya en el siglo XX. Montevideo: Ediciones de la Plaza.

QUIROGA, Y. y FRANÇA, C. (Org.) (2010). Consenso progresista. Política exterior de los gobiernos progresistas del Cono Sur: convergencias y desafíos. São Paulo: Fundación Friedrich Ebert, Red de Fundaciones Progresistas del Cono Sur.

RUSSELL, R. (1990). Política exterior y toma de decisiones en América Latina. Buenos Aires: Grupo Editor Latinoamericano.

URUGUAY, Presidencia de la República Oriental del. (25 de Junio de 2012). Mujica rechazó sanciones económicas ante "golpe de Estado parlamentario" en Paraguay. Disponible en: 


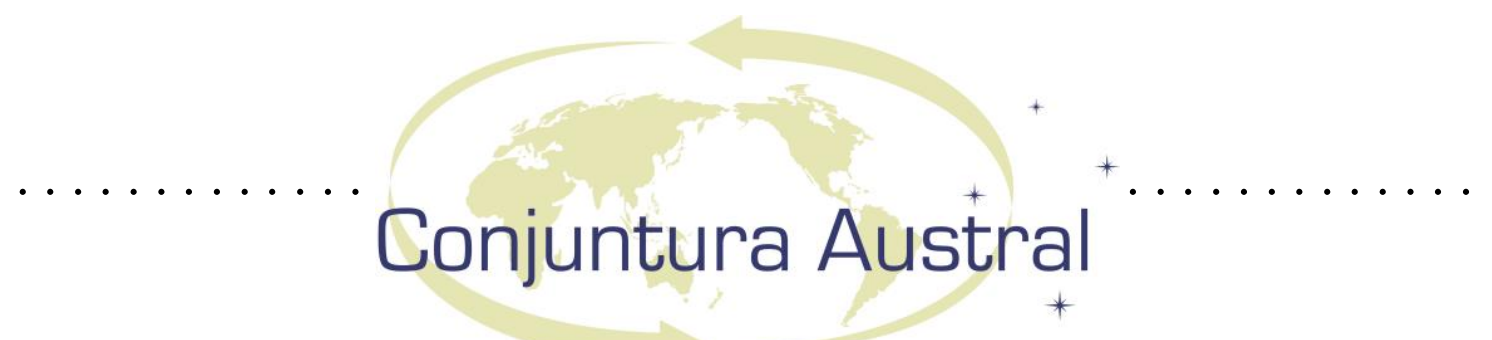

http://www.presidencia.gub.uy/comunicacion/comunicacionnoticias/mujica-paraguaygolpe-estado-parlamentario-canciller-sanciones-economicas-cumbre-mercosur.

URUGUAY, Ministerio de Relaciones Exteriores del. (25 de Julio de 2012). Uruguay aceptó en Perú ingresar a la Alianza del Pacífico como observador. Disponible en: http://www.presidencia.gub.uy/comunicacion/comunicacionnoticias/mujica-paraguaygolpe-estado-parlamentario-canciller-sanciones-economicas-cumbre-mercosur.

Consultado el 02/04/2014

URUGUAY, Presidencia de la República Oriental del. (31 de julio de 2012). Comunicado Conjunto Presidencial: Un nuevo paradigma para la relación BrasilUruguay. Disponible en: http://medios.presidencia.gub.uy/jm_portal/2012/noticias/NO_F064/comunicado.pdf

URUGUAY, Presidencia de la República Oriental del. (10 de mayo de 2013). Uruguay negocia con Brasil eliminación de la frontera para algunos bienes y servicios. Disponible en: http://www.presidencia.gub.uy/Comunicacion/comunicacionNoticias/porto-vicenciller.

URUGUAY, Ministerio de Relaciones Exteriores del. (21 de octubre de 2013). Encuentro entre Uruguay $\mathbf{y}$ Brasil. Disponible en: http://www.mrree.gub.uy/frontend/page?1,inicio,ampliacionppal2,O,es,0,PAG;CONP;1961;11;P;encuentro-entre-uruguay-y-brasil;8;PAG

VAN KLAVEREN, A. (1992). Entendiendo las políticas exteriores latinoamericanas: modelo para armar. Revista de Estudios Internacionales, Instituto de Estudios Internacionales, Universidad de Chile, (98), año XXV, pp. 169-216.

\section{Resumen}

El $1^{\circ}$ de marzo de 2005, la coalición de partidos políticos progresistas Frente Amplio asumió el Poder Ejecutivo luego de haber ganado las elecciones presidenciales de 2004, acontecimiento electoral y político sin precedentes en Uruguay. La conformación del primer gobierno de izquierda en este país supuso cambios en su política exterior y un nuevo modelo de inserción internacional. A continuación, analizaremos en primer lugar la política exterior uruguaya durante los gobiernos progresistas a partir de una caracterización general de esta y de la dimensión internacional en el programa de gobierno frenteamplista. Seguiremos con una breve reseña de la política exterior de José Mujica y de su relacionamiento con el Brasil de Dilma Rousseff, para finalizar, en un tercer apartado, con la dimensión global, regional y bilateral de las actuales agendas de cooperación

\section{Palavras Claves}

Uruguay; Brasil; política exterior, bilateralidad 


\title{
Conjuntura Austral
}

\begin{abstract}
On March 1st, 2005 a coalition of progressist political parties 'Frente Amplio' assumed the Executive Power after winning the presidential election in 2004, which constituted a singular electoral and political event. The formation of the first leftist government in this country marked changes in its foreign policy and established a new model of international insertion. In this paper we will analyse, first, the Uruguayan foreign policy during the progressist governments with a general characterization, and the international dimension in the 'frenteampista' program of government. Second, we will continue with a brief overview of the foreign policy of José Mujica and the relationship with Dilma Rousseff's government. Third, we will conclude with the global, regional and bilateral dimension of current cooperation agendas.
\end{abstract}

Keywords

Uruguay; Brazil; foreign policy, bilateralism

Artigo recebido em 15 de dezembro de 2014. Aprovado em $1^{\circ}$ de fevereiro de 2015. 


\section{Conjuntura Austral}

\section{O PAPEL DAS CIDADES-GÊMEAS DE FRONTEIRA NA INTEGRAÇÃO REGIONAL SUL-AMERICANA}

\section{The role of the twin cities border in the South American \\ regional integration}

Fábio Régio Bento ${ }^{1}$

\section{Introdução}

Fronteiras são espaços físicos, geográficos, de distinção para a afirmação de identidades coletivas situadas nesses territórios específicos. Fronteiras são invenções culturais, territoriais, de comunidades antigas com territórios e identidades culturais diferentes. Os Estados Modernos não criaram as fronteiras, mas as sofisticaram, intensificaram a racionalização de seus territórios com critérios jurídicos internacionais, ou seja, institucionalizaram burocraticamente as fronteiras. E, nesse processo de racionalização e significação política de suas fronteiras, podemos identificar duas fases com dois significados distintos e complementares, não antagônicos atribuídos por alguns Estados, entre eles o Brasil, às suas fronteiras físicas: fronteira como espaço de divisão para a afirmação de identidade e defesa de ameaças provindas de territórios vizinhos e fronteira como espaço para a integração entre as populações lindeiras de Estados territorialmente vizinhos.

Apesar da visão negativa que talvez seja indiretamente propagada junto à opinião pública internacional por grupos que se apresentam como sendo "sem fronteiras", fronteiras não são defeitos da humanidade, mas instrumentos de afirmação de identidades e proteção de tais identidades coletivas (DEBRAY, 2010).

\footnotetext{
${ }^{1}$ Doutor em Ciências Sociais pela Pontifícia Universidade S. Tommaso D'Aquino (Roma). Professor Adjunto II na Universidade Federal do Pampa. Leciona no curso de Relações Internacionais. Email: frbento@hotmail.com
} 


\section{Conjuntura Austral}

A função política oficial das fronteiras não é definida pelas fronteiras, mas pelos centros político-administrativos dos Estados. Na fase de nascimento dos Estados, as fronteiras territoriais cumprem o papel de distinguir o que é de um Estado do que é do Estado lindeiro. Fronteira, em tal fase inicial de vida dos Estados, é espaço para a distinção territorial, espaço de afirmação de identidade nacional. Na fase atual, porém, do Estado Brasileiro, caracterizada pela busca da integração com os Estados vizinhos como forma de defesa de seus interesses nacionais, prioridade de política externa definida pela Constituição de 1988, a função política da fronteira não é somente a de afirmação de identidade, distinção. Todavia, antes mesmo que o Estado Brasileiro definisse a integração regional como uma sua prioridade de política externa, em algumas cidades brasileiras de fronteira já havia a compreensão prática da fronteira como espaço de encontro para a integração entre sujeitos diferentes. Assim, nesse artigo queremos destacar que as experiências de integração regional não ocorrem somente entre sujeitos da cúpula de Estados (integração de vértice), mas, também, por meio de outras possibilidades, como a integração entre as populações que vivem nas cidades de fronteira (integração de base). Nesse sentido, sustentaremos que as cidades-gêmeas de fronteira cumprem um papel integrador original e relevante na integração regional, enquanto sujeitos de integração de base.

Nossa hipótese investigativa será apresentada ao longo das três seções desse artigo. A primeira, dedicada à compreensão da fronteira como espaço de separação ou de integração, conforme a docência prática das cidades de fronteira caracterizadas pela experiência da integração de fato; a segunda, voltada para a compreensão das diferenças e complementaridade da ação dos sujeitos da integração de vértice e de base; e a terceira, que antecede nossas considerações conclusivas, visa identificar os sujeitos coletivos fronteiriços que protagonizam os processos de integração de base.

\section{Fronteira como espaço de separação e de integração}

Para o geógrafo Otto Maull, as finalidades principais da fronteira são "distinguir o meu do teu; proteger o território nacional; isolá-lo, quando necessário, e facilitar-lhe o intercâmbio, quando conveniente" (apud MATTOS, 2011, p.112). 


\section{Conjuntura Austral}

O significado institucional das fronteiras não é definido oficialmente nas fronteiras, mas no miolo político-jurídico-administrativo dos Estados. Em tais miolos de Estado são definidos o significado e função oficiais de suas bordas territoriais. Assim, na fase de formação dos Estados, considera-se como objetivo principal das fronteiras o de proteger a diversidade de identidade territorial de um Estado sublinhando sua função de separação, para "distinguir o meu do teu” em relação ao Estado lindeiro (Ibidem, p.112).

Mesmo se estudos geográficos e antropológicos sobre fronteiras manifestam que comunidades indígenas possuíam sistemas de organização de fronteiras, com formas de demarcação e patrulhamento (STEIMAN; MACHADO, 2002, p.03), a linha reta vertical de Tordesilhas passou a ser a primeira referência oficial de fronteira no Brasil.

Quando o Tratado de Tordesilhas foi assinado, na cidade espanhola que lhe emprestou seu nome, em 04 de junho de 1494, Espanha e Portugal traçaram sua primeira fronteira oficial, uma linha reta, vertical, para terras americanas descobertas e a serem descobertas (GARCIA, 2010). Criaram uma fronteira exógena, definida de fora para dentro, por sujeitos externos ao território habitado por comunidades indígenas locais. De Tordesilhas até a consolidação das fronteiras brasileiras pela obra diplomática do Barão do Rio Branco, houve alternância entre uso da força da diplomacia e da força militar na resolução dos conflitos territoriais fronteiriços. Nas disputas de tratados entre Portugal e Espanha, depois da linha reta vertical de Tordesilhas passou-se ao arco definido pelo Tratado de Madri, em 1750, quando Alexandre de Gusmão obteve a legalização da expansão de fato pelo território desenvolvida pelos portugueses, com o recurso do princípio do uti possidetis, segundo o qual a posse da terra é de quem a ocupou e colonizou por primeiro (GARCIA, 2010).

Após o arco vertical definido pelo Tratado de Madri, as disputas continuaram com o Tratado de El Pardo, de 1761; com o Tratado de Santo Ildefonso, de 1777, quando Colônia do Sacramento retorna para o domínio da Espanha. Ao longo desses anos, os conflitos entre Espanha e Portugal definiam e redefiniam as fronteiras nas colônias sulamericanas. Posteriormente, em 1820, a Banda Oriental do Uruguai é anexada ao Brasil colônia. Em seguida, em 1822, com a independência do Brasil, o Uruguai veio junto como herança territorial, mas por pouco tempo. Antes disputado entre Espanha e Portugal, 


\section{Conjuntura Austral}

depois disputado entre Brasil e Argentina, pelo acordo de 1828, entre Rio de Janeiro e Buenos Aires, ocorre o reconhecimento da independência da República Oriental do Uruguai. Pelo exemplo citado sobre a parte sul do Brasil percebe-se que o processo histórico de criação de fronteiras é complexo, carregado de conflitos, com seus sujeitos coletivos atuando de forma militar e diplomática nessa disputa territorial acirrada que está por trás da construção política e militar das fronteiras brasileiras e sul-americanas.

Tal processo de construção, redefinição e consolidação das fronteiras territoriais brasileiras, de sul a norte, receberá contribuição destacada da obra intelectual-geográfica, política e diplomática do Barão do Rio Branco, no final de 1800 e início de 1900 (JORGE, 1999). Nesse período entre o fim da monarquia e o início da república, busca-se a consolidação da distinção territorial nas relações do Brasil com os Estados vizinhos. Em tal fase, a fronteira territorial serviu para a afirmação de identidade, distinção de identidade, defesa da identidade nacional pela separação territorial. Desempenharam papel fundamental as comissões de demarcação, que materializavam os limites jurídicos com a edificação de marcos. Além dos marcos, o papel de materialização da separação territorial foi desempenhado também pela construção de fortes, fortalezas e fortins pelo interior do Brasil, com a função de defesa armada, e, também, defesa pela vivificação, povoamento do território desenvolvido com a atuação destacada dos militares brasileiros

que se deslocavam para tais regiões remotas munidos de equipamentos de defesa e material para a agricultura (MATTOS, 2011, p.106-113).

Assim, ao longo de séculos, por meio de derrotas e vitórias militares e diplomáticas, construiu-se e defendeu-se a atual fronteira terrestre brasileira, que, do Oiapoque ao Chuí, corresponde a $15.719 \mathrm{~km}$ de fronteira, mais do que o dobro dos 7.408 $\mathrm{km}$ do litoral brasileiro, com a distância entre os pontos extremos de leste-oeste de 4.328 $\mathrm{km}$, maior que a distância norte-sul, que é de $4.320 \mathrm{~km}$. Tais números territoriais grandiosos, se comparados aos da maioria dos Estados do mundo, em vez de produzir triunfalismo nacionalista, revelam o peso da responsabilidade pela gestão sustentável das fronteiras do Brasil com Uruguai, Argentina, Paraguai, Bolívia, Peru, Colômbia, Venezuela, Guiana, Suriname, Guiana Francesa. Esses dados territoriais revelam as responsabilidades continentais do Brasil na gestão compartilhada de suas fronteiras. 


\section{Conjuntura Austral}

As fronteiras brasileiras, demarcadas, consolidadas no início de 1900, são espaços geográficos habitados ou não que cumpriram e realizam a função de distinção de identidades nacionais, de separação entre o que é de um e o que é do outro em relação aos Estados vizinhos. Tal função territorial das fronteiras físicas de um Estado é permanente, junto com a função de defesa em relação ao que entra e sai de um Estado, pessoas e mercadorias, pelas suas bordas físicas ou pelas fronteiras jurídicas criadas nos aeroportos internacionais. Porém, as fronteiras físicas não cumprem apenas a função de defesa-filtro (de pessoas e mercadorias) e afirmação de identidade nacional. Além dessas funções permanentes de uma fronteira física, há, também, a possibilidade de a fronteira física, habitada, ser um espaço de encontro entre sujeitos nacionais diferentes para a integração de fato entre tais populações nacionalmente distintas.

Segundo o parágrafo único do Art. $4^{\circ}$ da Constituição Federal de 1988, “a República Federativa do Brasil buscará a integração econômica, política, social e cultural dos povos da América Latina, visando à formação de uma comunidade latino-americana de nações". Para tal artigo constitucional, a integração latino-americana, mais do que uma prioridade de política externa de governo é uma prioridade de política externa de Estado, definida pela Assembleia Constituinte que elaborou a Carta Constitucional de 1988. No projeto de "formação de uma comunidade latino-americana de nações", está contida a busca da "integração econômica, política, social e cultural dos povos da América Latina"; integração de povos (da América Latina) para a formação de uma comunidade de nações (latino-americanas). De um lado, identifica-se o objetivo mais estrutural do que conjuntural: comunidade latino-americana de nações, e, de outro, o meio para a sua realização: integração multifacetária dos povos da América Latina.

Portanto, a integração regional sul e centro americana é um objetivo explícito contido na Carta Constitucional de 1988, o que interpretamos como uma prioridade permanente de Estado, prioridade de política externa de Estado, definida constitucionalmente, independente do governo que assuma temporariamente o comando conjuntural do executivo federal. De 1988 até hoje, foram desenvolvidas algumas iniciativas com a participação do Brasil no sentido de se construir essa integração multifacetária, "econômica, política, social e cultural dos povos da América Latina”, com 


\section{Conjuntura Austral}

a criação de alguns instrumentos de integração regional para a formação dessa comunidade de nações latino-americanas.

Os motivos dos processos de integração regional de Estados são complexos (HURREL, 1995). Podem ser expressão de maturidade dos Estados em sua trajetória de afirmação de identidade nacional, ou podem ser vias para a construção da maturidade nacional dos Estados que aderem a tais instrumentos de integração. Não entraremos na tipologia da integração regional de Estados, porque nosso objetivo é verificar o papel das cidades de fronteira como sujeitos de integração de base. E sobre isso, destacamos que antes mesmo da publicação dos motivos constitucionais citados, e antes das mudanças recentes pró-integração no cenário internacional, nas cidades integradas de fronteira já havia integração de fato. A integração regional não é uma novidade, mas uma experiência "tradicional" nas cidades integradas de fronteira. Assim, ao significado tradicional (fronteira para a afirmação da identidade territorial com defesa-filtro do fluxo de pessoas e mercadorias) é acrescentado o significado integrador: fronteira como espaçopossibilidade de encontro para a integração entre sujeitos coletivos diferentes, lindeiros. Tal segundo significado, porém, não é uma produção original do miolo político-jurídicoadministrativo do Estado, mas uma criação de vanguarda, mesmo se involuntária, das populações das cidades integradas de fronteira. O que o miolo do Estado realiza é o reconhecimento oficial, de acordo com seus hodiernos interesses, dessa docência prática relativamente antiga, integracionista, das populações integradas das cidades gêmeas e conurbadas de fronteira. Ou seja, a fronteira como espaço de integração é significado "antigo" na experiência de base das populações das cidades de fronteira com integração de fato. A novidade institucional nessa questão está no reconhecimento e reprodução dessa produção de significado também no âmbito do miolo político-administrativo do Estado.

Com o reconhecimento dessa modalidade de integração de base, por razões de interesse nacional na integração regional, o que o miolo do Estado passa a fazer é ecoar o discurso prático integracionista (integração de fato) produzido pelas populações das cidades integradas de fronteira. Aumenta-se, assim, o quantitativo de políticas públicas federais e estaduais para cidades e regiões de fronteira. No Brasil, recentemente, para 


\section{Conjuntura Austral}

citar apenas alguns exemplos, foram criadas universidades federais especificamente em cidades de fronteira, como a UNILA, Universidade Federal da Integração LatinoAmericana (2007), a UNIPAMPA, Universidade Federal do Pampa (2008), a UFFS, Universidade Federal da Fronteira Sul (2009). Outro exemplo da chegada dessa ampliação do significado de fronteira no miolo do Estado foi o reconhecimento federal da cidade gaúcha de Santana do Livramento, declarada, em 2009, cidade símbolo da integração brasileira com os países do Mercosul (Lei n ${ }^{\circ} 12.095$ de 19 de novembro de 2009). Antes disso, com a Lei $\mathrm{n}^{\mathrm{o}} 11.161 / 2005$, torna-se obrigatória a oferta, pela escola, do ensino de espanhol. Em suma, as ações integradoras informais desenvolvidas por razões de necessidade nas cidades integradas de fronteira, passam a receber $o$ reconhecimento institucional no miolo do Estado. Entendidas oficialmente apenas como lugar para a separação em relação aos Estados lindeiros, as fronteiras habitadas passam a ser compreendidas institucionalmente pelo miolo do Estado, mesmo se de forma incipiente, também pelo que já são de fato, ou seja, espaço-laboratório de integração de base entre as populações fronteiriças.

\section{Integração de vértice e de base}

Os sujeitos coletivos protagonistas dos processos de construção das experiências de integração regional de Estados são sujeitos localizados no vértice institucional de poder dos Estados e na base popular constitutiva de tais Estados. Porém, enquanto as experiências de integração de vértice podem ser caracterizadas pela transitoriedade dos eventos institucionais, e pela assinatura de acordos para a realização de projetos nem sempre executados, a integração de base é um dado permanente, fático, real, entre as populações das cidades integradas de fronteira.

Na medida em que o Estado vai adotando a integração regional como estratégia de defesa dos interesses nacionais com os demais Estados envolvidos em tais processos de participação articulada no cenário internacional multipolar, muda-se a compreensão do significado de fronteira e emerge o reconhecimento oficial do papel integrador fático das cidades de fronteira. 


\section{Conjuntura Austral}

Antes semiesquecida pelo miolo do Estado, reduzidas ao papel tradicional de defesa e afirmação de identidade, o miolo do Estado "descobre" a existência de cidades de fronteira que já vivem de forma integrada com as cidades dos Estados lindeiros antes mesmo do reconhecimento oficial da integração regional como valor político-estatal.

Especificamente, para citar alguns exemplos, nas seis áreas de cidades-gêmeas entre Brasil e Uruguai - Barra do Quaraí e Bella Unión, Quaraí e Artigas, Santana do Livramento e Rivera, Aceguá e Aceguá, Jaguarão e Rio Branco, Chuí e Chuy - a integração binacional com as cidades de Estados vizinhos já era consuetudinária antes mesmo que se falasse em integração regional entre Estados vizinhos no âmbito do miolo político-jurídico-administrativo dos Estados da América do Sul. Ou seja, a integração fática de base, nas fronteiras, precedeu os projetos de integração de vértice. De qualquer forma, porém, ambas são relevantes e complementares nos processos de integração regional de Estados dentro e fora do âmbito de suas fronteiras nacionais e regionais. A integração de base necessita do reconhecimento do miolo do Estado não para existir, pois já existe independentemente de tal reconhecimento, mas para a qualificação da integração de base, nas cidades integradas de fronteira, do ponto de vista de áreas específicas como saúde, educação, assistência social, segurança pública, onde a integração fática enfrenta impedimentos jurídicos derivados de uma legislação voltada para quem vive no miolo dos Estados e não nas áreas fronteiriças integradas (PUCCI, 2010).

Assim, para os fins integracionistas do Estado, certamente não são suficientes os meetings de vértice de Estado, com suas atividades de integração ao redor dos trabalhos de sujeitos dos altos e médios escalões dos Estados. Junto com a integração de vértice, emerge a constatação da necessidade do reconhecimento e promoção institucional das experiências de integração de base, que envolve diretamente e permanentemente as populações fronteiriças. Tal integração de base se desenvolve, sobretudo, de duas formas. Em primeiro lugar, pelas experiências de integração entre as populações (permanentes) das cidades-gêmeas e conurbadas das fronteiras brasileiras com seus vizinhos sulamericanos. Porém, além dessa modalidade principal de integração de base, há, também, a que ocorre por meio dos deslocamentos (tour) de setores das populações sul-americanas pela América do Sul por motivos de trabalho, eventos profissionais, estágios de estudo, 


\section{Conjuntura Austral}

turismo cultural. Tais eventos, concretamente, podem ser congressos internacionais de medicina, engenharia, sociologia, relações internacionais, educação física, enfermagem, psicologia realizados em cidades da América do Sul, como já ocorre em Santiago, Montevidéu, Brasília, São Paulo, Rio de Janeiro, Lima, Quito, Buenos Aires.

Integração de vértice, portanto, que se realiza por meio dos meetings de funcionários dos ministérios da defesa, saúde, educação, justiça, além dos meetings de chefes de Estado e de governo sul-americanos, associada à integração de base que se realiza há décadas entre as populações das cidades-gêmeas e conurbadas de fronteira, associada também, mais recentemente, à experiência de integração realizada circunstancialmente por grupos de profissionais, estudantes, pesquisadores sulamericanos, mais os cidadãos que praticam turismo cultural e ambiental pelo território sul-americano.

\section{Cidades conurbadas de fronteira e integração de base}

As cidades de fronteira atuam no âmbito da integração regional de base pela interação permanente entre as populações de cidades vizinhas, de Estados diferentes, situadas nas regiões de fronteira. Todavia, entre as cidades de fronteira, há as que interagem internacionalmente de forma mais ou menos intensa, sobretudo, pela proximidade geográfica em relação à linha-limite de fronteira. Assim, podem ser identificados três tipos diferentes de cidades de fronteira, com maior ou menor grau de interação fronteiriça de base: 1.cidades da faixa de fronteira, 2.cidades-gêmeas de fronteira e 3.cidades conurbadas de fronteira.

As cidades da faixa de fronteira são as 588 cidades que se encontram na faixa de $150 \mathrm{~km}$ da linha-limite para o interior do território brasileiro (MI, 2005, p.9-11). A interação internacional, fronteiriça de tais cidades é de menor intensidade em relação à que ocorre nas cidades-gêmeas de fronteira, que são as que se situam na linha-limite de fronteira ou bem próximas a ela, com uma cidade correspondente do outro lado da linhalimite de fronteira do Brasil com seus vizinhos sul-americanos (Ibidem, p.152-164). Qual a diferença entre cidades-gêmeas e cidades conurbadas de fronteira? Nem todas as cidades-gêmeas são cidades conurbadas, mas todas as cidades conurbadas são gêmeas. 


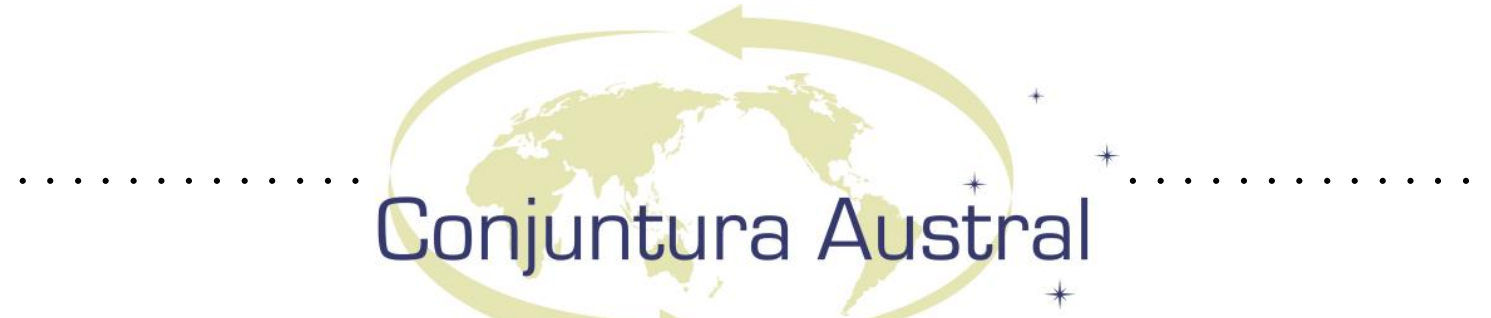

Não é suficiente afirmar que cidade conurbada de fronteira é a que apresenta a mesma malha urbana compartilhada com a cidade estrangeira lindeira. Cidades conurbadas binacionais de fronteira são as que entre elas não há acidentes geográficos (montanhas, rios) nem controle de pessoas e mercadorias na linha-limite por elas compartilhada.

Citando como referência o elenco da Portaria n.125, de 21 de março de 2014, do Ministério da Integração Nacional, publicado em 24 de março de 2014 no Diário Oficial da União, 29 são as cidades-gêmeas brasileiras de fronteira, a saber, desde o Norte até o Sul do país: 29.Oiapoque (Amapá) com Saint Georges (Guiana Francesa); 28.Bonfim (Roraima) com Lethem (Guiana); 27.Pacaraima (Roraima) com Santa Elena de Uairén (Venezuela); 26.Tabatinga (Amazonas) com Letícia (Colômbia); 25.Santa Rosa do Purus (Acre) com Santa Rosa (Peru); 24.Assis Brasil (Acre) com Bolpebra (Bolívia) e Iñapari (Peru); 23.Epitaciolândia (Acre) com Cobija (Bolívia); 22.Brasiléia (Acre) com Cobija (Bolívia); 21.Guajará-Mirim (Rondônia) com Guayaramerín (Bolívia); 20.Corumbá (Mato Grosso do Sul) com Puerto Suarez (Bolívia); 19.Porto Murtinho (Mato Grosso do Sul) com Puerto Palma Chica (Paraguai); 18.Bela Vista (Mato Grosso do Sul) com Bella Vista (Paraguai); 17.Ponta Porã (Mato Grosso Sul) com Pedro Juan Caballero (Paraguai); 16.Paranhos (Mato Grosso do Sul) com Ypeju (Paraguai); 15.Mundo Novo (Mato Grosso do Sul) com Salto de Guayra (Paraguai); 14.Guaíra (Paraná) com Salto del Guayra (Paraguai); 13.Foz do Iguaçu (Paraná) com Puerto Iguazu (Argentina) e Ciudad Del Este (Paraguai); 12.Barracão (Paraná) com Bernardo de Irigoyen (Argentina); 11.Dionísio Cerqueira (Santa Catarina) com Bernardo de Irigoyen (Argentina); 10.Porto Xavier (Rio Grande do Sul) com San Javier (Argentina); 9.São Borja (Rio Grande do Sul) com Santo Tomé (Argentina); 8.Itaqui (Rio Grande do Sul) com Alvear (Argentina); 7.Uruguaiana (Rio Grande do Sul) com Paso de Los Libres (Argentina); 6.Barra do Quaraí (Rio Grande do Sul) com Bella Unión (Uruguai) e Monte Caseros (Argentina); 5.Quaraí (Rio Grande do Sul) com Artigas (Uruguai); 4.Santana do Livramento (Rio Grande do Sul) com Rivera (Uruguai); 3.Aceguá (Rio Grande do Sul) com Aceguá (Uruguai); 2.Jaguarão (Rio Grande do Sul) com Rio Branco (Uruguai); 1.Chuí (Rio Grande do Sul) com Chuy (Uruguai). 


\section{Conjuntura Austral}

Posteriormente, a Portaria n.320, de 22 de julho de 2014, do Ministério da Fazenda, eliminou 03 entre as 29 cidades-gêmeas da portaria anterior, destacando que dentre elas 26 poderão ter regulação aduaneira peculiar para os objetivos da lei de regulamentação das lojas francas do lado brasileiro das fronteiras terrestres. As 03 cidades-gêmeas retiradas do elenco da portaria do Ministério da Integração Nacional são: 1.Santa Rosa do Purus (Acre) com Santa Rosa (Peru); 2.Paranhos (Mato Grosso do Sul) com Ypeju (Paraguai); 3.Barracão (Paraná) com Bernardo de Irigoyen (Argentina).

Dentre as 26 cidades-gêmeas elencadas, apenas 06 são cidades conurbadas de fronteira, com a metade delas concentrada no Rio Grande do Sul, especificamente na fronteira do Brasil com o Uruguai: 6.Tabatinga (Amazonas) com Letícia (Colômbia); 5.Ponta Porã (Mato Grosso do Sul) com Pedro Juan Caballero (Paraguai); 4.Dionísio Cerqueira (Santa Catarina) com Bernardo de Irigoyen (Argentina); 3.Santana do Livramento (Rio Grande do Sul) com Rivera (Uruguai); 2.Aceguá (Rio Grande do Sul) com Aceguá (Uruguai); 1.Chuí (Rio Grande do Sul) com Chuy (Uruguai).

Nas cidades conurbadas de fronteira, assim como nas cidades-gêmeas que não são conurbadas, também é feito o controle do fluxo de pessoas e mercadorias, mas ele é deslocado para fora da região metropolitana binacional conurbada. Pela vista aérea, percebe-se uma mesma malha urbana, mas, de fato, são duas cidades de dois Estados diferentes situadas em um mesmo território compartilhado. No caso das cidades-gêmeas brasileiras não conurbadas, pode haver razoável distância, separadas por rios com ou sem pontes entre as cidades, o que diminui a intensidade da interação entre elas, dado que se exige, em muitas situações, a travessia de barco entre uma cidade e outra. Além disso, nas cidades-gêmeas onde há rios e pontes, geralmente o controle de pessoas e mercadorias ocorre na linha-limite, antes da travessia da ponte internacional entre as duas cidadesgêmeas, o que representa, num certo sentido, uma interrupção na interação binacional entre as populações, diferente da situação das cidades conurbadas binacionais onde não há interrupção territorial e há fluxo contínuo de pessoas e mercadorias, interação sem interrupção uma vez que, como destacamos, o controle de pessoas e mercadorias é deslocado para fora da região conurbada internacional compartilhada pelas populações dos dois Estados das duas cidades binacionais lindeiras. 


\section{Conjuntura Austral}

Portanto, o processo de integração binacional de base é favorecido pela intensidade de interação entre as populações das cidades conurbadas de fronteira, diferente do que ocorre entre as cidades-gêmeas separadas por acidentes geográficos e com controles de Estado na linha-limite de fronteira. Porém, por sua vez, tal processo de integração-interação de base é mais intenso entre as populações das cidades-gêmeas de fronteira, não conurbadas, se comparadas às cidades da faixa de fronteira que não são cidades-gêmeas e podem se encontrar a $150 \mathrm{~km}$ da linha-limite de fronteira.

\section{Considerações finais}

A integração de fato nas cidades integradas da fronteira brasileira é uma realização das próprias fronteiras, que o fizeram sem a ajuda do miolo do Estado. Dessa forma, a política externa integracionista do Estado e o cenário internacional mais favorável à integração regional serviram apenas para o reconhecimento dessa experiência de integração de fato que lhes é anterior.

Integração não significa anulação de identidade, uniformização, mas estadoprocesso de unidade na diversidade dos sujeitos. Em linhas-gerais, pelo que se observa nas cidades conurbadas de fronteira do estado do Rio Grande do Sul, caracterizadas pela unidade na diversidade, chega-se à conclusão aberta de que os motivos da integração de base entre as populações de tais cidades conurbadas de fronteira são, sobretudo, motivos fáticos, materiais, ou seja, tal integração não é consequência de projetos (ideais) de integração, não é consequência de uma metafísica da integração, mas consequência da ausência de acidentes geográficos, o que possibilita fluxo contínuo de pessoas e mercadorias, e resultado da necessidade fática de sobrevivência econômica das populações binacionais dessas cidades de fronteira que se encontram distantes dos centros administrativos de seus respectivos Estados de pertencimento.

No caso de Santana do Livramento (Brasil) e Rivera (Uruguai), além do fator geográfico e econômico-comercial, a integração de fato entre as populações das duas cidades é condicionada também pela experiência dos casamentos binacionais, com a criação ao longo do século passado de famílias fronteiriças onde os filhos e netos dessas uniões mistas binacionais se consideram mais brasileiros ou mais uruguaios, ou seja, 


\section{Conjuntura Austral}

carregam em si (identidade fronteiriça) as duas nacionalidades, mesmo se com a identificação de dosagens diferentes (Ibidem, p.72).

Assim, as cidades integradas de fronteira, mesmo se involuntariamente, são cidades de vanguarda do ponto de vista dos hodiernos interesses integracionistas do Estado, pelos resultados que produziram ao longo de décadas em termos de integração de fato. Cabe saber se o miolo do Estado saberá valorizar e promover concretamente essa produção sociocultural, política e econômica das cidades integradas da fronteira brasileira. Porém, com ou sem o apoio institucional do Estado, as cidades de fronteira continuarão realizando o que já fazem há décadas sem o apoio do Estado: a prática cotidiana da integração fronteiriça como instrumento fático de existência, ou mesmo de sobrevivência.

\section{Referências}

ASEFF, Marlon. Retratos do exílio - Solidariedade e resistência na fronteira. Santa Cruz do Sul: Edunisc, 2009.

AUTOR. Cidades de fronteira e integração sul-americana. Jundiaí (SP): Paco Editorial, 2013.

DABÈNE, Olivier. A América Latina no século XX. Porto Alegre: EDIPUCRS, 2003.

DEBRAY, Régis. Éloge des frontières. Paris: Gallimard, 2010.

GARCIA, Fernando Cacciatore. Fronteira iluminada - História do povoamento, conquista e limites do Rio Grande do Sul a partir do Tratado de Tordesilhas. Porto Alegre: Sulina, 2010.

HURREL, Andrew. "O ressurgimento do regionalismo na política mundial". Contexto Internacional, Rio de Janeiro, v.17, n.1, jan/jul. 1995, p.23-59.

JORGE, Arthur Guimarães de Araújo. Rio Branco e as fronteiras do Brasil. Brasília: Editorial do Senado federal, 1999.

MATTOS, Carlos de Meira. Geopolítica - Vol.01. Rio de janeiro: Editora FGV, 2011.

MINISTÉRIO DA INTEGRAÇÃO NACIONAL (MI). Proposta de reestruturação do programa de desenvolvimento da faixa de fronteira. Brasília: 2005. 


\section{Conjuntura Austral}

PUCCI, Adriano Silva. O Estatuto da fronteira Brasil-Uruguai. Brasília: FUNAG, 2010.

SÁNCHEZ, Andrea Quadrelli. A fronteira inevitável: um estudo sobre as cidades de fronteira de Rivera (Uruguai) e Santana do Livramento (Brasil). Porto Alegre: UFRGS, 2002 (tese doutoral).

STEIMAN, Rebeca; MACHADO, Lia Osorio. Limites e Fronteiras Internacionais: uma discussão histórico-geográfica. Rio de Janeiro: Grupo RETIS, 2002. Disponível em: http://www.retis.igeo.ufrj.br/producao/artigos/limites-e-fronteiras-internacionaisuma-discuss\%c3\%a3o-hist\%c3\%b3rico-geogr\%c3\%a1fica/\#.U-jQiWq5fIU. Acesso em: $11 / 08 / 2014$.

\section{Resumo}

O objetivo do artigo é compreender a perspectiva brasileira sobre o papel das cidadesgêmeas de fronteira e, entre elas, as cidades conurbadas de fronteira como sujeitos coletivos protagonistas de integração de base no processo de integração regional sulamericana.

\section{Palavras-chave}

América do Sul; cidades-gêmeas de fronteira; integração regional

\section{Abstract}

The aim of the article is understand the role of twin cities border and among them, the border cities characterized by the binational conurbation as collective subjects protagonists of people integration on the South American regional integration process.

\section{Keywords}

South America; border twin cities; regional integration

Artigo recebido em 22 de outubro de 2014. Aprovado em 20 de fevereiro de 2014. 


\title{
Conjuntura Austral
}

\section{CHILE E BOLIVIA E O CONFLITO PARA ALCANÇAR O OCEANO: GUERRA DO PACIFICO E MUDANÇAS NAS RELAÇÕES ENTRE OS DOIS PAÍSES}

Chile and Bolivia and the conflict to achieve the ocean:
Pacific War and changes on relations between the two countries

\author{
Eduardo Ernesto Filippi ${ }^{1}$ \\ Carla Carpim Charão ${ }^{2}$
}

\section{Introdução}

A Guerra del Pacífico também conhecida como a 'Guerra dos dez centavos', ocorrida entre os anos de 1879 a 1884, foi o evento que deu origem aos problemas diplomáticos e fronteiriços entre Chile e Bolívia. O presente artigo busca mostrar as dificuldades das relações internacionais entre estes dois países, remetendo ao período da referida guerra como ponto de partida e trazendo as informações históricas sobre as tentativas de acordo dessa questão até os dias atuais.

A organização deste artigo foi realizada da seguinte forma: após a introdução se apresenta relatos históricos sobre as relações entre Chile e Bolívia, bem como imagens relacionadas à geografia da área de disputa, e fatos referentes às tentativas de tratados entre estes dois países. Finalizando com considerações sobre as possibilidades do que pode ocorrer após as decisões tomadas recentemente pelos atuais governos de Bolívia e Chile.

\footnotetext{
${ }^{1}$ Eduardo Ernesto Filippi - Doutor em Economia Política (Université de Versailles Saint-Quentin-enYvelines, França), Mestre em Economia Rural (UFRGS) e Bacharel em Ciências Econômicas (UFRGS). Professor e pesquisador nos Programas de Pós-Graduação em Economia (PPGE). Email: edu_292000@yahoo.com.br.

${ }^{2}$ Carla Carpim Charão - Estudante do Programa de Pós-Graduação em Estudos Estratégicos Internacionais Contemporâneos da Faculdade de Ciências Econômicas (UFRGS), Bacharel em Secretariado Executivo Trilíngue (Ulbra). Email: leecharao@yahoo.com.br.
} 


\title{
Conjuntura Austral
}

\section{Um breve histórico do litigio Chile x Bolívia}

O passado dos países sul-americanos está amarrado. Suas diferenças, hoje, podem ser nada além do que a necessidade de identidade de seus povos. A história de Chile e Bolívia como estados, e não mais colônias da Espanha, inicia-se na preocupação e disposição para demandar a independência do que hoje conhecemos como Estado peruano.

Por volta de 1819, o Chile soma forças com as 'Províncias Unidas do Rio da Prata $^{3}$ ' para promover e levar forças militares na 'Expedición Libertadora del Perú'. Essa expedição tinha como objetivo independizar o Estado peruano da coroa espanhola.

Conforme Dozer (1966), o estado chileno teria sido o principal patrocinador desta demanda, e já naquele período contava com empréstimos da Inglaterra. O autor também comenta que:

\begin{abstract}
As causas dessa desamizade remonta às guerras de independência, quando Chile financiava a expedição de San Martin contra Lima, esperando ser reembolsado dos custos da expedição. Nunca, porém, fora pago, nem recebera do Peru qualquer quantia por conta de uma pequena parte do empréstimo de um milhão de libras, que o Chile transferira ao país limítrofe em 1822, a fim de que os patriotas peruanos pudessem financiar a sua guerra contra as forças do vice-rei. (DOZER, 1966, p. 324)
\end{abstract}

O estado chileno auxiliou nas batalhas tanto terrestres quanto marítimas para garantir a independência dos países envolvidos nesta busca pela soberania. E isso não foi impeditivo para que Peru e Bolívia, mais tarde, assinassem um tratado secreto de "parceria" caso houvesse necessidade de combater qualquer estado que pudesse ameaçar sua soberania ou território.

Rosales (2011) relata que, ao final do ano de 1860, havia alguma proximidade entre os dois países, pois existia o interesse em finalizar as controvérsias comerciais relacionadas aos limites comerciais. No ano de 1866, foi possível a assinatura do Tratado que especificava o paralelo 24 de latitude meridional, a partir do Pacifico até os limites orientais do Chile, tema que se encontrava pendente desde a declaração de independência

\footnotetext{
${ }^{3}$ Leia-se aqui: Republica de Bolívar = Bolívia, Estado Oriental del Uruguay = Uruguai e Confederación Argentina = Argentina.
} 


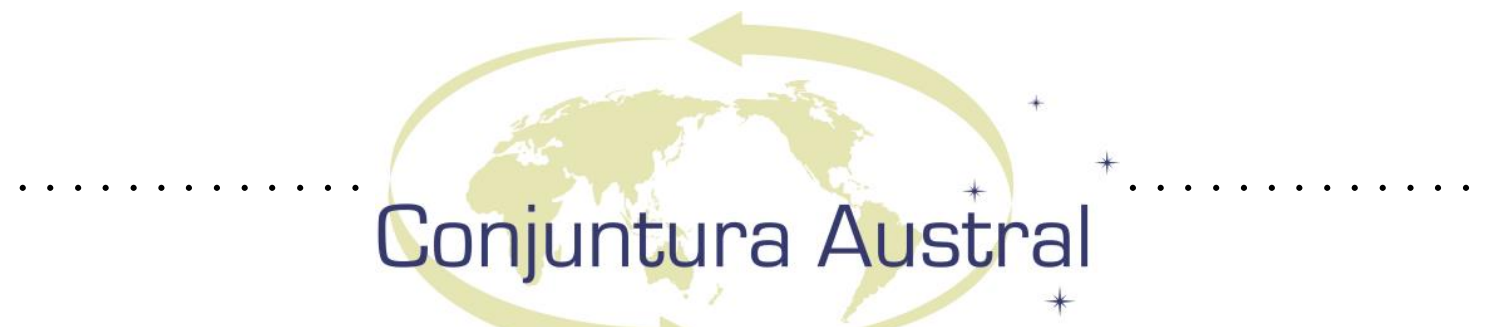

da Bolívia, em 1825. Conforme a autora, este tratado deveria estipular a distribuição equitativa da exploração dos depósitos do guano localizado na cidade de Mejillones, bem como o direito de exportação dos minerais extraídos daquele território.

As zonas salitreiras na divisa de Chile, Peru e Bolívia eram, por volta de 1860, as regiões mais disputadas pelos países andinos, conforme afirma Moreira (2010). Os ingleses foram os descobridores das propriedades do guano e do salitre para o cultivo de alimentos e fabricação de munição, conforme descrito por Eduardo Galeano (1970) no trecho a seguir:

\footnotetext{
O guano teve suas propriedades fertilizantes reveladas nos laboratórios britânicos; a partir de 1840, desde a costa peruana, começou sua exportação em grande escala. Os alcatrazes e as gaivotas, alimentados pelos fabulosos cardumes de correntes que lambem as margens, tinham acumulado nas ilhas e ilhotas, desde tempos imemoriais, grandes montanhas de excrementos ricos em nitrogênio, amoníaco, fosfatos e sais alcalinos: o guano se conservava puro nas costas sem chuva do Peru. Pouco depois do lançamento internacional do guano, a química agrícola descobriu que eram ainda maiores as propriedades nutritivas do salitre, e em 1850 já era muito intenso o seu emprego como adubo em campos europeus. As terras do velho continente dedicadas ao cultivo do trigo, empobrecidas pela erosão, [...], recebiam avidamente os carregamentos de nitrato de soda provenientes das salitreiras peruanas de Tarapacá e em seguida, da província boliviana de Antofagasta. (GALEANO, 1970, p. 188)
}

Empresários ingleses eram os principais responsáveis pela exportação destas matérias primas para os países da Europa, e estes estavam atrelados à sociedade chilena. A Bolívia, por sua vez, passava por um período de instabilidade política, o que ocasionou situações de revoltas em determinadas cidades. Dozer (1966) explica que faltava ao país o poder de uma constituição escrita. A cidade de Santa Cruz reduziu a anarquia e harmonizou as rivalidades das seis cidades fundamentais do altiplano boliviano, "cada uma delas no núcleo de localismo e isolada das outras por semanas de viagem em lombo de mula através de ermos caminhos nas montanhas" (DOZER, 1966, p. 338). O autor ainda cita que houve líderes como José Ballivián, presidente que subiu ao poder através do exército, no ano de 1841, que reconhecidamente se esforçou para promover estabilidade, paz e desenvolvimento econômico à nação. Ballivián renunciou em 1847, 


\section{Conjuntura Austral}

desgostoso com o estado, e deixou o país. José Mariano Melgarejo, em 1864, também fez esforços para reviver o nacionalismo entre os bolivianos.

A Bolívia passou por sérias dificuldades econômicas ao longo do século XX. Enquanto o Chile já possuía uma estrutura que lhe permitia organizar a sociedade, a Bolívia estava longe de estabelecer como organizar-se administrativamente e qual seria seu formato, tanto de política interna quanto externa.

De acordo com Dozer (1966), a abertura para a colonização europeia no século XIX realizada no Chile foi, comparando-a aos demais países sul americanos, de ordenação, crescimento e desenvolvimento para a região:

Durante a presidência do general Bulnes, o Chile experimentou um verdadeiro despertar intelectual. Fundou-se uma sociedade literária chilena em 1842, e no mesmo ano surgiu a Universidade do Chile; [...] a nova instituição incluía cinco Faculdades. (DOZER, 1966, p. 328).

Os líderes chilenos optaram por diminuir o poder da igreja católica e criaram acordos econômicos com o governo inglês, além de receber apoio norte-americano para alguns projetos específicos, a exemplo:

[...] Em 1840 foi inaugurada a primeira companhia de navegação marítima, que se destinava a explorar não só o tráfico costeiro, mas também o comércio com a Europa. Essa companhia, financiada por capitais londrinos, foi organizada por um cidadão norte-americano, William Wheelwright. Em particular, a corrida do ouro da Califórnia estimulou o comércio do Chile com os Estados Unidos, criando neste último país uma nova procura de trigo chileno." (DOZER, 1966, p. 326).

\section{Os Tratados}

Conforme Rosales (2011), vários tratados foram assinados entre Chile e Bolívia na tentativa de regularizar as disputas referentes aos limites territoriais entre os dois países, bem como de dividir a exportação do salitre. Houve o tratado que foi o estopim da Guerra do Pacifico, conforme $\operatorname{Santos}^{4}$ (2002), citado por Reyes (2009, p. 172): “[...]

\footnotetext{
${ }^{4}$ SANTOS, L. C. V. G. O império e as republicas do Pacífico. Curitiba: Ed. UFPR, 2002. 177 p.
} 


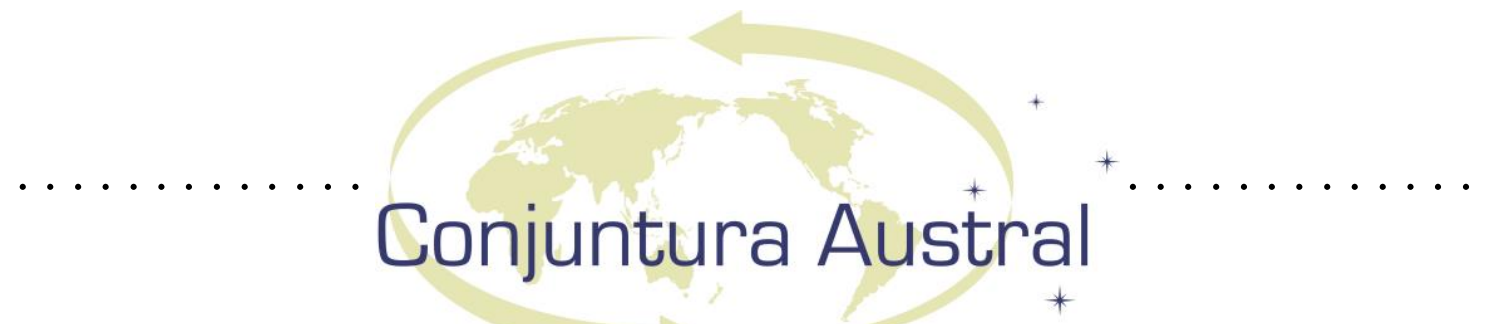

havia um acordo estabelecido entre Bolívia e Chile, no ano de 1874, que protegia o capital chileno de novos impostos por um período de 25 anos".

A Bolívia estava sofrendo uma forte pressão por parte do governo peruano, de acordo com Dozer (1966), para que tomasse providências contra os investimentos do Chile no território vizinho, pois o Peru padecia, com o poder de exportação "chileno", algo que eles consideravam uma concorrência desleal, já que as empresas chilenas possuíam o apoio estrangeiro. E a Bolívia em crise - conforme afirma Rosales (2011) então governada por Hilarión Daza, decide que a melhor estratégia seria aumentar os valores dos impostos, algo que o governo chileno interpreta como uma violação do tratado de 1874, o que, para Ortega (1984), gera a ocasião perfeita para a elite chilena, que já pregava internamente tomar o controle daqueles territórios.

Empresas chilenas diretamente afetadas se negaram a pagar a diferença dos 10 centavos de peso para cada 100kg de salitre extraídos do território boliviano.

Marton (2012) afirma que o governo boliviano ameaçou tomar as empresas chilenas. O 'Tratado de Alianza defensiva', firmado entre Peru e Bolívia, tinha como principal objetivo proteger os recursos naturais e também o deserto de Atacama. Tal tratado, considerado secreto pelo governo chileno, foi assinado no dia 6 de fevereiro de 1873. O mesmo obriga o segundo país a participar em seu favor numa possível declaração de guerra. A seguir, a tradução livre para o primeiro artigo deste tratado:

Artigo $1^{\circ}$ - As partes contratantes se unem para garantir mutuamente sua independência, sua soberania e a integridades de seus territórios respectivos, obrigando-se nos termos do presente tratado a defender-se de toda agressão externa, assim seja de um ou outro Estado independente ou de uma força sem bandeira que não obedeça a nenhum poder reconhecido. Tratado de Aliança Defensiva PeruBolívia 5 .

\footnotetext{
${ }^{5}$ Articulo I.- Las altas partes contratantes se unen y ligan para garantizar mutuamente su independencia, su soberanía y la integridad de sus territorios respectivos, obligándose en los términos del presente tratado a defenderse de toda agresión exterior, bien sea de uno u otros Estados independientes, o de una fuerza sin bandera que no obedezca a ningún poder reconocido. - Tratado de Alianza Defensiva Perú-Bolivia. (Tradução nossa.)
} 


\section{Conjuntura Austral}

Autores como Reyes (2009) e Galeano (1970) afirmam que houve por parte da elite chilena, e também do empresariado inglês, um forte apoio à proclamação de guerra contra a Bolívia pela ofensa na tentativa não apenas da cobrança de impostos, como também de tentar tomar as instalações das empresas alojadas em território boliviano.

[...] A venda das concessões de exploração da área e a entrega do guano e do salitre a John Thomas North, proprietário da Liverpool Nitrate Company (MERCADO, 1988, p. 20) levaram o Chile, contando com apoio inglês, a atacar o Peru e a Bolívia, tomando desses países esse árido território que além de conter diversas riquezas minerais era a porta de saída da Bolívia para o Oceano Pacifico, deixando claro que os interesses econômicos impõem uma definição clara dos limites. [...] (MERCADO, 1998 apud REYES, 2009, p. 172)

Roca (2004), porém, informa de outra maneira este episódio. A Compañía de Salitres y Ferrocarril de Antofagasta, era anglo-chilena e seu principal acionista era Agustín Edwards Ross. Esta empresa teria recebido privilégios do governo boliviano, entre eles o da companhia ter se tornado uma sociedade anônima. As concessões e benefícios dados foram permitidos até o ano de 1878, quando foi ratificada a lei que ocasionou a guerra. $\mathrm{O}$ autor reproduz em seu texto o artigo único da lei traduzido, a seguir:

Aprova-se a transação efetuada pelo Executivo de 27 de novembro de 1873, com o procurador da Cia. de Salitres y Ferrocarril de Antofagasta a condição de pagar em dinheiro, pelo menos um imposto de 10 centavos por quintal de salitre exportado ${ }^{6}$. (ROCA, 2004, p. 24)

A Guerra do Pacífico, iniciada em 1879, que deu ao Chile, em menos de cinco anos, toda a região que hoje é conhecida como o norte do país (algo que pertenceu tanto ao Peru quanto à Bolívia) pode ter sido motivada exclusivamente por interesses de uma única empresa, tendo tirado da Bolívia a sua soberania para o mar e seus portos.

A Guerra do Pacífico só terminou oficialmente com a assinatura do Tratado de Ancón. Reyes (2009) diz que a guerra do Pacífico acabou com a assinatura deste

\footnotetext{
${ }^{6}$ Se aprueba la transaccíon efectuada por el Ejecutivo de 27 de noviembre de 1873, con el apoderado de la Cia. De Salitres y Ferrocarril de Antofagasta a condición de hacer efectivo, como mínimo, un impuesto de 10 centavos por quintal de salitre exportado. (Tradução nossa.)
} 


\section{Conjuntura Austral}

documento, no dia 20 de outubro de 1883, e que a trégua entre Bolívia e Chile só foi assinada oficialmente no dia 04 de abril de 1884. Ambos os acordos, no entanto, consagraram o triunfo chileno com a entrega do litoral boliviano e das esplêndidas províncias de Antofagasta e Tarapacá ao Chile. Galeano (1970) ressalta também que a perda do estado boliviano é superior ao que a maioria dos autores informa, se acrescentarmos ao cálculo a privação da maior mina de cobre do país, localizada em Chuquicamata, conforme trecho a seguir [...] A Bolívia por sua vez não se deu conta do que perdera com a guerra: a mina de cobre mais importante do mundo atual, Chuquicamata, localiza-se exatamente na província agora chilena de Antofagasta. [...] (GALEANO, 1970, p. 190)

O primeiro mapa ${ }^{7}$ anexado a este artigo mostra um fator importante: situar e compreender como cada país coloca as questões de seus limites territoriais. A região salitreira concorrida pelos países andinos situa-se entre a Cordilheira dos Andes e o Oceano Pacífico. É localizado, entre os paralelos 19 e 25 do Hemisfério Sul.

\section{Figura 1:}

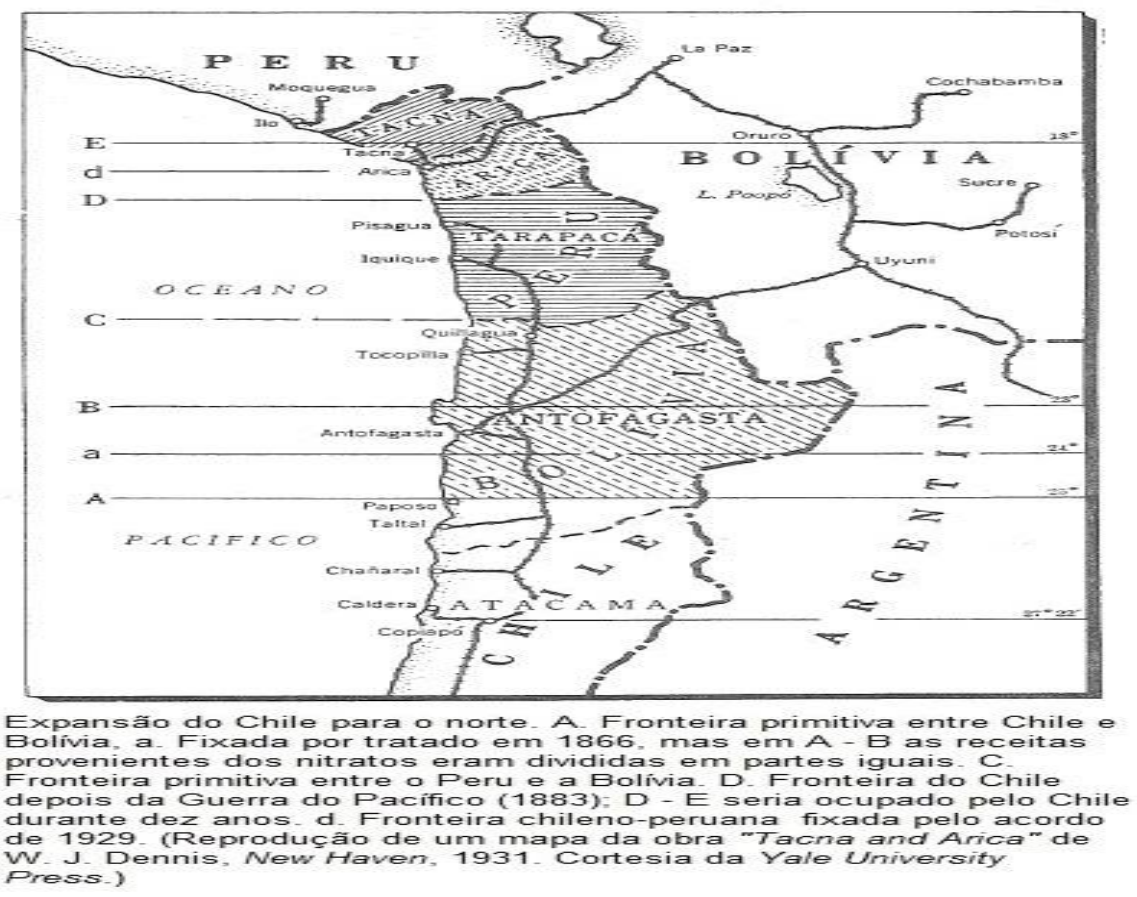

\footnotetext{
${ }^{7}$ DOZER, Donald Marquand. América Latina uma perspectiva histórica. Porto Alegre: Globo, 1966. 393 p.
} 


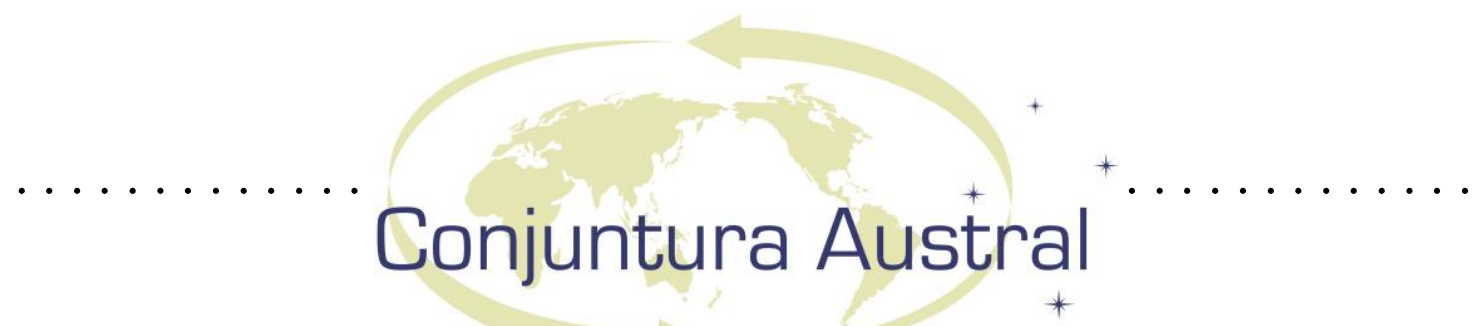

Moreira (2010) cita a indenização territorial entre Chile e Bolívia, herdada do período colonial que se manteve até 1866 , quando ambos os países assinaram um tratado limítrofe no qual se fixava o paralelo 24 como linha demarcatória que determinava a soberania referente ao deserto de Atacama, área salitreira, que também continha o guano. Sendo assim, o sul desta linha passava a ser território chileno, e o norte pertencia à Bolívia. "[...] O tratado previa a exploração compartilhada entre empresas chilenas e bolivianas do guano produzido entre os paralelos 23 e 25 , bem como a repartição das entradas fiscais pelas exportação do salitre" [...] (MOREIRA, 2010, p. 92). Apesar do autor aceitar essas demarcações, há incoerência entre as informações documentadas na Biblioteca Nacional do Chile e o que apresentam outras publicações sobre o tema. Como mostra o segundo mapa do livro de Jaime Eyzaguirre ${ }^{8}$, os chilenos contestam, através de alguns de seus historiadores, que a região norte que o Chile ocupou fosse de fato boliviana. Sob alegações de que havia poucos nativos na região quando os exploradores chilenos chegaram naquelas províncias.

O Chile atraiu muito, em especial, os capitais ingleses - sobretudo a cidade de Valparaíso, que se tornou um porto mais britânico do que chileno. As exportações de cobre, nitratos, salitre e guano atingiram cifra inéditas, e entre 1845 e 1857, o comércio exterior do Chile triplicou, fazendo de Valparaíso o porto mais movimentado da costa ocidental, abaixo apenas de São Francisco da Califórnia. (DOZER, 1966, p. 330)

O guano e o salitre possuíam utilidade como fertilizantes e também eram utilizados para a fabricação de munição, pois, manipulados, podiam ser transformados em nitrato de sódio. Para a indústria bélica européia, esse interesse chega ao fim no ano de 1909, quando os químicos alemães Fritz Haber e Carl Bosch ${ }^{9}$ descobrem como manipular, em escala industrial, os elementos nitrogênio e hidrogênio, transformando-os em amoníaco. Esse processo, após ser patenteado, ganha o nome de Síntese de HaberBosch. Galeano (1970, p. 193) comenta que o aperfeiçoamento desta síntese derruba a

\footnotetext{
${ }^{8}$ En torno de los antecedentes de la reclamación marítima boliviana hasta el Tratado de Paz de 1994 entre Chile y Bolivia y dos Negociaciones durante el siglo XX. Biblioteca Del Congresso Nacional de Chile. Disponível em: <http://www.bcn.cl/bibliodigital/pbcn/estudios/estudios_pdf_estudios/nro291.pdf> ${ }_{9}^{9}$ Síntese de Haber-Bosch. Disponível em <http://pt.wikipedia.org/wiki/S\%C3\%ADntese_de_HaberBosch>
} 


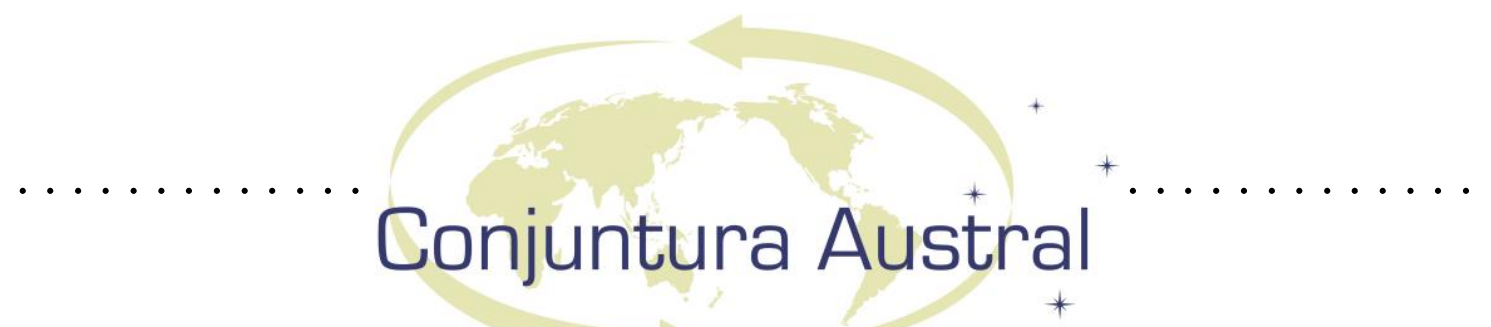

importância da exportação do salitre, o que, consequentemente, gera uma profunda crise econômica no Chile. Seguindo os passos dos exploradores californianos, o empresariado chileno passa a focar sua força de trabalho na exploração de cobre e ouro.

\section{Negociações entre os dois países no século XX}

No dia 20 de outubro de 1904, o embaixador boliviano Alberto Gutiérrez e o ministro de Relações Exteriores de Chile, Emilio Bello Codecido, assinaram, em Santiago, o Tratado de Paz, Amizade e Comércio. Roca (2004) retrata que, por meio deste, a Bolívia foi obrigada a abdicar formalmente "[...] não apenas a totalidade de seu litoral marítimo sobre o Oceano Pacifico, o qual Chile já ocupava desde 1879, se não mais, uns 7.000 $\mathrm{Km}^{2}$ adicionais no altiplano (Chilcaya e Ascotán) ${ }^{10}[\ldots]$.. (ROCA, 2004, p. 11). Essas províncias não estavam incluídas no Pacto de Trégua, assinado em abril de 1884. De acordo com o mesmo autor, existiam reservas de minerais ricos cuja exploração estava em pleno andamento. O Chile concedeu compensações econômicas no intuito de suavizar as perdas bolivianas, na tentativa de esquecer o passado e restabelecer o conceito de boa vizinhança. Na passagem a seguir, Roca (2004) expõe o sentimento boliviano sobre o impacto que causou ao país a perda de sua saída para o mar:

\footnotetext{
Porém, não obstante o século que leva ao Tratado foi incapaz de fechar feridas abertas pela guerra. Continua o mar sendo recordação de uma época em que um país forte agrediu a um país fraco, deixando-o incompleto, mutilado e reduzido ao enclausuramento. O que o sentido da frase do presidente Carlos Mesa quando disse faltando poucas semanas de assumir seu mandato, afirmou que entre a Bolívia e o Chile existe paz, mas não amizade ${ }^{11}$. (ROCA, 2004, p. 12)
}

\footnotetext{
10 “[...] sólo la totalidade de su litoral marítimo sobre el Océano Pacífico que Chile ya ocupaba desde 1879, sino, además. Unos $7.000 \mathrm{Km}$ cuadrados adicionales en el altiplano (Chilcaya y Ascotán)[...]" (ROCA, 2004. p. 11) (Tradução livre.)

${ }^{11}$ Pero, no obstante el siglo que lleva de vida, el Tratado ha sido incapaz e cerrar las heridas abiertas por la guerra. Continúa el mal recuerdo de una época en la que un país fuerte agredió a otri débil, dejándolo incompleto, mutilado y reducido al enclaustramiento. Eso explica el sentido de una frase del presidente Carlos Mesa cuando, a las pocas semanas de asumir el mando, afirmó que entre Bolivia y Chile existe paz, no así amistad. (p. 12) (Tradução nossa.)
} 


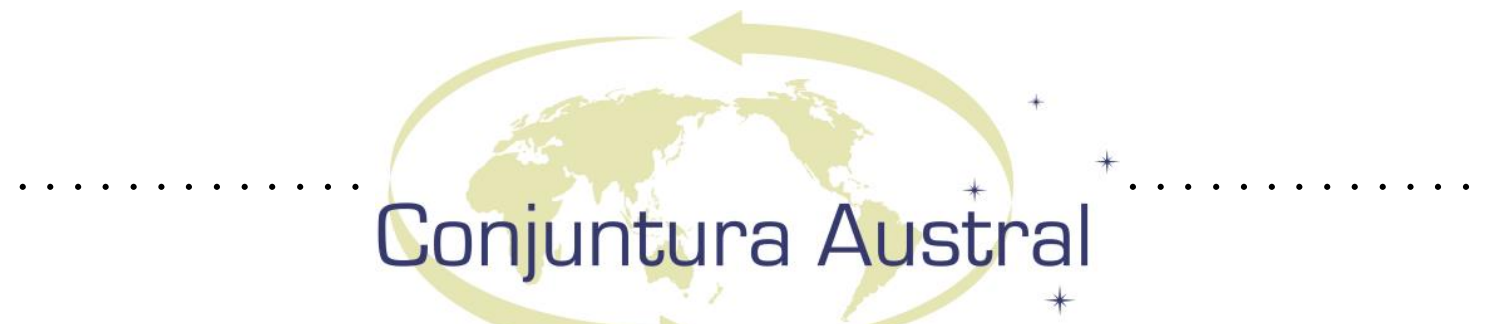

Seguindo com o mesmo autor, houve esforços por parte do governo boliviano tentando para o Tratado de Paz, em 1910, com o presidente Eliodoto Villazon, o qual empenhou-se em cancelar o acordo. $\mathrm{Na}$ proposta deste presidente constava que os territórios de Árica e Tacna poderiam ser cedidos para Bolívia como forma de indenização. O governo do Chile recebeu "friamente tal informação", enquanto o do Peru posicionou-se favorável, caso Tacna permanecesse como seu território. Isto porque no Tratado de Ancón, de 1881, assinados entre Chile e Peru, permanecia pendente a definição destas duas províncias (algo que só se resolveria em 1929). O Chile pretendia permanecer com ambas as regiões. Sendo assim a consulta boliviana foi logo esquecida.

Ainda de acordo com Roca (2004), o governo boliviano de Bautista Saavedra em 1922, solicitou a então recém criada ONU que intercedesse e aplicasse o artigo 19 de sua carta constitutiva, para revisar o tratado de Paz:

\begin{abstract}
A Assembleia poderá, em qualquer momento, convidar os membros da Sociedade para que façam uma nova avaliação dos tratados que tenham deixados de ser aplicáveis, assim como das situações internacionais cuja permanência poderia colocar em perigo a paz no mundo ${ }^{12}$.
\end{abstract}

Havia por parte da diplomacia chilena uma forte pressão, que encontrou apoio em outras delegações, e a solicitação da Bolívia foi rejeitada. [...] No ano seguinte, o chanceler Ricardo Jaimes Freyre incitou o Chile para que, por via bilateral, o tratado fosse modificado de maneira que a Bolívia voltasse ao mar. A resposta foi rigorosamente negativa ${ }^{13}[\ldots] .($ ROCA, 2004, p.13)

\title{
A proposta de Kellogg
}

No ano de 1926, o secretário de Estado norte-americano Frank Billings Kellogg encaminhou ao Chile, Bolívia e Peru uma nota, como observa Rosales (2011),

\footnotetext{
${ }^{12}$ La Asamblea podrá, en cualquier tiempo, invitar a los miembros de la Sociedad a que procedan a un nuevo examen de los tratados que hayan dejado de ser aplicables, así como de las situacione internacionales cuyo mantenimiento podría poner en peligro la paz del mundo. (ROCA, 2004, p.13) (Tradução livre.)

${ }^{13} \mathrm{Al}$ año siguiente, el canciller Ricardo Jaimes Freyre exhortó a Chile a que, por la vía bilateral, el tratado fuera modificado de manera que Bolivia volviera al mar. La respuesta fue una terminante negativa.. (ROCA, 2004, p.13) (Tradução livre.)
} 


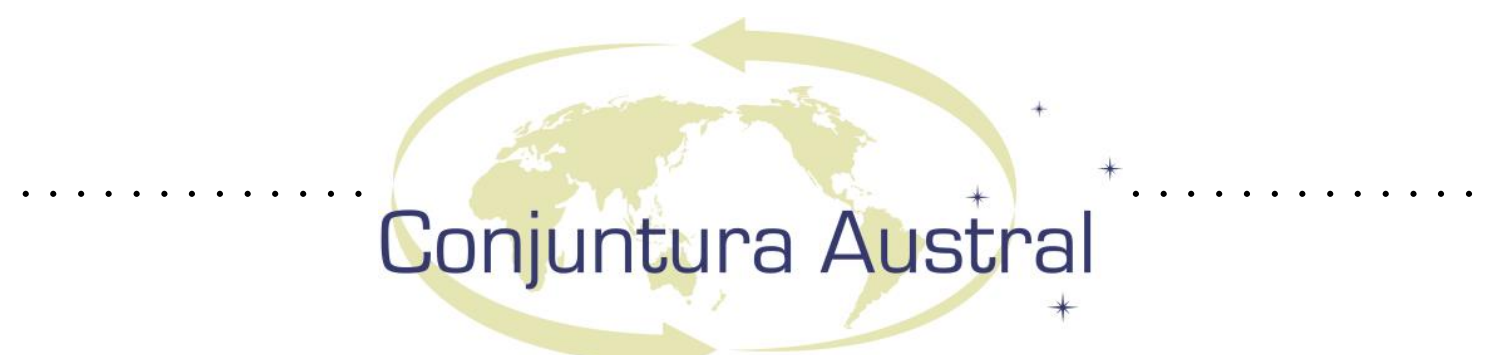

considerando alternativas distintas. A proposta era que Chile e Peru transferissem à Bolívia as províncias de Tacna e Árica. O documento estipulava que houvesse compensações econômicas das quais a Bolívia deveria pagar pela mudança dos direitos territoriais. A proposta foi bem recebida pelo governo boliviano, tendo sido aceita formalmente através de seu chanceler. Aqui, os autores confirmam como teria sido a aceitação do Chile a este pedido. Roca (2004) diz que este foi recebido com simpatia pelo governo chileno. Porém, houve uma forte negativa por parte do governo peruano. Rosales (2011) relata que a diplomacia chilena assumiu uma atitude flexível. Porém, as expectativas foram anuladas pelo Peru, tendo sido sua resposta para a Proposta de Kellogg a seguinte:

\begin{abstract}
A controvérsia de Tacna e Árica se relaciona intima e estreitamente com a honra e a dignidade do Peru. Tacna e Árica foram, desde o tempo colonial até o presente, parte integrante do nosso território. Estas regiões que formam um pedaço do coração nacional, não podem ser transferidas a uma terceira potência, em plena paz, sem que a honra nacional seja prejudicada, sem que a dignidade do país fique manchada e sem que as expectativas do Peru sejam desrespeitadas ${ }^{14}$. (ROSALES, 2011, p. 15)
\end{abstract}

Assim, foram fechadas as portas para a eventual saída da Bolívia ao mar. Conforme Roca (2004), ficou decidido, três anos após este episódio, em 1929, que Tacna seria devolvida ao Peru, enquanto Árica continuaria sendo parte do território chileno. Determinou-se que nenhum deles desistiria de todo ou parte daquelas províncias a uma "terceira potência" (neste caso a Bolívia), sem o assentimento do outro. “[...] Desta forma, e como se tem repetido tantas vezes, Chile colocou um cadeado à saída ao mar, enquanto o Peru ficou com a chave ${ }^{15}$. [...]" (ROCA, 2004, p. 14)

\footnotetext{
${ }^{14}$ La controversia de Tacna y Arica se relaciona íntima y estrechamente con el honor y la dignidad del Perú. Tacna y Arica se relaciona fueron, desde la época colonial hasta el presente, parte integrante de nuestro territorio. Estos territorios, que forman un pedazo de corazón nacional, no pueden ser transferidos a una tercera potencia, en plena paz, sin que el honor nacional sufra menoscabo, sin que la dignidad del país quede mancillada y sin que las más caras expectativas del Perú queden burladas. (Maira, Luis y Murillo de la Rocha, Javier, Óp. Cit., pág. 47, Apud Rosales, 2011, p. 15) (Tradução nossa.)

15 [...]De esa manera, y como se ha repetido tantas veces, Chile puso el candado a nuestra salida al mar mientras Perú se quedó con la llave. [...] (ROCA, 2004, p. 14) (Tradução nossa.)
} 


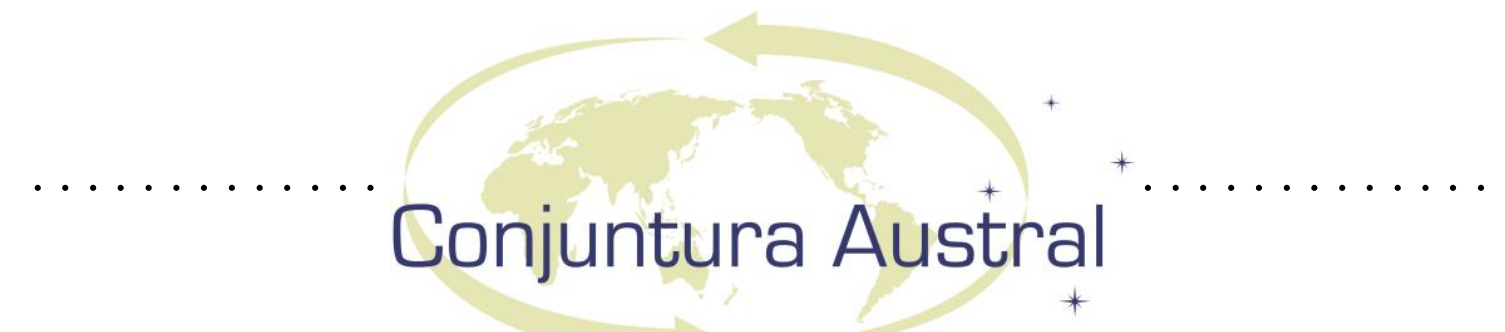

O historiador e diplomata, Ramiro Prudêncio recorda-se que se o Chile aceitasse dar um corredor ao norte de Árica, teriam que consultar ao Peru devido ao Tratado de 1929. Por isso, -“Sempre devemos ter muito boa relação com o Peru, e ainda mais depois do acordo, porque além das 80 milhas de possível mar boliviano vem o mar peruano e se deverá negociar o livre transito."- É 'óbvio' que para concretizar qualquer mudança de territórios ao norte de Árica é 'indispensável' o consentimento do Peru, conforme o ex chanceler (boliviano) Javier Murillo, que assim determina o Protocolo Adicional do Tratado de $1929 . .^{16}$

\title{
As tratativas entre o presidente chileno Gabriel González Vilela (1946 - 1952) e Enrique Hertzog Garaizabal (1947 - 1949)
}

O documento da Biblioteca Nacional do Congresso do Chile ${ }^{17}$ (2005), com base nas pesquisas do historiador chileno Oscar Pinochet, afirma que o governo do presidente Gabriel González Vilela cogitou, em 1950, realizar o acordo de soberania ao mar para Bolívia, no intuito de explorar o lago Titicaca para produzir energia. O lago está situado a 3810 metros de altitude, com uma extensão de $8100 \mathrm{~km}^{2}$. É considerado o lago mais alto do mundo.

Nesta mesma passagem, o documento ressalta a visita do presidente chileno a Washington e o interesse do então presidente americano no desenvolvimento da região e seu apoio a estes dois acordos.

O documento da Biblioteca Nacional do Chile, ainda informa:

\begin{abstract}
O presidente González Videla contou em suas memórias que se inspirou nos planos de irrigação utilizando o lago Titicaca feitos em 1922 pelo engenheiro chileno Luis Lagarrigue, referente a milhares de hectares, e seu uso para a produção de energia elétrica destinada as novas industrias e as ferrovias ${ }^{18}$. (p. 45)
\end{abstract}

\footnotetext{
${ }^{16}$ El historiado y diplomático Ramiro Prudêncio recuerda que si Chile acepta dar un corredor al norte de Arica, se tiene que consultar al Perú de acuerdo con El Tratado de 1929. Por eso, "siempre debemos tener una muy buena relación con Perú, y más aún después del fallo, porque más Allá de las 80 millas del potencial mar boliviano viene el mar peruano y se deberá negociar el libre tránsito". Es "obvio" que, para concretar cualquier transferencia de territorios al norte de Arica, es "indispensable" el consentimiento del Perú, secunda el excanciller Javier Murillo, que recuerda que así lo determina el Protocolo Adicional al Tratado de 1929. Noticia: Se reaviva la oferta de Charanã, y Perú surge como factor clave - La Razón Edición Impresa / Ricardo Aguilar Agramon (Tradução nossa.)

17 En torno de los antecedentes de la reclamación marítima boliviana hasta el Tratado de Paz de 1994 entre Chile y Bolivia y dos Negociaciones durante el siglo XX. Biblioteca Del Congresso Nacional de Chile. Disponível em: 〈http://www.bcn.cl/bibliodigital/pbcn/estudios/estudios_pdf_estudios/nro291.pdf>

${ }^{18}$ PINOCHET DE LA BARRA, Oscar. ¿Puerto para Bolivia? Centenaria negociación. Santiago, Chile, Editorial Salesiana, 1987, 112 p. - "El presidente González Videla há contado en sus Memorias que se
} 


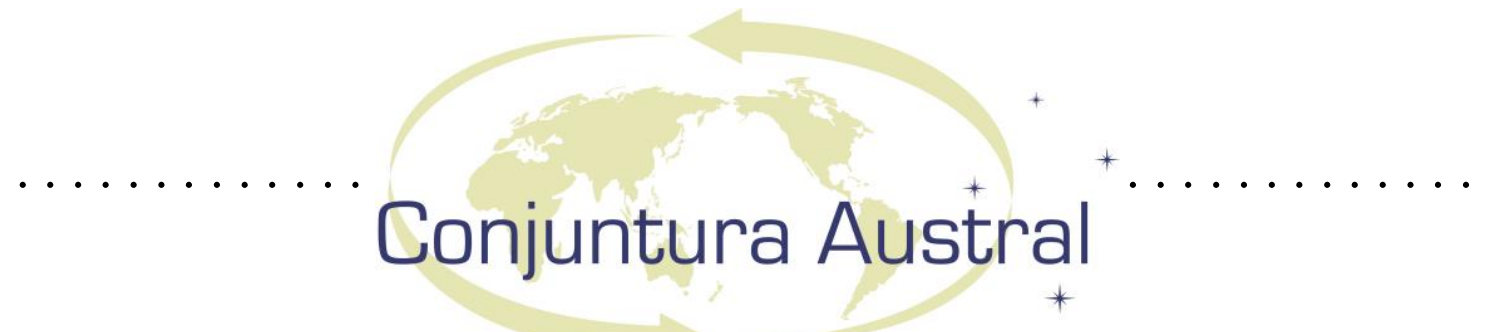

\section{As tratativas entre Hugo Banzer e Augusto Pinochet}

Em 1973, com o total apoio da CIA (Central Intelligence Agency) e patrocínio dos EUA, sobe ao poder o general Augusto Pinochet, que, por provável pressão pública, não firma o acordo negociado entre os anos de 1985 a 1987 de saída ao mar para a Bolívia, conforme declaração do ex-cônsul da Bolívia no Chile Jorge Siles, em entrevista a Ricardo A. Agramont ${ }^{19}$ (2014) que teria participado de toda a negociação.

As tratativas para um acordo de soberania ao mar para Bolívia, entre os governos de Augusto Pinochet e Hugo Banzer recebe o nome da região onde as reuniões aconteceram. Chamado como El Abrazo de Charanã, ou, ainda, Negociación de Charaña.

Ricardo A. Agramont, jornalista do periódico boliviano La Razón, teve uma matéria/entrevista publicada em fevereiro de 2014 relembrando o que aconteceu durante a negociação de Charaña.

A negociação de Charaña começou no dia 08 de fevereiro de 1975 com a Ata de Charaña, assinada pelos ditadores Hugo Banzer, da Bolívia, e Augusto Pinochet, do Chile. O documento tinha a pretensão de acertar as bases para solucionar o problema marítimo boliviano ${ }^{20}$.

O periodista constatou que, em agosto de 1975, o embaixador boliviano Guillermo Gutiérrez entregou ao chanceler do Chile, Patrício Carvajal, uma proposta renovada. A ideia era fornecer à Bolívia um corredor ao norte de Árica, com 50 quilômetros de extensão, preferencialmente próximo às regiões de Iquique, Antofagasta ou Pisagua ${ }^{21}$.

\footnotetext{
inspiró en los planes de regadío con aguas del lago Titicaca hechos en 1922 por el ingeniero chileno Luis Lagarrigue, de varios miles de hectáres, y su uso para producción de energía eléctrica destinada a las nuevas industrias y a los ferrocarriles.” (p. 45) (Tradução livre.)

${ }^{19}$ AGRAMONT, Ricardo Aguilar. Se reaviva la oferta de Charaña, y Perú surge como factor clave. La Razón, Disponível em: <http://www.la-razon.com/suplementos/animal_politico/reaviva-oferta-CharanaPeru-factor_0_1994800576.html>.

${ }^{20}$ La negociación de Charaña se inició el 8 de febrero de 1975 con el Acta de Charaña, firmada por los dictadores Hugo Banzer, de Bolivia, y Augusto Pinochet, de Chile. El documento tenía La pretensión de sentar las bases para solucionar el problema marítimo boliviano. (Traduçao livre)

${ }^{21}$ AGRAMONT, Ricardo Aguilar. Se reaviva la oferta de Charaña, y Perú surge como factor clave. La Razón, Disponível em: <http://www.la-razon.com/suplementos/animal_politico/reaviva-ofertaCharana-Peru-factor_0_1994800576.html>

${ }^{21}$ AGRAMONT, Ricardo Aguilar. Se reaviva la oferta de Charaña, y Perú surge como factor clave. La Razón, Disponível em: <http://www.la-razon.com/suplementos/animal_politico/reaviva-ofertaCharana-Peru-factor_0_1994800576.html>
} 


\section{Conjuntura Austral}

O diplomata chileno Ramiro Prudêncio respondeu à proposta de sessão soberana para um corredor ao norte da cidade de Árica, em dezembro de 1975. Haveria continuidade terrestre até o mar e uma extensão de costa de oito quilômetros. Nas palavras do diplomata, "Esta oferta é a mais importante por ser a mais concreta." Ele afirma que antes disso se falava apenas em solucionar o problema, mas não se comentava sobre negociações ${ }^{22}$.

Agramont cita também o historiador Máximo Quitral Rojas, que enumerou alguns dos principais motivos que levaram o presidente Augusto Pinochet a tentar a aproximação com a Bolívia: 1) O Chile vivia um momento de isolamento internacional por sua ruptura com a democracia (tendo o país sido expulso do G7 e de outras organizações internacionais); 2) a afinidade ideológica com o regime de Hugo Banzer, e 3) melhorar sua situação geopolítica, pois havia tensão com a Argentina (devido ao litígio referente às ilhas Nueva, Picton e Lennox) e com o Peru (por rumores de guerra com o país).

Charaña acabou não favorecendo a Bolívia. O governo chileno precisou consultar o governo peruano para tentar solucionar o enclausuramento boliviano. As exigências de ambos aniquilaram as chances da Bolívia aceitar a proposta. Eram elas: por parte do Peru, a trinacionalidade para a região a ser cedida; o Chile por sua vez exigia uma compensação territorial equivalente ao espaço a ser disponibilizado à Bolívia, além de disponibilizar o rio Lauca, para que fosse instalada uma hidroelétrica, e a Bolívia seria proibida de militarizar esta região. A opinião pública boliviana se opôs. Após o fracasso de Charaña, as relações diplomáticas entre os dois países se extinguiram uma vez mais.

Entre os dias 22 a 31 de outubro de 1979, a Bolívia foi o país anfitrião da Assembleia Geral da Organização dos Estados Americanos, e naquela semana de reuniões houve oportunidades de seus representantes discutirem sua questão da falta de soberania ao oceano, o que motivou a composição da Resolução 426, cuja página 56 declara o interesse hemisférico de encontrar uma solução equitativa em que Bolívia obtivesse acesso útil e soberano ao Oceano Pacifico ${ }^{23}$.

\footnotetext{
${ }^{23}$ AG/RES. 426 (IX-0/79). ACCESO DE BOLICIA AL OCENAO PACIFICO. (Resolución aprobada en la duodécima sesión plenaria el 31 de octubre de 1979). LA ASAMBLEA GENREAL, DECLARA: Que es de interés hemisférico permanente encontrar una solución equitativa por lo cual Bolivia obtenga acceso
} 


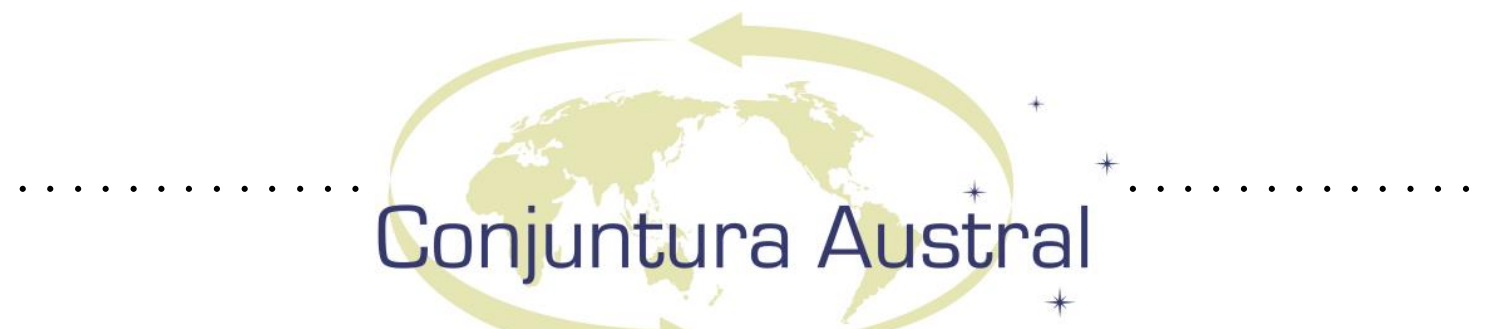

\section{Michelle Bachelet, Evo Morales e o sexto item da Agenda de 13 puntos}

Nos anos 2000, a América Latina passou por uma transformação, e governos considerados socialistas são democraticamente escolhidos para subir ao poder. Apesar de demonstrarem respeito mútuo, Michelle Bachelet, a presidente do Chile entre os anos de 2006 a 2010, e Evo Morales (no mesmo período, e ocupando o cargo até a presente data), presidente da Bolívia, assinaram, em julho de 2010, a Agenda de 13 Puntos $^{24}$.

Esta agenda estava sendo construída entre os ministros das relações exteriores de ambos os países a partir de 2006. Em 2007, o Ministério das Relações Exteriores do Chile publicou em seu site oficial a Ata da XVII reunião entre os representantes de ambos os países. Neste documento consta o que vinha sendo acordado, e apresenta-se o sexto item desta tão aclamada Agenda, chamado de "Tema Marítimo". Este aborda a necessidade de ambos secretários de Relações Exteriores trocarem informações de maneira ampla, franca e realista sobre o assunto e aprofundar o diálogo. O texto não passa de dois parágrafos superficiais sobre o tema, e absolutamente nenhuma palavra indica que algo será realizado a respeito durante os respectivos mandatos:

Logo que seja feito um balanço dos avanços alcançados nas relações bilaterais a partir dos últimos diálogos e tendo em conta as condições que prevalecem tanto no Chile quanto na Bolívia no que diz respeito ao tema e seus possíveis enfoques, ambas delegações concordaram da necessidade de manter o diálogo bilateral em uma perspectiva construtiva com a finalidade de aprofundar as linhas de trabalho que considerem efetivamente os critérios que foram compartilhados ${ }^{25}$.

\footnotetext{
sobreaño y útil al Océano Pacífico, y CONSIDERANDO: Que es necesario conseguir, con espíritu de fraternidad e integración americana, el objetivo señalado en el punto anterior y consolidar una paz estable, que estimule el progreso económico y social en la área de América directamente afectada por las consecuencias del enclaustramiento de Bolivia, RESUELVE: 1. Recomendar a los Estados a los que este problema concierne directamente, que inicien negociaciones encaminadas a dar a Bolivia una conexión territorial libre y soberana con el Océano Pacifico. Tales negociaciones deberán tener en cuenta los derechos e intereses de las Partes involucradas y podrían considerar, entre otros elementos, la inclusión de una zona portuaria de desarrollo multinacional integrado y asimismo, tener en cuenta el planteamiento boliviano de no incluir compensaciones territoriales. 2. Continuar la consideración del tema "Informe sobre el problema marítimo de Bolivia" en el próximo período de sesiones de la Asamblea General.

${ }^{24}$ Agenda de 13 puntos foi estabelecida entre os anos de 2006 e 2010, pelos chanceleres de Chile e Bolívia, que trabalharam na formulação desta agenda cujo o sexto item cita a questão da saída ao mar para Bolívia.

${ }^{25}$ Luego de hacer un balance de los avances logrados en la relación bilateral desde las últimas conversaciones y teniendo en cuenta las condiciones prevalecientes en Chile y Bolivia respecto al tema y sus posibles enfoques, ambas delegaciones coincidieron en la necesidad de mantener el diálogo bilateral en
} 


\section{Conjuntura Austral}

A mídia de ambos os países especularam, ao longo dos anos, de forma bastante analítica, como governos ditos socialistas - neste caso o de Michelle Bachelet e Evo Morales - não ultrapassaram eventuais diálogos, e só aprovaram uma agenda que não foi levada adiante.

Rosales (2011) expôs que durante o centenário do Tratado de Paz e Amizade ocorrido no dia 20 de outubro de 2004, o chanceler boliviano Juan Ignacio Siles do Vale declarou ser favorável a reiniciar as negociações de Charaña estagnadas desde 1978. Porém, houve um comentário que incomodou realmente as autoridades chilenas, tendo sido declarado por um dos ministros bolivianos que um possível novo acordo fosse desta vez realmente de "paz e amizade".

\section{O processo em Haia}

As relações entre os governos de Evo Morales e Sebastian Piñera foram pouco amistosas, com séries de declarações entre ambos os presidentes de cunho ofensivo e degradante. Em 17 de abril de 2014, a Bolívia apresentou suas memórias perante Haia ${ }^{26}$, Evo Morales e sua equipe criaram o plano Diremar, com apoio de historiadores, juristas e especialistas, para montar a demanda que foi apresentada no Tribunal de Haia. O governo boliviano se preocupou em fazer pesquisas para saber qual seria a impressão causada por sua administração na visão de sua nação, bem como pelas estrangeiras, caso apresentassem tal demanda. Tendo tido uma avaliação favorável, o presidente Evo Morales optou por seguir com o processo. Conforme informações do Tribunal, o Chile terá até 18 de fevereiro de 2015 para responder.

Os autores dos Estudos e Investigações Militares do Exército chileno detalharam sobre o funcionamento da Corte Internacional de Justiça, que vem substituir a "Corte Permanente de Justiça Internacional”, criada em 1922, ocorrida junto com o Pacto da

una perspectiva constructiva, con la finalidad de profundizar las líneas de trabajo que consideren efectivamente los criterios que han sido compartidos. (Tradução nossa.)

${ }^{26}$ A apresentação da demanda ao Tribunal de Haya aconteceu no dia 24 de abril de 2013, tendo sido entregue por uma comissão liderada pelo chanceler boliviano David Choquehuanca, de acordo com NÚNES (2014). 


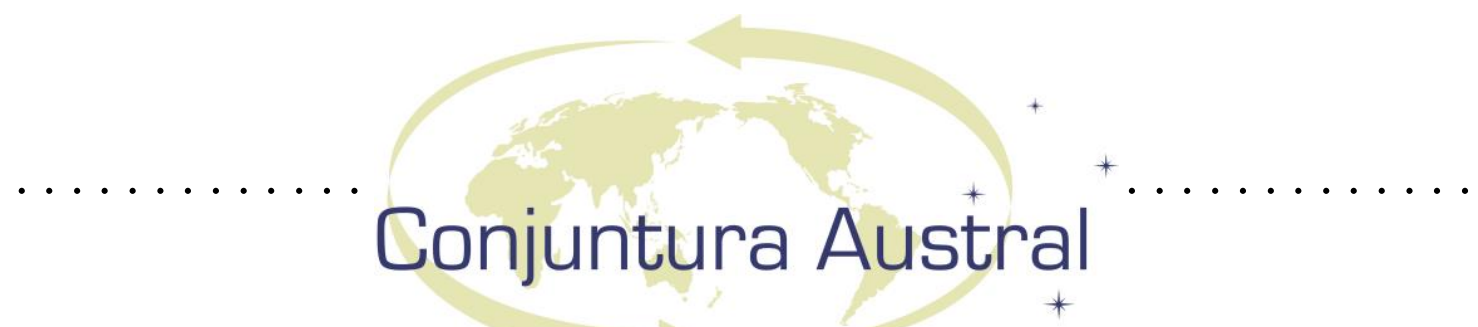

Sociedade das Nações, válido até a Segunda Guerra Mundial, tendo sido, esta organização internacional, o primeiro tribunal designado para resolver as diferenças por meios pacíficos. Entretanto, sua competência era reconhecida na ocasião em que as partes envolvidas em uma disputa deliberavam espontaneamente submeter-se a tal magistratura. Mesmo assim, um Estado poderia assumir previamente seu reconhecimento antecipando futuras disputas. Tal formato cujo ponto de vista era unilateral induzia o comparecimento do outro Estado perante a corte.

Este tribunal internacional é o principal órgão judicial da ONU, de acordo com este documento do exército chileno:

[...] O estatuto que rege seu funcionamento é parte da Carta das Nações Unidas, assim como seu regulamento próprio. Todos os Estados integrantes da ONU são partes do dito estatuto; adicionalmente um Estado membro pode chegar a ser parte deste, previa aceitação expressa de suas regras, pelo compromisso de cumprir as decisões da corte e contribuir para se sustentar. Sua sede está localizada no Palácio de La Paz, Países Baixos ${ }^{27}$. (p. 11)

O documento da Biblioteca Nacional do Chile assegura que a Bolívia nunca possuiu acesso ao mar efetivamente. Algumas destas afirmações mais relevantes sustentam que a Bolívia não participou de nenhuma das batalhas marítimas travadas durante a Guerra do Pacífico, algo que pode ser analisado levando-se em conta apenas a falta de organização do capital boliviana para investir em tecnologia de guerra naquela época.

A Bolívia, em seu Livro Azul, defende que no ano de 1837 criou o Departamento do Litoral, e que este se dividia em duas províncias: La Mar, da qual a capital era Cobija, e Atacama, da qual a capital era São Pedro de Atacama. Afirma que esta região teria em torno de 3.700 habitantes no ano de 1825, quando a Bolívia se tornou independente. Com

\footnotetext{
${ }^{27}$ Este tribunal internacional es el principal órgano judicial de la Organización de Naciones Unidas. [...] El estatuto que rige su funcionamiento es parte de la Carta de Naciones Unidas, así como su reglamento proprio. Todos los Estados integrantes de la ONU son partes de dicho estatuto; adicionalmente un Estado no miembro puede llegar a ser parte de este, previa aceptación expresa de sus reglas, al compromiso de cumplimiento de las decisiones de la corte, y contribuir a solventar sus gastos. Su sede se encuentra en el Palacio de la Paz, en La Haya, Países Bajos. (p. 11) (Tradução livre.)
} 


\section{Conjuntura Austral}

base nisso, pode-se inferir que a população local era demasiada pequena para garantir a soberania local quando os exploradores chilenos chegaram com o capital estrangeiro.

Os analistas e historiadores chilenos afirmam que a Bolívia não teria direito a sua saída para o mar, por ser o país perdedor da Guerra do Pacifico, e que sua demanda em qualquer tribunal internacional fere o tratado de Paz e Amizade de 1904. Além disso, sustentam que não há como mudar a região fronteiriça do país sem consultar o Peru, devido ao Tratado assinado entre Chile e Peru, no ano de 1929. Ramiro Orias (2003) cita em seu artigo que muitas foram as tentativas por parte do governo chileno de ajudar a Bolívia a conquistar a sua saída para o mar, mas que o segundo país não se mostrou interessado em negociar de fato sobre o tema, sempre rompendo as relações diplomáticas entre os dois países.

A doutora em direito internacional Maria Teresa Infante (2004) comenta o que impede estes dois países, hoje, de acordarem sobre a questão marítima. Para ela, falta, por parte da Bolívia, maturidade e consenso de união, enquanto que, no Chile, sobra conservadorismo e incapacidade analítica na sua elite diplomática.

\section{Considerações finais}

Avaliando o que foi dito até aqui, acredita-se que, sim, a Bolívia pode conquistar, através de Haia, uma decisão positiva ao seu pedido de saída soberana ao mar. Caso o resultado seja favorável ao país, pode-se esperar uma grande rejeição por parte do governo e da população chilena, e possivelmente uma resposta violenta. Porém, os autores concordam com o que foi citado nos tratados estudados aqui, quando estes afirmam que este acordo terá que analisar também a situação fronteiriça com o Peru, cuja pretensão de reaver o território de Árica (hoje a última cidade ao norte de jurisdição chilena) está muito viva para a população e seus líderes. 


\section{Conjuntura Austral}

\section{Referências}

AG/RES. 426 (IX-0/79). Acceso de bolicia al oceano pacifico. Noveno Período Ordinario de Sesiones - Actas y Documentos Volumen I. Organización de los Estados Americanos - Asamblea General. La Paz, Bolivia. Del 22 al 31 de octubre de 1979. Disponível em: <http://scm.oas.org/pdfs/agres/ag03793S01.PDF> Acessado em: 19 de junho de 2014.

Chile en el Tribunal Internacional de La Haya. Centro de Estudios e Investigaciones Militares. Memorial del Ejército de Chile, $\mathrm{n}^{\circ}$ 484. Departamento Comunicacional del Ejército. Agosto - 2010.

En torno de los antecedentes de la reclamación marítima boliviana hasta el Tratado de Paz de 1994 entre Chile y Bolivia y dos Negociaciones durante el siglo XX. Depesex/BCN/Serie Estudios, Año XV, n 29. C Biblioteca Del Congresso Nacional de Chile. Santiago de Chile. Ago. 2005. Disponível em: <http://www.bcn.cl/bibliodigital/pbcn/estudios/estudios_pdf_estudios/nro291.pdf> Aces sado em: 12 de abril de 2014.

Evo Morales reinvindica vigência de fallida agenda de 13 puntos com Chile. Mar. 2012. Disponível em <http://www.americaeconomia.com/politica-sociedad/politica/evomorales-reivindica-vigencia-de-fallida-agenda-de-13-puntos-con-chile> Acessado em: 06 de agosto de 2014.

FUNDACION, HANNS SEIDEL. A cien años del Tratado de paz y Amistad de 1904 entre Bolivia y Chile. Fundación Boliviana para la Capacitación Democracia y la Investigación, 2004- Disponível em: <http://www.hss.de/fileadmin/americalatina/Bolivia/downloads/67_A_CIEN_A\%C3\%9 1OS_DEL_TRATADO_DE_PAZ_Y_AMISTAD_DE_1904_ENTRE_BOLIVIA_Y_C HILE.pdf>. Acessodo em: 27 de abril de 2014.

GOVERNO DO CHILE. Acta de la XVII reunión del mecanismo de consultas políticas Chile-Bolivia. Página do Ministerio das Relaciones Exteriores de Chile. Chile. $19 . \quad$ out. $2007 . \quad$ Disponível em: <http://www.minrel.gob.cl/minrel/site/artic/20080716/pags/20080716180444.html>. Ac essado em: 19 de julho de 2014.

WIKIPEDIA. Expedición Libertadora del Peru. Jun. 2014. Disponível em <http://es.wikipedia.org/wiki/Expedici\%C3\%B3n_Libertadora_del_Per\%C3\%BA>, Acessado em: 25 de junho de 2014.

WIKIPEDIA. Provincias Unidas del Río de la Plata. Jul. 2014. Disponível em <http://es.wikipedia.org/wiki/Provincias_Unidas_del_R\%C3\%ADo_de_la_Plata>, Acessado em: 25 de junho de 2014. 


\section{Conjuntura Austral}

WIKIPEDIA. Síntese de Haber-Bosch. Mai. 2013. Disponível em <http://pt.wikipedia.org/wiki/S\%C3\%ADntese_de_Haber-Bosch>, Acessado em: 18 de julho de 2014.

AGRAMONT, Ricardo Aguilar. Se reaviva la oferta de Charaña, y Perú surge como factor clave. La Razón, La Paz, 09, fev. 2014. Disponível em: <http://www.larazon.com/suplementos/animal_politico/reaviva-oferta-Charana-Perufactor_0_1994800576.html>. Acessado em: 14 de abril de 2014.

AGRAMONT, Ricardo Aguilar. De cómo en la demanda marítima triunfó la idea de los 'actos unilaterales'. La Razón, La Paz, 13, abr. 2014. Disponível em: $<$ http://www.la-razon.com/suplementos/animal_politico/demanda-maritima-triunfoactos-unilaterales_0_2032596735.html>. Acessado em: 19 de julho de 2014.

ALMARZA, Alberto Sepúlveda. La Creación de Chile. Santiago de Chile: RIL Editores, 2008.

DOZER, Donald Marquand. América Latina uma perspectiva histórica. Porto Alegre: Globo, 1966.

GALEANO, Eduardo. As veias abertas da América Latina. Porto Alegre. L\&PM, 1970.

GUZMÁN, Alcibíades. Fronteras de Bolivia: Discusión con la prensa de Chile acerca de la soberania de Bolivia en Chilcaya. La Paz: Edición Ordenada Por el Ministerio de Relaciones Externas, 1902.

INFANTE, Maria Teresa. Chile Y Bolivia en cuatro obras. Revista de Estúdios Internacionales. $\mathrm{N}^{\mathrm{o}}$ 148. 2004.

LLOSA, Álvaro Vargas. La Haya y la sombra de Bolivia. La Tercera, Chile. 16, out. 2012. Disponível em: <http://www.analisislatino.com/notas.asp?id=5547>. Acessado em: 19 de julho de 2014.

MARTON, Fabio. A incrível história de como a Bolívia perdeu metade de seu território - e sua saída para o oceano Pacífico. 02 fev. 2012. Disponível em: $<$ http://guiadoestudante.abril.com.br/aventuras-historia/saiba-mais-guerra-pacifico676070.shtml> Acessado em: 25 de junho de 2014.

MOREIRA, Luiz Felipe Viel; QUINTEROS, Marcela Cristina; SILVA, André Luiz Reis da. As relações internacionais da América Latina. Petrópolis: Vozes, 2010. 


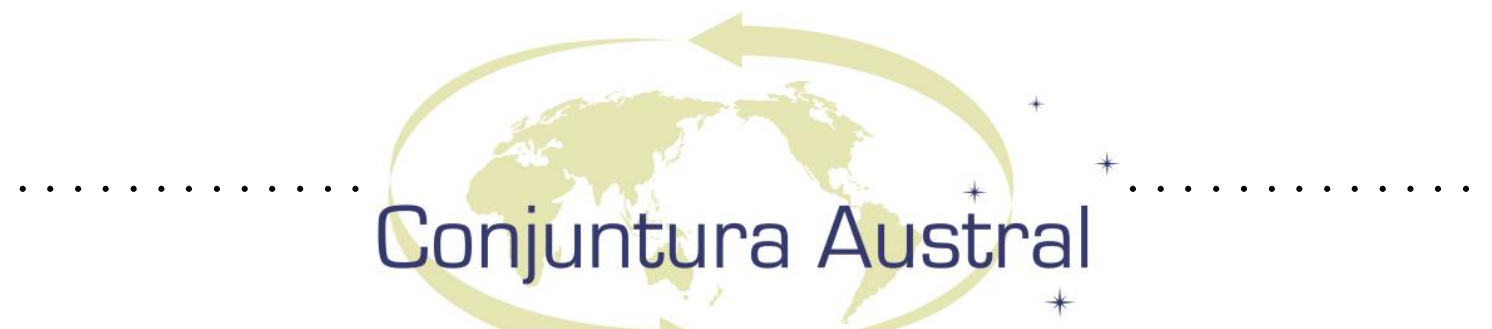

NÚNES, Maria Paz. Las seis frases clave que han marcado la demanda boliviana contra Chile en La Haya. Desde que se presentó la demanda en abril de 2013 hasta hoy, representantes de ambos países han marcado el tono en el que se desarrolla la controversia en la Corte Internacional de Justicia de La Haya.15 jul. 2014. Disponível em: <http://www.latercera.com/noticia/politica/2014/07/674-586888-9-las-seis-frasesclave-que-han-marcado-la-demanda-boliviana-contra-chile-en-la.shtml> Acessado em: 18 de setembro de 2014

ORIAS, Ramiro. Bolivia-Chile: La cuestión de la mediterraneidad. Algunas consideraciones desde el Derecho Internacional. Revista Fuerza Armadas y Sociedad. Año 18. No 1 -2. PP. 51 -73. Diciembre de 2003.

ORTEGA, Luis. Los empresários, la política y los Orígenes de la Guerra del Pacifico. FLACSO - Facultad Latino Americana de Ciencias Sociales. Santiago. No 24. Abril 1984.

ROCA, José Luis. 1904: Un tratado que restableció la Paz pero no la Amistad. Opiniones y Analisis, La Paz, Primera edición, p. 11 - 12, mar. 2004.

REYES, Fernando Siliano. As perdas territoriais do Estado Boliviano (1825 - 1935). GEOUSP - Espaço e Tempo, São Paulo, Edição Especial, pp. 161 - 181, 2009.

ROSALES, Gabriela. Las relaciones chileno-bolivianas durantes los Gobiernos de la Concertación en Chile. Tesis (Grado para Licenciatura en Relaciones Internacionales) Universidad Nacional de Rosario. Fundación para la Integración Federal, Buenos Aires, 2011.

SANTIVÁÑEZ, José María. Bolivia I Chile - Cuestion de Límites. Cochabamba: Imprenta Del Siglo, 1864.

VALDÉS, Julio Cesar. Asuntos Internacionales Bolivia y Chile - Antecedentes Históricos. Discusión Diplomática, - Estado Actual de la Cuestión. Santiago de Chile: Imp. Centro Editorial La Prensa, 1900.

\section{Resumo}

Este artigo procura destacar os principais fatos históricos que levaram a fragmentação das relações bilaterais de Chile e Bolívia, país que perdeu sua saída para o mar. Inicia-se com as pretensões que levaram estes a Guerra do Pacifico, e o texto segue com as tentativas de acordo entre os respectivos presidentes ao longo do século $\mathrm{XX}$, chegando aos dias atuais, expondo a inépcia de proporcionar um acordo que permitisse a Bolívia (por parte do Chile) restabelecer sua soberania ao mar. Ocasionando a exigência boliviana de sua saída ao oceano, em abril de 2013, no Tribunal de Haia

Palavras-chave

Chile e Bolívia; conflito; território 


\title{
Conjuntura Austral
}

\begin{abstract}
This article seeks to distinguish some of the historical events that led to the fragmentation of bilateral relations of Chile and Bolivia, which lost access to the sea. It begins with the claims that led to the Pacific War, and the text continues with the attempts of agreement between the respective presidents throughout twentieth century, reaching the present day, exposing ineptitude to provide an agreement that would allow to Bolivia (by Chile) reestablish their sovereignty to the ocean. Resulting in Bolivian demand for their output to the ocean, on April 2013, on the Hague Tribunal.
\end{abstract}

\section{Keywords}

Chile and Bolivia; conflict; territory

Artigo recebido em 26 de novembro de 2014.

Aprovado em 06 de fevereiro de 2015. 


\section{Conjuntura Austral}

\section{O PAPEL DA COORDENÇÃO DE APERFEIÇOAMENTO DE PESSOAL DE NÍVEL SUPERIOR (CAPES) NA COOPERAÇÃO BRASILEIRA PARA O DESENVOLVIMENTO INTERNACIONAL (COBRADI)}

\section{The role of the Brazilian federal agency for the support and evaluation of graduate education (CAPES) in the Brazilian cooperation for international development (COBRADI)}

Thais Mere Marques Avero ${ }^{1}$

\section{Introdução}

No mundo cada vez mais interdependente, a cooperação entre nações é processo constante e necessário. O Brasil, que até a década de 1970 era apenas receptor da cooperação norte-sul, passa, a partir desse momento, a apoiar a cooperação sul-sul. Nessa primeira fase, as atividades eram pontuais, voltadas para o recebimento de estrangeiros para cursos e capacitação.

A partir da década de 1980, o país começa a, de fato, investir nessa cooperação, financiando bolsas de estudo e apoiando o intercâmbio em cooperação técnica. Importante iniciativa ocorreu em 1987, quando é criada a Agência Brasileira de Cooperação (ABC) pelo Ministério das Relações Exteriores (MRE) visando ampliar a atuação do país nas ações de cooperação com parceiros do sul. Corrêa observa que $o$ Brasil foi, nesse momento, um dos primeiros países não doadores tradicionais a criar um órgão específico para coordenar ações de cooperação internacional para o desenvolvimento (CORRÊA, 2010. P. 177).

\footnotetext{
${ }^{1}$ Doutoranda em cotutela pelo Programa de Pós-Graduação em Desenvolvimento, Sociedade e Cooperação Internacional do Centro de Estudos Avançados Multidisciplinares (CEAM/UnB) e Université Paris 13, mestre em Relações Internacionais pela UnB, analista em Ciência \& Tecnologia da CAPES, Bolsista CAPES. E-mail: taveiro@hotmail.com
} 


\section{Conjuntura Austral}

Com o processo de redemocratização no Brasil e a globalização no contexto mundial, o país ganha cada vez mais projeção como potência regional assumindo relevante papel como interlocutor entre as grandes e pequenas potências e agente promotor da cooperação sul-sul. Atualmente, no Brasil, observamos um número crescente de órgãos da administração pública fomentando a cooperação para o desenvolvimento internacional. As negociações internacionais e a atuação na cooperação sul-sul fazem parte das atividades rotineiras dessas instituições. A capacidade científica, tecnológica, técnica, educacional e material alcançada pelas diferentes instituições brasileiras atenção dos países do sul que demandam cada vez mais o investimento brasileiro para o desenvolvimento dessa região. Hoje, o Brasil é importante provedor de cooperação para o desenvolvimento nas diferentes modalidades de apoio.

Muito embora tenha havido a expansão da cooperação brasileira no eixo sul com ações desenvolvidas pelas diferentes entidades governamentais, não há um órgão centralizador da cooperação sul-sul no país e tampouco um grupo de trabalho que discuta e coordene essas ações. Ao contrário, a cooperação brasileira é marcada pela descentralização da atuação dos órgãos. Como resultado, até o ano de 2009, não era possível averiguar o volume total investido pelo Brasil na cooperação para o desenvolvimento.

Assim, em 2010, reconhecendo a necessidade de se conhecer o total dos investimentos em cooperação prestada, a $\mathrm{ABC}$ e o IPEA (Instituto de Pesquisa Econômica Aplicada), com o apoio da Casa Civil, propuseram a criação de um relatório com todos os valores investidos na Cooperação Brasileira para o Desenvolvimento Internacional (COBRADI). Foi criado, então, um modelo sistematizado para a coleta de informações, haja vista a diversificação da cooperação sul-sul e a inexistência de um método estruturado para aferição dos dados. O levantamento buscou, então, identificar, quantificar e classificar a totalidade dos recursos humanos, físicos e financeiros investidos pelo governo federal brasileiro em outros países e organizações internacionais ao longo do quinquênio 2005-2009². (COBRADI 2005-2009, 2010. p. 12). Desse modo,

\footnotetext{
${ }^{2}$ O período de 2005 a 2009 foi estabelecido para facilitar a busca de dados. Inicialmente, pretendia-se levantar dados de 10 anos (2000-2009), contudo, constatada a dificuldade em se apurar dados mais antigos,
} 


\title{
Conjuntura Austral
}

os resultados da cooperação poderiam ser apurados e melhor direcionados.

Segundo o então presidente, Luiz Inácio Lula da Silva, no prefácio do Levantamento, a COBRADI representa o primeiro passo no sentido de construir uma política de cooperação internacional para o desenvolvimento integrada aos objetivos da política externa brasileira (COBRADI 2005-2009, 2010. p. 12). O relatório é um esforço inédito do governo brasileiro para a consolidação dos dados de cooperação brasileira para o desenvolvimento.

No levantamento, a cooperação brasileira para o desenvolvimento foi definida como:

\begin{abstract}
Totalidade de recursos investidos pelo governo federal brasileiro, totalmente a fundo perdido, no governo de outros países, em nacionais de outros países em território brasileiro, ou em organizações internacionais com o propósito de contribuir para o desenvolvimento internacional, entendido como o fortalecimento das capacidades de organizações internacionais e de grupos ou populações de outros países para a melhoria de suas condições socioeconômicas. (COBRADI 2005-2009, 2010. p. 11.)
\end{abstract}

Essa conceituação buscou contemplar as formas de investimento do Brasil. Muito embora tenha sido criada uma dinâmica própria para o levantamento dos dados, não se deixou de considerar os conceitos tradicionais utilizados para quantificação da cooperação, tendo em vista se permitir a comparabilidade dos dados apurados no país com os demais levantamentos internacionais. No primeiro levantamento, os recursos foram dispostos em cinco modalidades de cooperação: assistência humanitária; bolsas de estudo para estrangeiros; cooperação técnica, científica e tecnológica; contribuições para organizações internacionais; e operações de paz, de acordo com o tipo de cooperação: bilateral e multilateral.

O que o levantamento aponta como bolsas de estudo para estrangeiros no primeiro relatório é uma das modalidades de cooperação mais tradicionais do país. Essa modalidade representou entre 2005 e 2009, quase $10 \%$ do total investido na COBRADI, sendo a segunda modalidade de maior alocação de recursos no período. Já no relatório de

optou-se por um período mais curto. Após o primeiro estudo, foi acordado entre os órgãos participantes que o levantamento passaria a ser anual. 


\section{Conjuntura Austral}

2010, essa cooperação figurou com um percentual de 3,8\% dos gastos. No segundo relatório, essa modalidade passou a ser denominada cooperação educacional, o que melhor reflete a atuação dos ministérios envolvidos nessa cooperação ${ }^{3}$.

Muito embora, entre 2005 e 2008, os investimentos do Ministério da Ciência, Tecnologia \& Inovação tenham superado os investimentos do Ministério da Educação, a partir de 2009, a CAPES passa a ser, a instituição que mais investe na cooperação educacional prestada.

\section{A CAPES e a cooperação educacional}

Fundada em 1951, a CAPES subsidia o Ministério da Educação na formulação de políticas nacionais para as áreas de educação básica, educação à distância e pósgraduação. A agência atua em cinco grandes linhas: formação de recursos humanos de alto nível no País e exterior, avaliação da pós-graduação stricto sensu (mestrado e doutorado), cooperação internacional, acesso e divulgação da produção científica e formação de pessoal qualificado à educação básica (presencial e a distância).

Como parte da missão da instituição, as atividades de intercâmbio e cooperação internacional são essências para a ampliação da competência científico-tecnológica do País. A intensificação dessas atividades pode ser demonstrada pela diversidade de modalidades de fomento que coexistem na agência, variando desde ações de caráter assistencial até atividades de cooperação em parcerias simétricas.

A atuação da Fundação também se pauta pela disponibilização de recursos para atividades, projetos e programas em vários países do mundo. A partir de 2004, a política de cooperação internacional da CAPES passou a dar ênfase à cooperação com países do eixo Sul-Sul, especialmente na América Latina e na África Lusófona.

Assim, em consonância com a política externa brasileira, a CAPES atua de modo crescente na disponibilização de recursos para atividades e programas em vários países do mundo e organizações internacionais no âmbito da Cooperação Brasileira para o

\footnotetext{
${ }^{3}$ As modalidades apresentadas na COBRADI 2010 foram: cooperação técnica, cooperação científica e tecnológica, cooperação educacional, cooperação humanitária, apoio e proteção a refugiados, operações de manutenção da paz e gastos com organismos internacionais.
} 


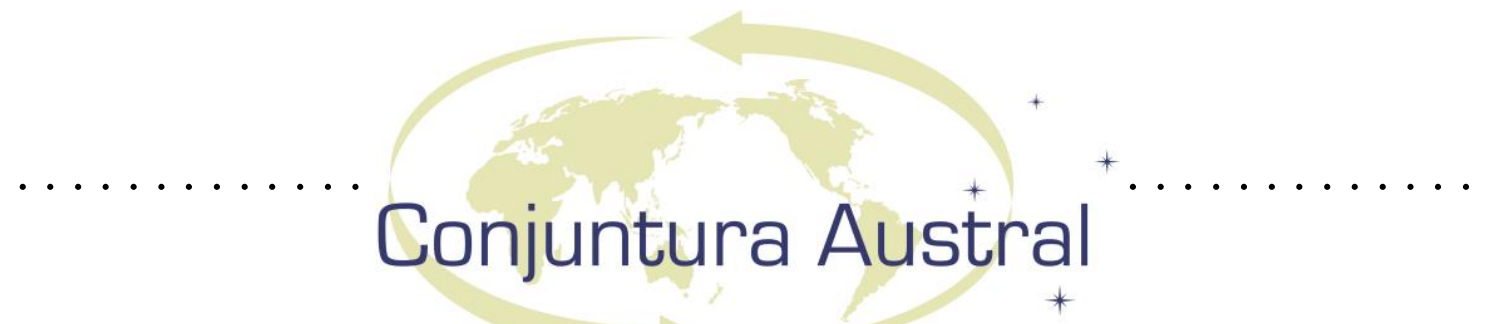

Desenvolvimento Internacional. A Coordenação apoia programas bilaterais e multilaterais com países como Argentina, Cuba, Haiti, Uruguai, Angola, Moçambique, Cabo Verde e Timor Leste, por meio de projetos conjuntos de pesquisa, parcerias universitárias, projetos especiais e bolsas individuais. Por meio desse investimento, o Brasil coopera para a capacitação de novos quadros nos países em desenvolvimento e para a promoção da melhoria da ciência e tecnologia produzida nesses países.

Os programas de cooperação da CAPES buscam potencializar a colaboração entre as universidades. Essa cooperação contribui para a promoção da integração educacional, cultural e científica dos países em desenvolvimento tendo como foco a formação de recursos humanos em todos os níveis de educação. Assim, contribui para o progresso desses países por meio da cooperação e concessão de bolsas de estudo para estrangeiros. Nesse processo, a participação das Universidades é essencial. Segundo Semedo ${ }^{4}$ :

\begin{abstract}
Se os documentos de cooperação rubricados entre os Estados constituem a base para se dinamizar a cooperação, as Universidades são, sem dúvida, as portas que se abrem para novos horizontes, pois como centros de excelência, constituem instrumentos essenciais para a concretização dos projetos e programas, configurando-se como construtoras da massa crítica tão necessária às nossas sociedades. (SEMEDO, 2009, p.119).
\end{abstract}

A cooperação educacional prevê: concessão de bolsas para que estrangeiros complementem sua formação em programas de graduação e pós-graduação no Brasil, capacitação no exterior por equipe brasileira, projetos conjuntos de pesquisa para fomentar o desenvolvimento científico e tecnológico conjunto e também capacitação à distância utilizando-se modelo já consolidado no Brasil.

Em termos de investimentos, a maior forma de fomento é o pagamento direto de bolsas de estudo para estrangeiros. Além dos valores das bolsas, deve ser considerado nessa modalidade, o custo do aluno na Universidade. Outra forma de financiamento é o custeio de professores brasileiros no exterior para capacitação dos locais. O auxílio a pesquisador (AUXPE) para fomento à cooperação científica e tecnológica é outro meio de repasse de recurso. Utilizando-se a experiência de ensino à distância, a agência passou,

\footnotetext{
${ }^{4}$ SEMEDO, Maria O. da C.Soares. Revisitando a cooperação Brasil/África face aos desafios dos novos tempos. In. Estudos de Sociologia. Rev. Prog. Pós-Graduação da UFPE, 2009, v. 15, n.2, p. 107-120. p.119
} 


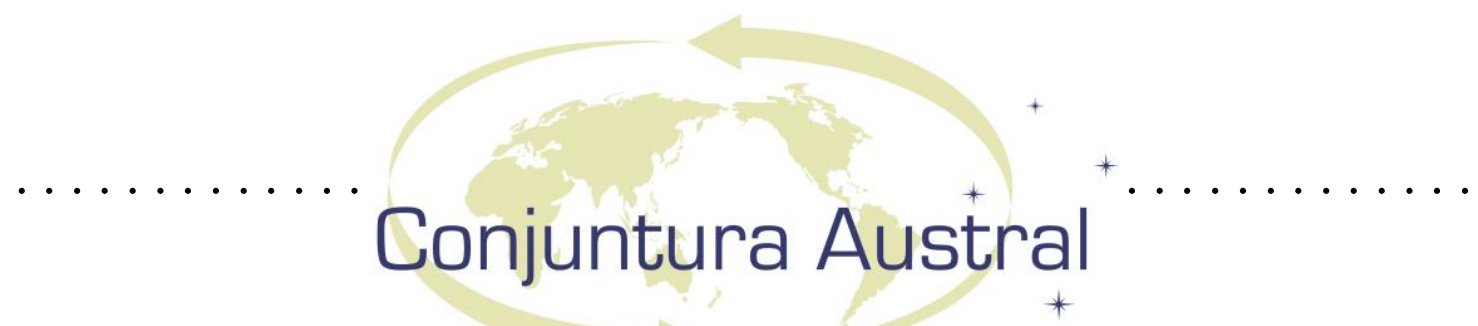

a partir de 2010, a implementar a essa modalidade no exterior por meio da Universidade Aberta do Brasil, disponibilizando infraestrutura, capacidade técnica e também financiando coordenadores, professores e tutores nos polos de apoio presencial. Além do repasse direto, é importante também mencionar o apoio à consolidação de cursos de pósgraduação no exterior e os custos indiretos para a disponibilização da cooperação como horas técnicas, passagens, diárias e pagamento de auxílio à avaliação educacional aos consultores que atuam nos projetos.

O primeiro e principal programa da Fundação na Cooperação Educacional para o Desenvolvimento Internacional é o Programa de Estudantes-Convênio de Pós-Graduação (PEC-PG). Desde sua criação em 1981, a CAPES vêm investindo cada vez mais na cooperação sul-sul e no estabelecimento de programas que atendam as demandas desses países.

\section{Principais programas de cooperação educacional da CAPES para o desenvolvimento internacional ${ }^{5}$}

O PEC-PG 6 é uma parceria entre a CAPES, o CNPq e o MRE, envolvendo países de quatro continentes. O programa visa incrementar a qualificação de professores universitários, pesquisadores, profissionais e graduados do ensino superior de países em desenvolvimento com os quais o Brasil mantém Acordo de Cooperação Cultural e/ou Educacional. Prevê-se, no PEC-PG, a concessão de bolsas de mestrado e doutorado em todas as áreas de conhecimento. Nesse programa, são financiadas bolsas aos alunos estrangeiros para o custeio de despesas como moradia e alimentação no Brasil. Ademais, inclui-se no valor investido, o custo-aluno na Universidade. A CAPES é responsável pelo financiamento das bolsas de doutorado, as bolsas de mestrado são financiadas pelo CNPq

\footnotetext{
${ }^{5}$ Informações obtidas nos relatórios de gestão da agência (2002-2012) e no Relatório de Gestão 20042011.

${ }^{6}$ Os países participantes do PEC-PG são: África do Sul, Angola, Argélia, Benin, Cabo Verde, Camarões, Costa do Marfim, Egito, Gabão, Gana, Guiné Bissau, Marrocos, Moçambique, Namíbia, Nigéria, Mali, Quênia, República Democrática do Congo, República do Congo, São Tomé e Príncipe, Senegal, Togo, Tunísia, Antígua - Barbuda, Argentina, Barbados, Bolívia, Chile, Colômbia, Costa Rica, Cuba, El Salvador, Equador, Guatemala, Guiana, Haiti, Honduras, Jamaica, México, Nicarágua, Panamá, Paraguai, Peru, República Dominicana, Suriname, Trinidad e Tobago, Uruguai, Venezuela, China, Índia, Líbano, Síria. Oceania: Tailândia, Timor Leste.
} 


\section{Conjuntura Austral}

e as passagens aéreas pelo MRE. Embora contemple estudantes de diversos vários países, os estudantes beneficiados são, majoritariamente, advindos da América Latina, com destaque para os pós-graduandos da Colômbia.

A parceria do Brasil com a Argentina é histórica. No âmbito da cooperação educacional, o primeiro acordo assinado entre a CAPES e o Ministério da Ciência, Tecnologia e Inovação Produtiva (Mincyt) data de 1998. O convênio prevê a concessão de bolsas por meio da seleção de projetos de pesquisa nas diversas áreas do conhecimento com o objetivo de fomentar o intercâmbio de doutorandos e o aperfeiçoamento de docentes e pesquisadores. Quatro anos após o estabelecimento do primeiro programa, foi criado, em 2002, o Programa Centros Associados de Pós-Graduação Brasil e Argentina (CAPG) entre a CAPES e a Secretaria de Políticas Universitárias (SPU) para o financiamento de parcerias universitárias em nível de pós-graduação. Essas parcerias têm por objetivo a formação de recursos humanos de alto nível nas diversas áreas do conhecimento por meio do fortalecimento e estímulo da associação acadêmica entre os programas de pós-graduação dos dois países e eventual cotutela. Nos mesmos moldes do CAPG/BA, foi lançado em 2007, também em parceria com a SPU, o Programa da CAPES com Centros Associados para o Fortalecimento da Pós-graduação (CAFP) visando incentivar a formação e a consolidação de grupos de pesquisa e criar mecanismos para redução das desigualdades regionais nos programas de pós-graduação de ambos os países. Tanto o programa CAPG quanto o CAFP possibilitaram maior aproximação acadêmica e curricular entre os dois países, promovem a mobilidade de estudantes e pesquisadores e contribuem para o desenvolvimento e a integração regional.

Outro importante programa de apoio à cooperação para o desenvolvimento, também estabelecido em 1998, foi com o Ministério da Educação Superior de Cuba (MES). O programa conta com duas modalidades de financiamento com foco na pósgraduação: projetos conjuntos de pesquisa e programa para formação de docentes cubanos no Brasil. A CAPES apoia projetos de cooperação científica entre Instituições de Ensino Superior (IES) do Brasil e de Cuba nas diversas áreas do conhecimento, visando ao estabelecimento de parcerias entre pesquisadores dos dois países e a formação de recursos humanos qualificados. Oferece, também, bolsas de estudo individuais a 


\section{Conjuntura Austral}

professores universitários cubanos nas modalidades de doutorado sanduíche (realizado em Cuba com um estágio de doutoramento no Brasil) e pós-doutorado.

Com o Uruguai, foi estabelecida, em 2007, parceria com a Universidad de La Republica - UDELAR para apoiar projetos conjuntos de pesquisa e capacitação de docentes, nos mesmos moldes dos programas estabelecidos com Cuba. Essa parceria, além de propiciar maior aproximação entre pesquisadores dos dois países fronteiriços, principalmente na região sul do Brasil, contribui para estreitar os laços de cooperação entre Brasil e Uruguai criando uma agenda positiva em política externa em ambos os lados.

A cooperação multilateral no âmbito do MERCOSUL é também bastante vigorosa. Vários são os programas desenvolvidos pela agência com parceiros do Cone Sul. Desde 2008, a CAPES atua em parceria com a Secretaria de Educação Superior SESU/MEC no âmbito do Programa de Mobilidade Acadêmica Regional em Cursos Acreditados (MARCA), visando à formação de recursos humanos, à circulação acadêmica no bloco regional e à aproximação curricular.

A partir de 2010, ademais do MARCA, a CAPES passou a apoiar uma série de novos programas com os países do Cone Sul, almejando a maior aproximação científica, tecnológica e educacional na região. O Programa de Associação para Fortalecimento da Pós-Graduação (PFPG) apoia a parceria universitária entre IES de países membros ou associados ao bloco para promover a associação acadêmica e o fortalecimento de cursos de pós-graduação na região. Já o Programa Projetos Conjuntos de Pesquisa-MERCOSUL (PPCP) apoia a aproximação de pesquisadores do Cone Sul, nas diversas áreas do conhecimento visando ao maior intercâmbio de estudantes no bloco e também a cooperação científica e publicação conjunta. O Programa de Parcerias Universitárias de Graduação em língua espanhola e portuguesa (PGPE) tem como foco o financiamento de parcerias universitárias nos cursos de Letras - português e espanhol - na modalidade de graduação-sanduíche possibilitando o intercâmbio para estimular o estudo e aperfeiçoamento de ambos os idiomas, bem como possibilitar a aproximação das estruturas curriculares. Além disso, a CAPES também possui o Programa Capes Bolsas de Doutorado para Docentes para professores universitários dos países membros do bloco 


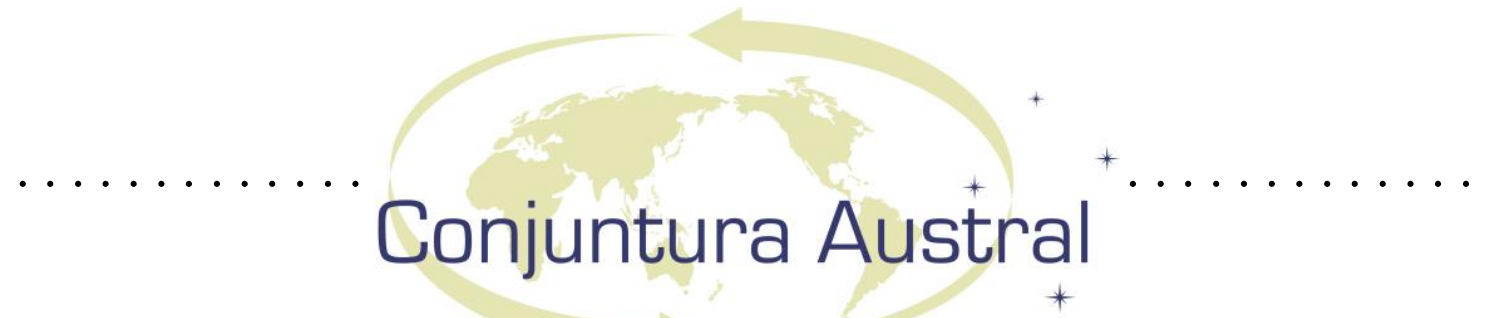

com o objetivo de apoiar a melhoria da qualidade do ensino e da pesquisa das universidades da região e o desenvolvimento sustentável dos membros do MERCOSUL.

Criado em 2010, o programa Pró-Haiti busca a reconstrução, o fortalecimento e a recomposição do sistema de educação superior daquele país após o terremoto. Além da capacitação em língua portuguesa, o Pro-Haiti prevê a concessão de 500 bolsas de graduação-sanduíche no Brasil para estudantes haitianos.

O apoio ao Timor Leste foi iniciado em 2004 com o estabelecimento do Programa de Qualificação de Docente e Ensino de Língua Portuguesa no Timor Leste - PQLP. Criado para fortalecer a língua portuguesa no país, o programa aproximou as duas nações e apoiou a consolidação da República Democrática de Timor Leste. Com o PQLP, são capacitados docentes timorenses nas áreas de antropologia, biologia, economia e métodos quantitativos, educação, educação artística, educação física, física, geografia, geologia, história, informática, matemática, pedagogia, psicologia, sociologia, química e português. O PQLP foi o primeiro programa do Governo Brasileiro a enviar professores para apoiar a formação de docentes no exterior.

Ampla também é a gama de programa de cooperação para o desenvolvimento que a CAPES mantém com países africanos. Em 2004, a CAPES apoiou a criação da universidade pública do Cabo Verde - Uni-CV -, e chefiou, nesse país, um Grupo de Trabalho para iniciar o processo de cooperação educacional. Como resultado, em 2007, foi criado, em parceria com a Universidade Federal do Rio Grande do Sul, sob demanda cabo verdiana, um projeto de Mestrado Interinstitucional Internacional (Minter Internacional), em edificação e planejamento urbano e em sociologia visando fortalecer a Uni-CV e qualificar recursos humanos nessas áreas.

Ainda com Cabo Verde, foi criado, em 2008, o Projeto Linguagem das Letras e dos Números, intitulado Projeto José Aparecido (Português) e Amilcar Cabral (Matemática) para treinar e capacitar professores cabo-verdianos do ensino fundamental e secundário dessas duas licenciaturas. A iniciativa foi tão bem-sucedida que, a partir de 2010, o programa passou também a ser implementado em Guiné Bissau. Em ambos os projetos, a capacitação dos professores é ministrada in loco por professores da Universidade Federal do Ceará (UFC). É ofertado também, um curso intensivo de um 


\section{Conjuntura Austral}

mês no Brasil, em julho, durante as férias escolares.

Outro projeto de destaque que contempla Angola, Cabo Verde e Moçambique é o Programa de Formação Científica (PROFOR) que tem por objetivo incentivar a iniciação científica. Os estudantes selecionados realizam estágio em laboratórios de universidades brasileiras por cerca de três meses - período de férias universitárias. O programa é executado em parceria com o MRE que financiam as passagens aéreas dos bolsistas contemplados. O PROFOR incentiva o amadurecimento acadêmico desses estudantes por meio da pesquisa, o que possibilita o desenvolvimento científico, tecnológico e inovação desses países.

A CAPES também apoia a Fundação Oswaldo Cruz (Fiocruz) na realização de cursos de Mestrado em Ciências da Saúde em Angola e Moçambique. As áreas ofertados são: biologia parasitária, medicina tropical, biologia celular e molecular, e ensino em biociências e saúde. A proposta é qualificar recursos humanos de alto nível para estruturar a pesquisa nessas áreas nos dois países e, assim, capacitar demais profissionais de saúde.

Em 2010, outra iniciativa de grande relevância estabelecida pela CAPES foi a implementação do sistema de educação à distância nos moldes da Universidade Aberta do Brasil (UAB) em Moçambique. O Programa UAB-Moçambique oferta cursos em pedagogia, administração pública e licenciaturas em matemática e biologia. A meta do programa é formar 7 mil professores e servidores da administração pública até 2017. O programa conta com a participação da $\mathrm{ABC}$.

Lançado em 2012, o programa Pró-Mobilidade Internacional de apoio à Associação das Universidades de Língua Portuguesa (AULP) visa fomentar a pesquisa, a docência e a mobilidade nos países de língua portuguesa fortalecendo seus vínculos culturais. Ademais, o AULP pretende estruturar, fortalecer, internacionalizar e consolidar a graduação, pós-graduação e pesquisa dessas universidades, bem como contribuir para a inclusão tecnológica e científica desses países. Além da mobilidade de docentes e pesquisadores, o programa também financia bolsas de estudos na modalidade sanduíche para graduação, mestrado e doutorado. 


\section{Conjuntura Austral}

Os dados abaixo apresentam a evolução dos investimentos da CAPES na cooperação educacional para o desenvolvimento internacional de 2005 a 2010. O gráfico demonstra o crescimento de mais de $100 \%$ nos investimentos feitos no período ${ }^{7}$.

Gráfico 1: Total de investimentos em Cooperação Brasileira para o Desenvolvimento Internacional (2005-2010)

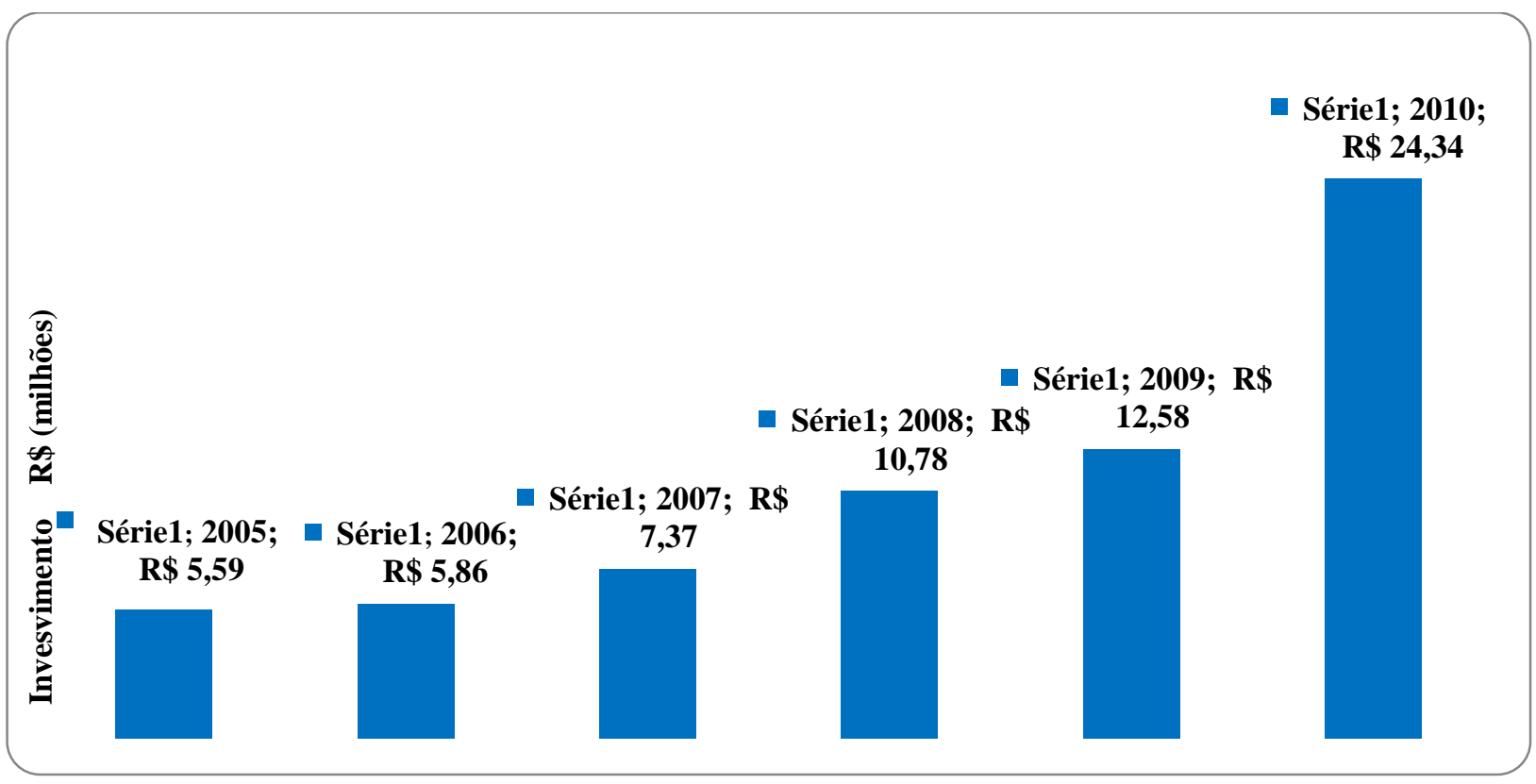

Fonte de Dados: COBRADI/DRI/CAPES

Essa evolução do investimento pode ser constatada também na evolução do número de estudantes financiados. Como já mencionado, foram contemplados estudantes e pesquisa de diversos países em desenvolvimento, com destaque para a América Latina e países de língua portuguesa, conforme demonstrado nos gráficos:

\footnotetext{
7 Ressalta-se, todavia, que os valores apresentados até 2009 não contabilizavam o custo do aluno na universidade. Portanto, o valor real investido entre 2005 e 2009 seria ainda maior. Essa inexatidão foi corrigida a partir de 2010 com a inclusão do valor do custo aluno na Universidade, contabilizado de acordo com os dados do Instituto Nacional de Estudos e Pesquisas Educacionais (INEP).
} 


\section{Conjuntura Austral}

Gráfico 2: Número de bolsistas financiados por ano

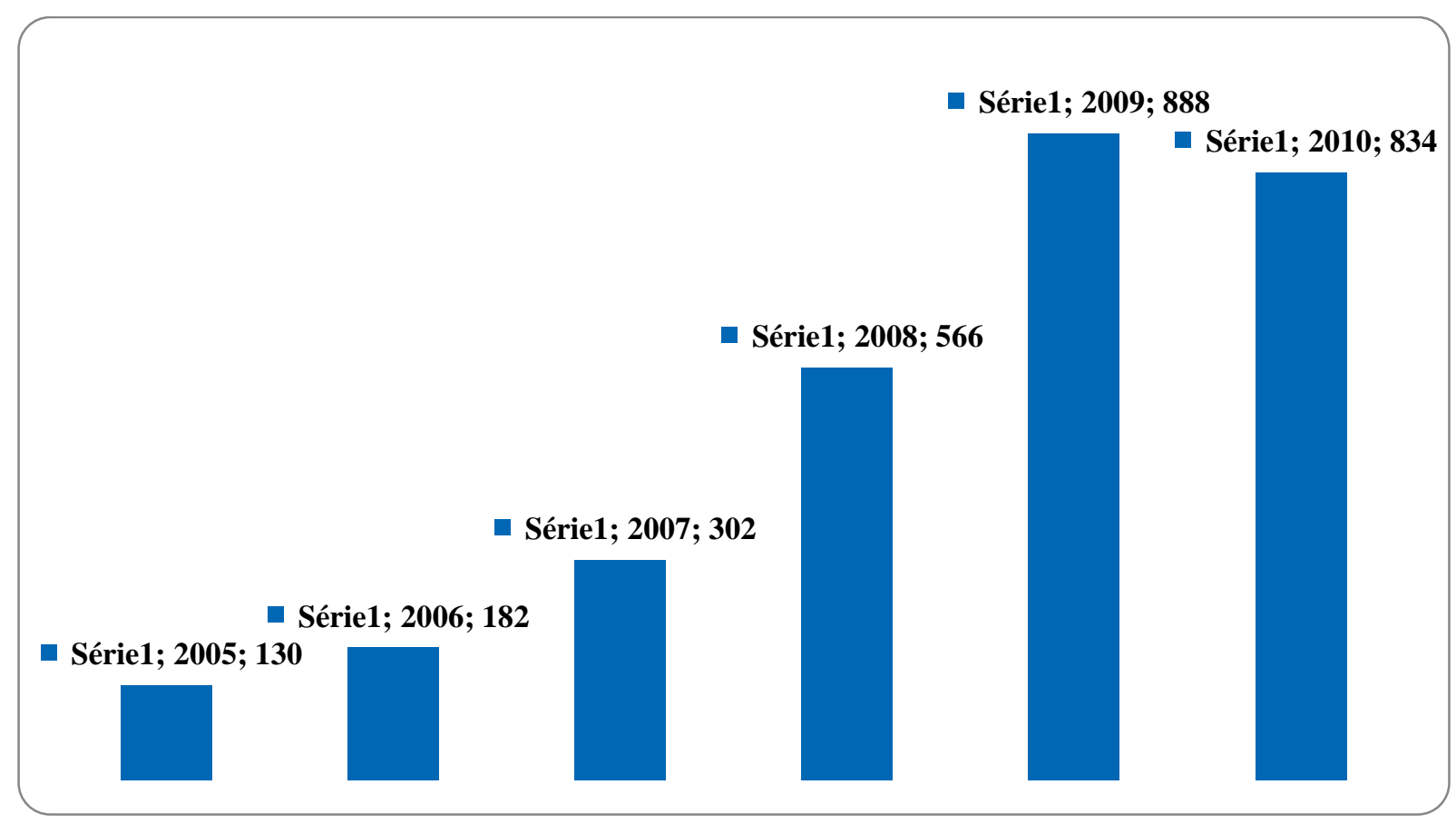

Fonte de dados: COBRADI/DRI/CAPES

Gráfico 3: Número de bolsistas por país ou bloco de país 2005-2010

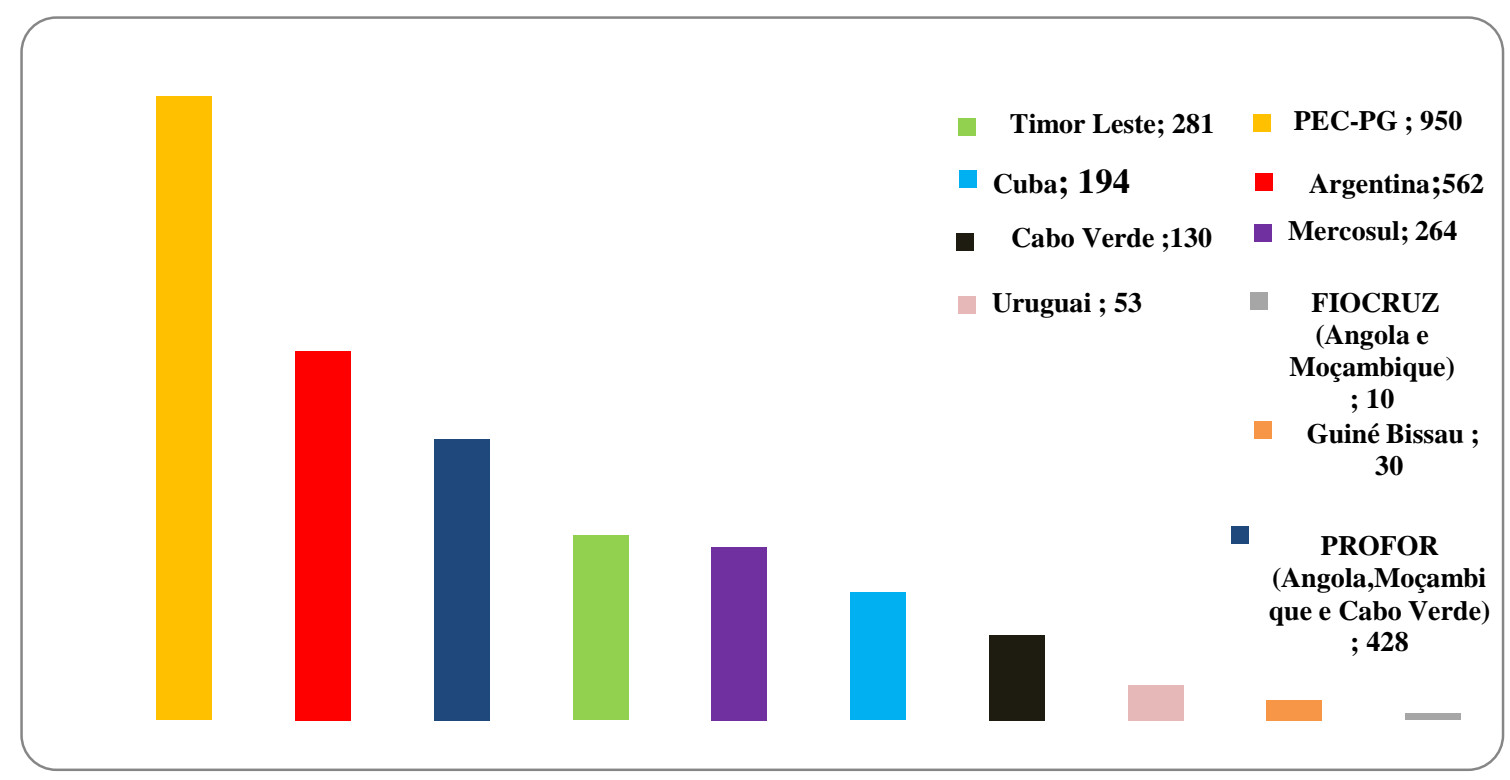

Fonte de dados: COBRADI/DRI/CAPES 


\section{Conjuntura Austral}

\section{Conclusão}

A cooperação internacional é vista como uma forma de se gerar benefícios mútuos para os cooperantes. No caso brasileiro, como princípio fundamental que rege as relações internacionais, a Constituição Federal dispõe:

Art. $4^{\circ}$ A República Federativa do Brasil rege-se nas suas relações internacionais pelos seguintes princípios:

(...) IX - cooperação entre os povos para o progresso da humanidade;

Parágrafo único. A República Federativa do Brasil buscará a integração econômica, política, social e cultural dos povos da América Latina, visando à formação de uma comunidade latino-americana de nações.

Como uma das modalidades de financiamento, a cooperação para o desenvolvimento vem ganhando espaço nas agendas dos diversos órgãos federais visando, como estabelecido na Carta Magna, ao progresso das nações, com especial ênfase aos países latino-americanos e aos países lusófonos. O levantamento da cooperação brasileira para o desenvolvimento tem possibilitado o conhecimento do volume de recursos investidos nessa cooperação o que segundo disposto na COBRADI, pode contribuir para o avanço da política externa nacional, da cooperação Sul-Sul do país e dos esforços globais para a redução da fome e da pobreza rumo ao desenvolvimento internacional sustentável. (COBRADI 2005-2009, 2010, p. 17). Desse modo, Corrêa argumenta que:

\footnotetext{
A cooperação para o desenvolvimento atua como instrumento capaz de alterar e elevar níveis de vida, promover o crescimento sustentável e contribuir para o desenvolvimento social. Em um mundo de agudas desigualdades e assimetrias de toda ordem, como particular ênfase para os alarmantes índices de pobreza e de fome, a cooperação internacional revela-se um instrumento indispensável e mesmo irrecusável para que nações compartilhem de seus conhecimentos, recursos e capacidades no sentido de catalisar processos de desenvolvimento, no limite de suas possibilidades. (CORRÊA, 2010, p.235).
}

O maior mérito do levantamento é consolidar os gastos do governo brasileiro nas diferentes formas de cooperação internacional apoiadas pelo país. A COBRADI veio justamente para que os vários órgãos da administração pública compilassem suas atividades de cooperação. A cada edição busca-se o aprimoramento da metodologia e da 


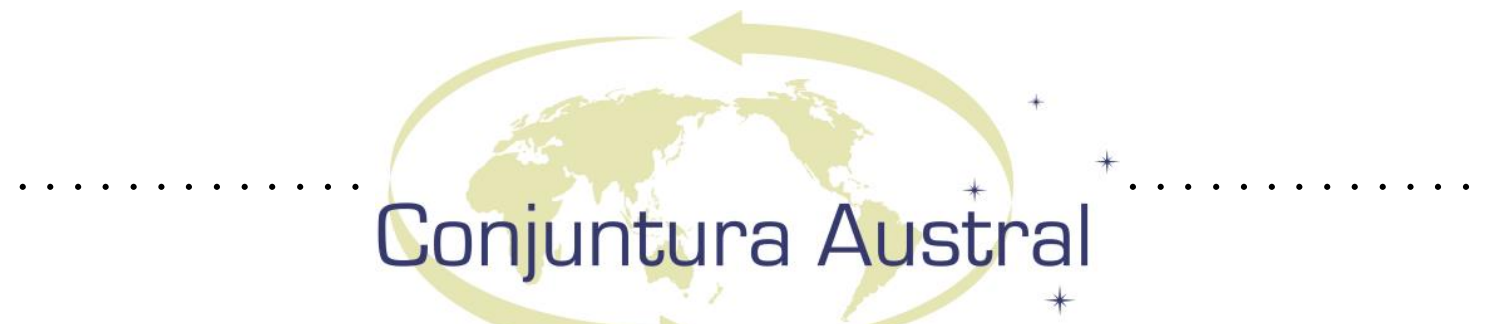

informação prestada. O relatório apresentou grandes melhorias de uma edição para outra. Apesar dos avanços positivos, os dados de 2011 ainda não foram divulgados. Há, todavia, expectativa de que o levantamento tenha continuidade, ainda que irregular. Mesmo que isso não ocorra, o passo inicial foi dado no sentido da criação de uma cultura institucional para apuração dos O levantamento é, sem dúvida, instrumento para auxiliar as instituições a melhor direcionar seus esforços na cooperação para o desenvolvimento. E, hoje, um dos maiores desafios colocados aos órgãos é dar continuidade ao projeto, mesmo que isoladamente.

Para a CAPES que vem ampliando e diversificando suas ações para o desenvolvimento internacional ${ }^{8}$, o levantamento auxilia, em grande medida, na definição da agenda. Nesse sentido, o relatório dispõe: No que se refere à CAPES, as diretrizes institucionais devem: priorizar programas de cooperação que favoreçam a intensificação das relações do Brasil com seus parceiros em desenvolvimento, principalmente com os países de interesse prioritário para a política externa brasileira; e assistir tecnicamente países com deficiências no ensino superior. (COBRADI 2010, 2013, p. 47).

Como uma das principais agências de fomento educacional do país, a CAPES vem atuando no sentido de apoiar o estabelecimento de parcerias entre universidades e institutos de pesquisa para promover por meio da cooperação, o desenvolvimento científico e tecnológico dos países receptores. Na cooperação brasileira para o desenvolvimento, a instituição tem relevante papel na modalidade educacional. Desde 2009, a CAPES é o órgão federal que mais investe nessa área. Hoje, mais de 50\% dos investimentos totais em cooperação educacional são realizados pela agência. Entre 2005 e 2010, houve um crescimento substantivo nos aportes da agência para essa cooperação. Os gastos da agência, com a cooperação para o desenvolvimento, nesse período (20052010), foram de R \$66.513.113,10. Esses dispêndios ocorrem majoritariamente na forma

\footnotetext{
${ }^{8}$ O Presidente da CAPES, Jorge Almeida Guimarães, anunciou no dia 23 de maio de 2014, o Programa "CAPES África" que "será um 'clone' da nossa Capes ou algo semelhante com o mesmo modelo". Serão montados, pelo Banco Mundial, centros de pesquisa em 10 países africanos que contarão com o apoio da CAPES, conforme informações disponíveis em: http://www.brasil.gov.br/educacao/2014/05/presidenteda-capes-recebe-homenagem-e-anuncia-capes-africa . Acessado em: 23 de julho de 2014.
} 


\section{Conjuntura Austral}

de bolsas de estudo, mas também são incluídas no cálculo horas técnicas de servidores e consultores; passagens e diárias; materiais e equipamentos que porventura sejam disponibilizados; eventuais suprimentos e demais custos administrativos associados quando houver.

Essa cooperação visa à capacitação de recursos humanos tanto no Brasil quanto no país apoiado. Ela se concretiza por meio da oferta de bolsas para estudantes estrangeiros em IES brasileiras, treinamento no próprio país de origem por equipe brasileira e capacitação à distância utilizando-se o modelo de sistema de universidade aberta do Brasil. Todo o esforço é implementado por servidores da agência, apoiados, geralmente, por acadêmicos. O suporte do parceiro no exterior também é fundamental.

A expectativa é de crescente incremento desse fomento. Essa iniciativa demonstra o empenho brasileiro na cooperação educacional e científica sul-sul, ferramenta fundamental para redução das assimetrias regionais e promoção e multiplicação dos avanços que estão sendo obtidos no Brasil.

Para os países em desenvolvimento, a cooperação é elemento essencial para sua inserção internacional. Nas palavras do ex-chanceler, Antônio Patriota, a cooperação internacional não é um fim em si mesmo. Por trás dos números e das metodologias aqui apresentados, estão nações e vidas humanas em busca de desenvolvimento econômico e social, com reflexos positivos sobre as sociedades e sua inserção na comunidade internacional. (COBRADI 2010, 2013, p.9). No caso da modalidade de cooperação educacional, seu maior mérito é a formação de capital humano para fortalecimento de organizações e instituições dos países apoiados.

Traço presente na política externa brasileira é o compromisso em contribuir para a promoção do desenvolvimento global, com ênfase na América Latina e em países de língua portuguesa. $\mathrm{O}$ crescente investimento das diferentes entidades do governo federal na COBRADI permite que o Brasil promova cada vez mais cooperação para o desenvolvimento dos parceiros, impulsione mudanças estruturais em suas economias, levando a um crescimento sólido que garanta inclusão social e respeito ao meio ambiente. Nesse sentido, a CAPES, como principal agente de promoção da cooperação educacional para o desenvolvimento internacional, tem relevante papel nos esforços do país para o 


\section{Conjuntura Austral}

desenvolvimento da ciência, tecnologia e melhoria dos níveis educacionais dos parceiros do eixo sul visando ao desenvolvimento internacional sustentável.

\section{Referências}

BRASIL. Constituição (1988). Constituição da República Federativa do Brasil. Brasília, DF: Senado Federal, 1988.

BRASIL. Ministério da Ciência, Tecnologia e Inovação. Livro Branco: Ciência, Tecnologia e Inovação. Brasília. MCT\&I, 2002.

Brasil. Ministério da Educação. Coordenação de Aperfeiçoamento de Pessoal de Nível Superior. CAPES (1952 a 1964). Boletins informativos (n. 01 ao 145). Documentos Disponíveis na Coordenação de Gestão de Documentos - CGD/ CAPES.

CAPES (1952 a 1964). Relatórios de atividades - Anos: 1953 a 1964. Documentos disponíveis na Coordenação de Gestão de Documentos - CGD/ CAPES.

CAPES. Relatórios de Gestão (2002-2009). Brasília, DF: CAPES. Disponíveis em: www.capes.gov.br

CAPES. Relatório de Gestão 2004-2011. Brasília, DF: CAPES, 2011.

BRASIL. Ministério das Relações Exteriores Agência Brasileira de Cooperação. Formulação de Projetos de Cooperação Técnica Internacional (PCT): Manual de Orientação. MRE. 2.ed. Brasília, 2004.

CAMPOS, Rodrigo P.; LIMA, João B. B.; GONZALEZ, Manuel José F. Questões conceituais em metodológicas sobre os estudos da cooperação brasileiras para o desenvolvimento internacional. In: Boletim de economia e política internacional IPEA. n.1, (jan./mar. 2010). Brasília: Ipea. Dinte, 2010.

Cooperação brasileira para o desenvolvimento internacional: 2005-2009. Instituto de Pesquisa Econômica Aplicada, Agência Brasileira de Cooperação - Brasília: Ipea: ABC, 2010.

Cooperação brasileira para o desenvolvimento internacional: 2010. Instituto de Pesquisa Econômica Aplicada, Agência Brasileira de Cooperação - Brasília: Ipea: ABC, 2013.

CÓRDOVA, Rogério de A. CAPES: origem, realizações, significações (1951-2002). Brasília: [s.n], 2003. 


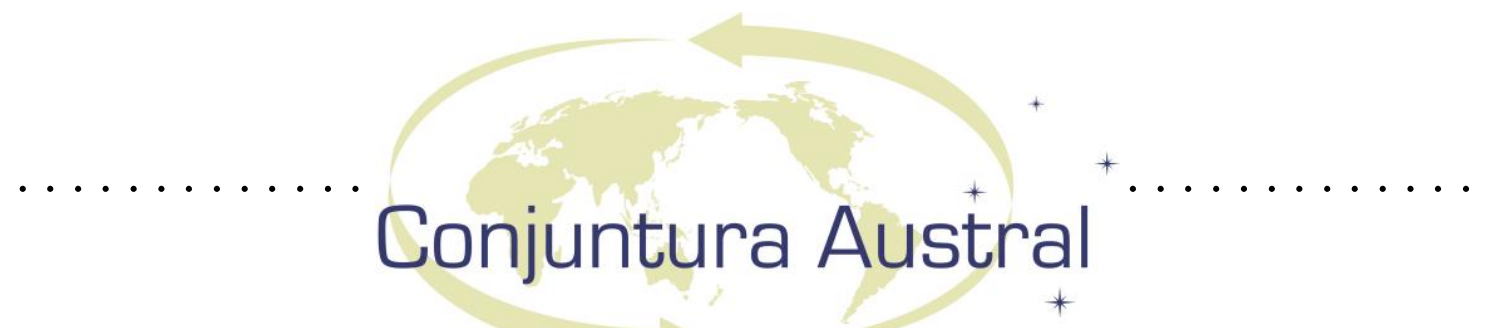

CORREA, Márcio L. Prática Comentada da Cooperação Internacional. Entre a hegemonia e a busca de autonomia. Brasília. [s.n.], 2010

KEOHANE, Robert; NYE, Joseph. Power and Interdependence. N.Y.: Longman, 1989.

LOPES, Luara L. A. L. O Brasil no regime da cooperação internacional para o desenvolvimento: quoi de neuf? In: $3^{\circ}$ ENABRI 2011, São Paulo. Disponível em: http://www.proceedings.scielo.br/scielo.php?script=sci_arttext\&pid=MSC00000001220 $11000300008 \& \operatorname{lng}=$ en \&nrm=abn. Acessado em: 13 de julho de 2014.

MARCOVITCH, Jacques (Org.). Cooperação Internacional: estratégia e gestão. São Paulo: Ed. USP, 1994.

OLIVEIRA, Camila D. C. A Cooperação para o Desenvolvimento no Governo Lula. $1^{\circ}$ Seminário Nacional de Pós-Graduação em Relações Internacionais. 2012, Brasília. Disponível em: http://www.seminariopos2012.abri.org.br/site/capa. Acessado em 14 de junho de 2014.

SEMEDO, Maria O. C. S. Revisitando a cooperação Brasil/África face aos desafios dos novos tempos. In. Estudos de Sociologia. Rev. Prog. Pós-Graduação da UFPE, 2009, v. 15, n.2, p. 107-120.

TOUVAL, Saadia; ZARTMAN, I. William. International Cooperation. USA. Ed. Cambridge, 2010.

\title{
Resumo
}

$\mathrm{O}$ artigo dedica-se a apresentar os dispêndios da CAPES com a cooperação para o desenvolvimento internacional a partir do relatório COBRADI. O estudo confirma a relevância da modalidade de cooperação educacional nesse fomento e a importante atuação da agência nesse processo, principalmente, por meio da concessão de bolsas a estrangeiros.

Palavras-chave

Cooperação Educacional; Desenvolvimento; CAPES

\begin{abstract}
The article is dedicated to present the outlay of CAPES with cooperation for international development based on the COBRADI report. The study confirms the relevance of the educational cooperation and the important role of the agency in this process, mainly through granting of scholarships to foreigners
\end{abstract}

Keywords

Educational cooperation; Development; CAPES

Artigo recebido em 31 de agosto de 2014. Aprovado em $1^{\circ}$ de fevereiro 2014. 


\title{
Conjuntura Austral
}

\section{OS (DES)ENCONTROS NAS RELAÇÕES ENTRE O BRASIL E O MÉXICO DE 2003 À 2013: UM BALANÇO PRELIMINAR ${ }^{1}$}

\section{The (mis)matches between Brazil and Mexico of 2003 to 2013: a preliminary balance}

\author{
Tomaz Espósito Neto ${ }^{2}$ \\ Nicole Figueiredo ${ }^{3}$
}

\section{Introdução}

Brasil e México são potências regionais com certa influência no continente americano, isto é "system-affecting states" " (KEOHANE, 1969, p.295-6). São economias de industrialização tardia, com graves problemas econômico-sociais, oriundos das desigualdades sociais. Ambos são considerados "países-chaves" em uma série de temas, como direitos humanos, meio ambiente, negociações comerciais e promoção da democracia na região (FRANCHINI, 2013; HOFMEISTER, 2007). Era de se imaginar que seus interesses internacionais similares, os-aproximassem. No entanto, não é isso que ocorre. Os dois países mantêm uma relação "cordial" de baixo perfil cooperativo, muito aquém de suas potencialidades.

\footnotetext{
${ }^{1}$ Esse trabalho contou com o apoio financeiro da PROPP/UFGD e da Fundect-MS.

${ }^{2}$ Professor Adjunto do Curso de Relações Internacionais da FADIR / UFGD (Universidade Federal da Grande Dourados). Doutor em Ciências Sociais pela PUC-SP. Email: tomazeneto@gmail.com

${ }^{3}$ Estudante do Curso de Relações Internacionais da UFGD. Bolsista Iniciação Científica do CNPq. Email nicolefigueiredo@ hotmail.com.br

${ }^{4}$ Segundo Robert Keohane (1969, p.295-6) system-affecting states são Estados que não podem afetar o sistema internacional sozinhos. No entanto, podem exercer um impacto importante nas relações internacionais por meio de coalizões e/ou grupos e/ou organizações internacionais de cunho global e/ou regionais.
} 


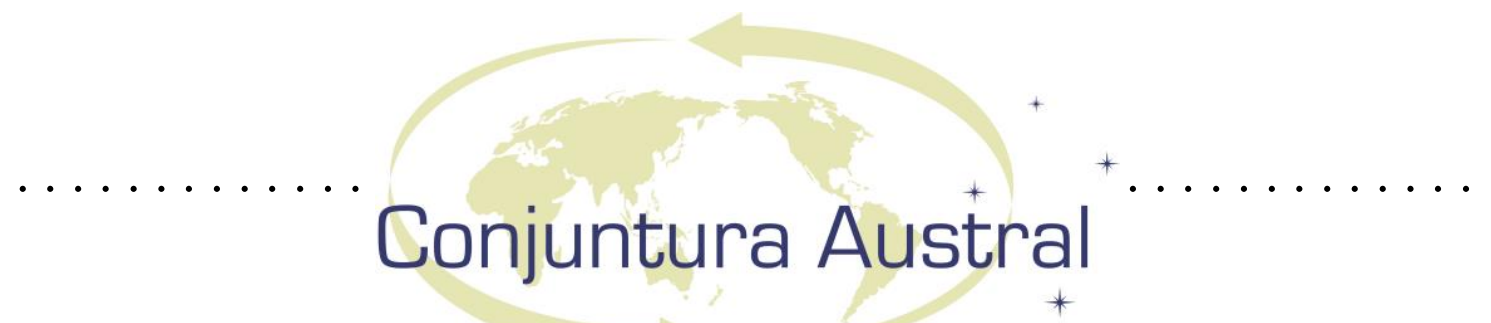

Este artigo objetiva descrever as relações brasileiro-mexicanas entre 2003 e 2013. Com isso, espera-se compreender os possíveis determinantes que impedem um maior adensamento dos laços bilaterais.

Parte-se da hipótese de que o baixo perfil cooperativo das relações brasileiromexicanas se deveu aos seguintes motivos:

(i) Os dois países adotaram diferentes estratégias de inserção internacional, principalmente, a partir dos anos 90. O México optou por uma "inserção atrelada" aos Estados Unidos, principalmente após a assinatura do NAFTA (Tratado Norte-Americano de Livre Comércio) em 1992, e, desde então - na visão de grande parte das autoridades brasileiras, como Samuel Pinheiro Guimarães - tornou-se uma espécie de "protetorado econômico" de Washington e, consequentemente, um empecilho às aspirações brasileiras no cenário mundial (GUIMARÃES, 2013; VIGEVANI; CEPALUNI, 2012). Por seu lado, o Brasil adotou uma estratégia de "autonomia pela diversificação" (CEPALUNI; VIGEVANI, 2007), com o objetivo de, entre outros, reduzir sua dependência do centro político-econômico mundial (RAMOS, 2012).

(ii) As economias de Brasil e México são muito similares, em especial manufaturas intensivas em mão de obra, e com baixo índice de complementariedade. Isto faz com que os produtos de grande parte das empresas dos dois países disputem os mesmos mercados. Quiçá, o maio exemplo seja os produtos automobilísticos. Aliás, esse setor esteve no centro de uma grande polêmica em 2012 (RODRIGUES, 2014).

Faz-se a ressalva de que, após a crise financeira mundial de 2008-9, as autoridades mexicanas procuraram reduzir sua dependência em relação ao seu "grande vizinho do Norte". Para tanto, o México procurou se acercar de outras potências emergentes, como China e Brasil, promovendo também a realização de grandes encontros, como a Comunidade de Estados Latino-Americanos e Caribenhos (CELAC) em 2010. Essas iniciativas foram recebidas com muitas reservas pelas autoridades brasileiras, que percebem o Estado mexicano muito mais como rival do que como potencial parceiro (VIGEVANI; CEPALUNI, 2012, p.124; VIGEVANI et al., 2014).

Nesta pesquisa, optou-se pelo método histórico-descritivo: foi feita a análise de uma bibliografia selecionada e de documentos e dados estatísticos disponíveis nos sites oficiais dos países, além de entrevistas com diplomatas mexicanos ${ }^{5}$ sediados em Brasília.

\footnotetext{
${ }^{5}$ Dr. Guillermo de J. Palacios y Olivares (Conselheiro para Assuntos Culturais e Educativos da embaixada do México no Brasil) e o Secretario Julio César Martínez (Encarregado dos assuntos econômicos da embaixada do México no Brasil). A entrevista, feita pela pesquisadora Nicole Figueiredo, ocorreu no dia 09 de maio de 2014 na Embaixada do México em Brasília, Brasil.
} 


\section{Conjuntura Austral}

A elaboração do texto foi influenciado pelo marco teórico da Escola Francesa (DUROSELLE; RENOUVIN, 1964: MILZA;1996) e do modelo de jogos de dois níveis de Robert Putnam (2010).

Além da introdução e das considerações finais, o presente trabalho divide-se em duas partes: a primeira apresenta uma breve descrição das linhas de inserção internacional adotadas por Brasil e México no período contemporâneo; a segunda aborda as relações entre os dois países no período de 2003 a 2013.

\section{Brasil e México: uma sucinta descrição}

Para uma melhor compreensão das relações brasileiro-mexicanas, é necessário examinar as peculiaridades de cada país e suas respectivas diretrizes de políticas externas nos últimos anos.

Antes de qualquer coisa, deve-se reconhecer a importância do Brasil e do México no Sistema interamericano (HOFMEISTER, 2007). Ambos são tidos como potências intermediárias (FONDEVILA, 2006; ACOSTA et al, 2012) e considerados líderes regionais: o Brasil na América do Sul e o México na América Central (ROSAS, 2008; ÁVILA, 2009; CRUZ; MILANI, 2010).

Brasil e México são os dois maiores países da América Latina. O território brasileiro é de $8.515 .767 \mathrm{~km}^{2}$, enquanto o mexicano apresenta uma área de 1.964.375 $\mathrm{km}^{2}$. Ambos possuem uma vasta população, o Brasil com aproximadamente 199 milhões de habitantes e o México com cerca de 121 milhões (BANCO MUNDIAL, 2012).

Os dois países são grandes democracias representativas, cujas sociedades enfrentam problemas - como a violência - oriundos principalmente das enormes desigualdades socioeconômicas (VELLOSO, 2009; FONDEVILA, 2006). Os Índices de Desenvolvimento Humano (IDH) ${ }^{6}$ são também muito semelhantes: O IDH mexicano é de 0,756, e o brasileiro é de 0,744 (BANCO MUNDIAL, 2014).

\footnotetext{
${ }^{6}$ O Índice de Desenvolvimento Humano (IDH) mede o grau de desenvolvimento econômico e social dos países.
} 


\section{Conjuntura Austral}

No recorte temporal abarcado por este trabalho, a Chefia de Estado do México foi exercida pelos seguintes mandatários: Vicente Fox (2000-2006), do Partido Acción Nacional (PAN), Felipe Calderón (2006-2012), também do PAN, e Enrique Peña Nieto (2012-atual), do Partido Revolucionário Institucional (PRI). São todos políticos de centro-direita, defensores do liberalismo econômico e de um estreitamento de laços com Washington. Já a Presidência da República do Brasil, no mesmo período, foi ocupada por Luiz Inácio "Lula" da Silva (2003-2010) e Dilma Rousseff (2010-atual), ambos correligionários do Partido dos Trabalhadores (PT), grupo de "centro-esquerda" que defende os preceitos do "nacional-desenvolvimentismo" e um afastamento político ideológico em relação ao "Ocidente”, em especial aos Estados Unidos (GARCIA, 2013; GUIMARÃES, 2006, 2008; FLORES, 2007; DÚRAN, 2012).

Brasil e México são países de economia capitalista em desenvolvimento, e seus processos de industrialização ocorreram na metade do século $\mathrm{XX}$, com a adoção de estratégias de substituição de importação. O esgotamento desse modelo de crescimento adveio com a crise da dívida nos anos 80 . Na década de 90, ambos adotaram reformas de cunho liberal na economia (FIORI, 1999).

Tabela 1: Crescimento do PIB entre 2003 e 2013

\begin{tabular}{|l|l|l|l|l|l|l|l|l|l|l|l|}
\hline & 2003 & 2004 & 2005 & 2006 & 2007 & 2008 & 2009 & 2010 & 2011 & 2012 & 2013 \\
\hline Brasil & 1,1 & 5,7 & 3,2 & 4,0 & 6,1 & 5,2 & $-0,3$ & 7,5 & 2,7 & 1,0 & 2,0 \\
\hline México & 1,4 & 4,2 & 3,1 & 5,00 & 3,2 & 1,4 & $-4,7$ & 5,2 & 3,8 & 3,9 & 1,1 \\
\hline
\end{tabular}

Fonte: CEPAL (2014)

A partir dos anos 90, os dois Estados seguiram caminhos diferentes. O México aprofundou as reformas liberais em curso, enquanto o Brasil adotou uma estratégia "neodesenvolvimentista". Essas escolhas também tiveram impactos sobre as estratégias internacionais dos dois países entre 2003 e 2013 ( CHAGAS BASTOS et al, 2012).

O México optou por uma estratégia de "atrelamento" político e econômico com os Estados Unidos, o que é totalmente compreensível para qualquer país que tenha uma fronteira tão grande com a maior potência econômica do mundo. Com isso, as autoridades 


\section{Conjuntura Austral}

mexicanas esperam obter: acesso preferencial ao mercado norte-americano de produtos e de créditos; transferência de tecnologia de ponta e mão de obra qualificada (como no setor aeroespacial e de produtos médicos); redução dos custos políticos de ações internacionais, como nas negociações comerciais; indicações para cargos de direção em organizações internacionais. Essa percepção se confirmou na entrevista do Secretário mexicano Julio Cézar Martinez.

[...] A diferenciação entre Brasil e Mexico acontece quase naturalmente, porque nesta época (a partir dos anos 90) começam, particularmente na área comercial, econômica e de investimentos, um processo mais dinâmico de regionalização, de integração de cadeias produtivas entre países próximos. [...] No caso da América do Norte foi quase natural essa aproximação entre EUA, Canadá e México, porque estão localizados regionalmente em uma posição que favorece [...] (MARTINEZ, 2014)

São marcos dessa estratégia iniciada nos anos 90: a participação do México no Tratado Norte-Americano de Livre Comércio (NAFTA) desde 1994, na Organização Mundial do Comércio (OMC) desde 1995 e na Organização de Cooperação para o Desenvolvimento Econômico (OCDE) a partir de 1994, bem como as condições e termos privilegiados das linhas de crédito oficiais norte-americanas oferecidos à economia mexicana, principalmente durante a grave crise econômica conhecida como "efeito Tequila”, em 1995 (ARBIX, 2002; FAUSTO: HERNANDEZ, 2012; ROCHA, 2003). Aliás, os Estados Unidos e o Canadá absorvem aproximadamente 90\% das exportações e fornecem cerca de 59\% das importações mexicanas, o que explicita a dependência da economia do México em relação aos "irmãos" do Norte (ABREU, 2007). Segundo o Conselheiro Palacios y Olivares:

[...] O argumento do governo era que a integração (NAFTA) já estava dada, apenas não tinha regulamento/regras. Desta forma, a adesão ao tratado teve como intenção formalizar um pouco o que já se estava dando naturalmente de uma maneira que prejudicava o México, mais do que beneficiava [...] (PALACIOS, 2014).

São evidentes os impactos político-ideológicos decorrentes dessa opção do Estado mexicano: o favorecimento de formas liberais de acordos comerciais e de 


\section{Conjuntura Austral}

integração regional acaba privilegiando os aspectos mercadológicos, em detrimento de outros. Isso pode ser percebido no grande número de acordos comerciais firmados pelas autoridades mexicanas e também na criação, em 2012, da Aliança para o Pacífico (AP), uma área de livre-comércio entre México, Peru, Chile e Colômbia. Ademais, o México firmou uma série de acordos bilaterais de comércio com vistas a obter o acesso privilegiado à uma série de mercados. Para tanto, os negociadores mexicanos tiveram de superar uma série de "pré-conceitos" dos demais países da América Latina, conforme ilustra o Conselheiro Palacios y Olivares :

[...] houve países que diziam que o México agora era América do Norte e não mais América Latina. Então, houve um esforço retórico e de discurso muito forte do governo mexicano para dizer que não: "nós continuamos sendo latino americanos, só que temos uma posição geopolítica que se faz impossível não ver o que está acontecendo aqui." [...] Mas o governo mexicano reafirmou constantemente a condição latino americana do México [...](PALACIOS, 2014).

Nesse mesmo período (2003-2013), o Brasil optou pela estratégia da "autonomia pela diversificação" (CEPALUNI: VIGEVANI, 2007), isto é, sob a influência de uma visão estruturalista (GUIMARÃES, 2006), passou a diversificar as parcerias com países da periferia do sistema internacional, também chamado de "Sul Global", para reduzir a dependência dos países centrais, em especial dos Estados Unidos, e, consequentemente, ampliar as margens da ação internacional brasileira. Dentro dessa estratégia, destacam-se a construção de grandes coalizões político-econômicas (como o G20) e de "parceiras estratégicas" com países emergentes, como os BRICS. Além de debates sobre a necessidade de reforma das instituições internacionais, a introdução de temáticas sociais na pauta da agenda global e a consolidação da América do Sul como zona prioritária da ação diplomática brasileira (LESSA, 2010; AMORIM, 2010; SARAIVA;VALENÇA, 2014; RICUPERO, 2010).

Nos últimos anos, as autoridades brasileiras optaram por formas de integração que privilegiam aspectos políticos e sociais, como democracia e direitos das minorias, em detrimento de aspectos mercadológicos. Veiga e Rios (2007) denominam essa forma de integração de "regionalismo pós-liberal". A União de Nações Sul-Americanas 


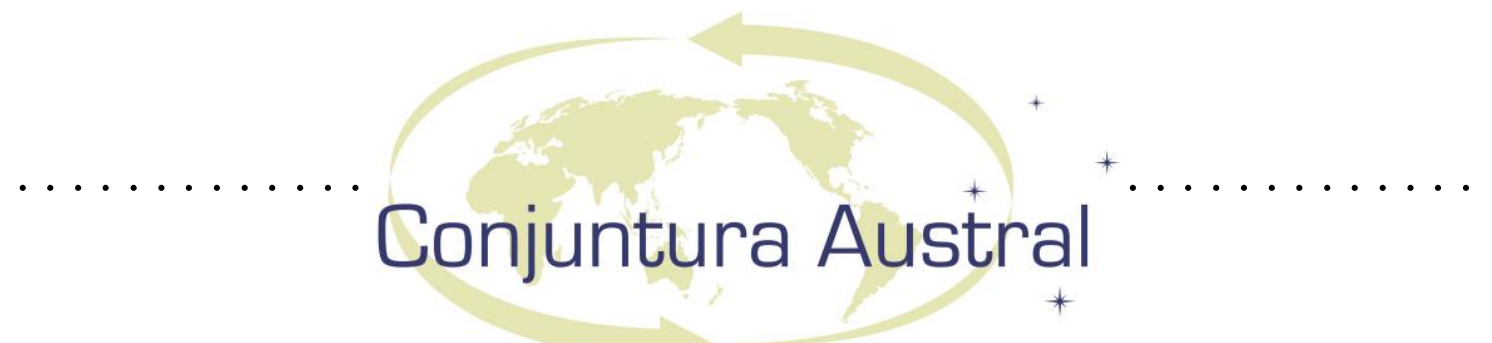

(UNASUL) e os atuais desdobramentos políticos do Mercado Comum do Cone Sul (MERCOSUL) são exemplos dessa opção (VIGEVANI, et al., 2014; SPEKTOR, 2011). Diante do cenário exposto, como se deram as relações brasileiro-mexicanas entre 2003 e $2013 ?$

\section{As relações Brasil-México entre 2003 e 2013}

Historicamente, as relações brasileiro-mexicanas apresentam uma característica pendular: ora se aproximam e ora se afastam, conforme, principalmente, as circunstâncias internacionais (ROSAS, 2008).

Na última década, Brasil e México vivenciaram um momento de afastamento em virtude das "percepções divergentes" das autoridades. O Brasil percebe o México como um obstáculo para sua liderança na América Latina, e, a partir da adesão mexicana ao NAFTA, um protetorado dos Estados Unidos. O México, por seu lado, vê o Brasil como um importante concorrente político e comercial (HOFMEISTER, 2007; RIOS, 2004). Após a assinatura do NAFTA, os produtos mexicanos conquistaram grande parte do mercado norte-americano, o que acabou por afetar fortemente as exportações brasileiras para esse mesmo mercado (MORALES et al, 2012, p. 121).

A postura da diplomacia brasileira, de se autodeclarar líder entre os países da região, sem de fato sê-lo, também incomoda parte da elite mexicana, e isso reflete nas divergências políticas entre os dois países, em especial nas instituições multilaterais (RICUPERO, 2012). A crítica mais ferrenha à postura brasileira foi feita pelo exchanceler Jorge Castañeda, que chamou o Brasil de "Anão diplomático":

Depende do grau de esquizofrenia da política externa brasileira. Um país que quer ser um líder com assento no Conselho de Segurança da ONU, que pretende ter mais peso no Banco Mundial, que desenha para si um papel decisivo na reunião de meio ambiente em Copenhague, pois bem, esse país vai ter que se conformar com certas responsabilidades. Não pode aparentar cumplicidade com radicais. Esse episódio da embaixada em Honduras é um desgaste. É coisa de república de banana [...] o Brasil é um gigante que se comporta como um anão diplomático. O Brasil não gosta de tomar partido em disputas. Então, para quê lutar por um assento no Conselho de Segurança? Para ficar se abstendo em questões difíceis? (CASTAÑEDA, 2009, p. 3-4). 


\section{Conjuntura Austral}

Os dois Estados discordam também sobre uma série de temas, como a reforma das instituições internacionais. Dois bons exemplos dessas divergências são a oposição do México às pretensões do Brasil por um assento no Conselho de Segurança da Organização das Nações Unidas (CSONU) (ROSAS, 2008; RODRIGUES, 2014) e a disputa entre representantes brasileiros e mexicanos pela Direção da Organização Mundial do Comércio (OMC).

Por terem economias similares, Brasil e México concorrem pelos mesmos mercados. A partir da entrada mexicana no NAFTA, as mercadorias mexicanas têm acesso preferencial ao mercado norte-americano, o que acabou por afetar as exportações brasileiras importantes, como da soja e dos manufaturados (RIOS, 2004; BATISTA, 2000).

Além do mais, existem cadeias produtivas, como a automotiva, que são o fulcro de discórdias comerciais entre autoridades brasileiras e mexicanas. Talvez o melhor exemplo disso seja a postura assumida pelo Brasil ao renegociar os termos do Acordo de Complementação Econômica no 55 (ACE-55), em 2012 (pelo acumulo de um déficit brasileiro de US\$1,6 bilhões em 2011, referentes ao comércio bilateral Brasil-México). Que inclusive é o setor que mais movimenta trocas econômicas nesta relação. Ainda, mesmo sendo o maior setor de troca econômica entre países, corresponde a somente 7\% deste setor na economia brasileira. (ANÁLISE BRASIL GLOBAL, 2013)

A despeito dessas divergências políticas, existiu, nesse período, um significativo aumento no número de acordos, direcionados à transferência de tecnologias e à formação e melhoria na qualificação da mão-de-obra dos dois Estados

Tabela 2: Número de novos acordos firmados entre o Brasil e o México entre 2003 e 2013

\begin{tabular}{|c|c|c|c|c|c|c|c|c|c|c|}
\hline 2003 & 2004 & 2005 & 2006 & 2007 & 2008 & 2009 & 2010 & 2011 & 2012 & 2013 \\
\hline 2 & 0 & 0 & 0 & 4 & 0 & 17 & 1 & 0 & 12 & 0 \\
\hline
\end{tabular}

Fonte: DAI/MRE (2014) 


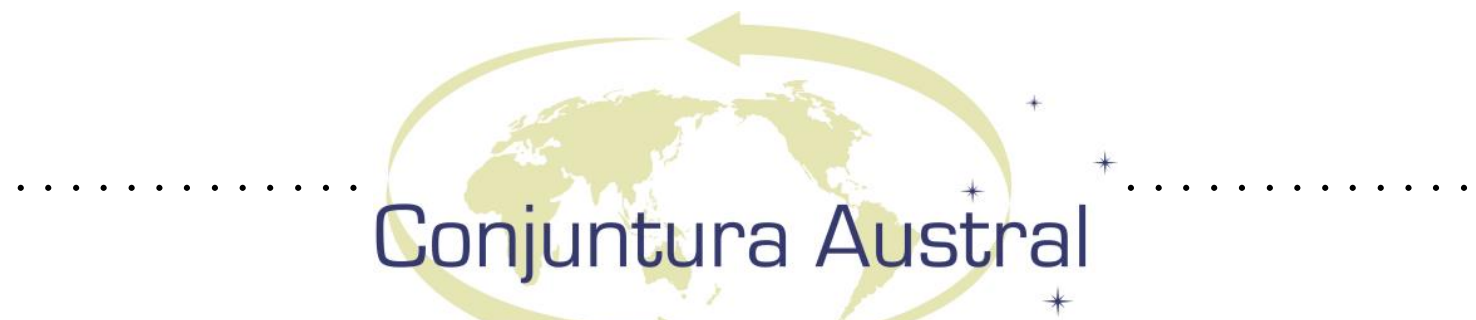

Neste sentido, em 2012 houve um novo aumento dos projetos de cooperação bilateral entre as agências estatais, objetivando principalmente a troca de informações e a transferência de tecnologias referentes aos setores: de energia, como o etanol oriundo da cana-de-açúcar e a retirada de petróleo em águas profundas (ÁVILA, 2009); agrícola, como o manejo de gado e técnicas de irrigação; e de saúde, como a expansão da rede do banco de leite. Apesar desse incremento, os projetos de cooperação entre Brasil e México ainda são poucos, quando comparados àqueles em vigência entre o Brasil e os demais países do mesmo porte na América Latina, como Venezuela e Argentina.

$\mathrm{Na}$ instância multilateral, as autoridades mexicanas organizaram a Cúpula da América Latina e do Caribe (CALC) em 2008, e foram as maiores incentivadoras da constituição da Comunidade dos Estados Latino-Americanos e Caribenhos (CELAC) em 2010. Os temas tratados nesses fóruns são predominantemente políticos e não comerciais (ANYUL et al, 2011; BARRETO, 2012). Percebe-se, portanto, que existe um enorme potencial inexplorado para uma aproximação política entre os dois países. O Secretário mexicano Julio César Martínez corrobora com essa visão.

[..] Particularmente, no aspecto político, nós percebemos que se o Brasil e o México vão juntos, em muitos temas, podemos defender juntos algumas posições. A região inteira vai avançando. Então para nós, o Brasil nos importa muito. Não somente na perspectiva econômico-comercial. [..] além disto, na parte política, nós reconhecemos que, quando o Brasil e o México convergem em suas posições, isso beneficia a América Latina em conjunto. (MARTINEZ, 2014)

Os fluxos comerciais bilaterais cresceram aproximadamente $300 \%$ entre 2003 e 2013 (ver a tabela 3), passando de cerca de USD 3,28 bilhões para aproximadamente USD 10,02 bilhões. Entretanto, o saldo deixou de ser amplamente favorável ao Brasil e passou a ser benéfico para o México (MDIC, 2014).

Em 2013, os principais produtos brasileiros exportados para o mercado mexicano foram automóveis, autopeças e produtos metalúrgicos. Em contrapartida, as importações brasileiras oriundas do território mexicano foram automóveis, autopeças e produtos químicos e petroquímicos. Nota-se, portanto, uma prevalência do comércio 


\section{Conjuntura Austral}

intrafirmas, em especial de grandes multinacionais, de manufaturados de grande valor agregado.

Empresas mexicanas do ramo de alimentação, como a Bimbo e a Del Valle, possuem grandes investimentos no Brasil, estimados em mais de USD 30 bilhões, a maior parte no setor de telecomunicações. Nos últimos anos, esses investimentos externos diretos têm apresentado uma tendência de queda (ANÁLISE BRASIL GLOBAL, 2013; ROSAS, 2008). Já os investimentos externos diretos brasileiros em território mexicano se focaram nos setores intensivos de mão-de-obra, como o têxtil, de móveis e autopeças (ROSAS, 2008), Além do projeto BRASKEM-IDESA, que tem gerado um dos investimentos mais importantes no setor petroquímico, nos últimos anos.

Tabela 3: Intercâmbio comercial Brasileiro-Mexicano

\begin{tabular}{|c|c|c|c|c|c|c|c|c|c|}
\hline \multirow{2}{*}{ Ano } & \multicolumn{3}{|c}{ EXPORTACAO } & \multicolumn{3}{c|}{ IMPORTACAO } & \multicolumn{3}{c|}{ RESULTADO } \\
\cline { 2 - 10 } & US\$FOB (A) & Var.\% & Part. \% & USS FOB (B) & Var.\% & $\begin{array}{c}\text { Part. } \\
\%\end{array}$ & SALDO (A-B) & $\begin{array}{c}\text { CORRENTE } \\
\text { (A+B) }\end{array}$ & $\begin{array}{c}\text { COBERTURA } \\
\text { (AB) }\end{array}$ \\
\hline 2003 & 2.747 .079 .530 & 17,12 & 3,75 & 533.045 .833 & $-8,16$ & 1,10 & 2.214 .033 .697 & 3.280 .125 .363 & 5,15 \\
\hline 2004 & 3.957 .953 .379 & 44,08 & 4,09 & 703.836 .843 & 32,04 & 1,12 & 3.254 .116 .536 & 4.661 .790 .222 & 5,62 \\
\hline 2005 & 4.073 .738 .458 & 2,93 & 3,44 & 843.567 .727 & 19,85 & 1,15 & 3.230 .170 .731 & 4.917 .306 .185 & 4,83 \\
\hline 2006 & 4.458 .202 .270 & 9,44 & 3,24 & 1.310 .320 .093 & 55,33 & 1,43 & 3.147 .882 .177 & 5.768 .522 .363 & 3,40 \\
\hline 2007 & 4.260 .440 .716 & $-4,44$ & 2,65 & 1.979 .284 .005 & 51,05 & 1,64 & 2.281 .156 .711 & 6.239 .724 .721 & 2,15 \\
\hline 2008 & 4.281 .324 .607 & 0,49 & 2,16 & 3.125 .389 .354 & 57,91 & 1,81 & 1.155 .935 .253 & 7.406 .713 .961 & 1,37 \\
\hline 2009 & 2.675 .888 .299 & $-37,50$ & 1,75 & 2.783 .560 .712 & $-10,94$ & 2,18 & -107.672 .413 & 5.459 .449 .011 & 0,96 \\
\hline 2010 & 3.715 .465 .125 & 38,85 & 1,84 & 3.858 .605 .891 & 38,62 & 2,12 & -143.140 .766 & 7.574 .071 .016 & 0,96 \\
\hline 2011 & 3.959 .713 .376 & 6,57 & 1,55 & 5.130 .946 .594 & 32,97 & 2,27 & -1.171 .233 .218 & 9.090 .659 .970 & 0,77 \\
\hline 2012 & 4.003 .013 .124 & 1,09 & 1,65 & 6.074 .916 .685 & 18,40 & 2,72 & -2.071 .903 .561 & 10.077 .929 .809 & 0,66 \\
\hline 2013 & 4.230 .325 .231 & 5,68 & 1,75 & 5.794 .492 .898 & $-4,62$ & 2,42 & -1.564 .167 .667 & 10.024 .818 .129 & 0,73 \\
\hline
\end{tabular}

Fonte: MDIC(2014) 


\section{Conjuntura Austral}

\section{Considerações Finais}

Brasil e México são potências intermediárias, com capacidade limitada de influência no sistema interamericano. Os dois países mantêm uma relação de baixo perfil cooperativo, muito aquém de suas potencialidades.

Isso se deve, aparentemente, às políticas internacionais divergentes dos dois países no período analisado. O México adotou uma inserção voltada ao NAFTA, e à assinatura de outros acordos bilaterais, de cunho liberal. O Brasil, por seu lado, utilizou-se de uma estratégia "nacional desenvolvimentista" com ênfase na ampliação da autonomia internacional. Para tanto, enfatizou a redução da dependência do Estado brasileiro em relação à grande potência do norte, por meio, principalmente, da diversificação das parcerias.

Essas opções decorrem, em grande medida, do perfil ideológico distinto das elites governantes. Ademais, os dois Estados disputam os mesmos espaços político-econômicos no cenário internacional - como cargos em organismos multilaterais - , pois ambos se percebem como os "verdadeiros" líderes da América Latina, disputando os mesmos espaços, não só na área política, como econômica.

Sendo assim, é possível afirmar que estes dois países nunca possuíram uma relação intensa, muito menos uma parceria estratégica. Existe um enorme espaço para uma aproximação política em setores convergentes, tais como Direitos Humanos, promoção da democracia e proteção ao meio ambiente. É necessário, para tanto, que as elites políticas dos dois países (re)pensem as relações brasileiro-mexicanas.

\section{Referências}

ABREU, Marcelo P. Comércio exterior: interesses do Brasil. 1. ed. Rio e Janeiro: Elsevier, 2007.

ACOSTA, Virginia García; OLIVERA, Mercedes; OLIVEIRA, Luís Roberto Cardoso;

RAMOR, Alcida Rita. Diálogos México-Brasil. Desacatos, n. 39, mayo-agosto. Ciudad del México, México, 2012. 


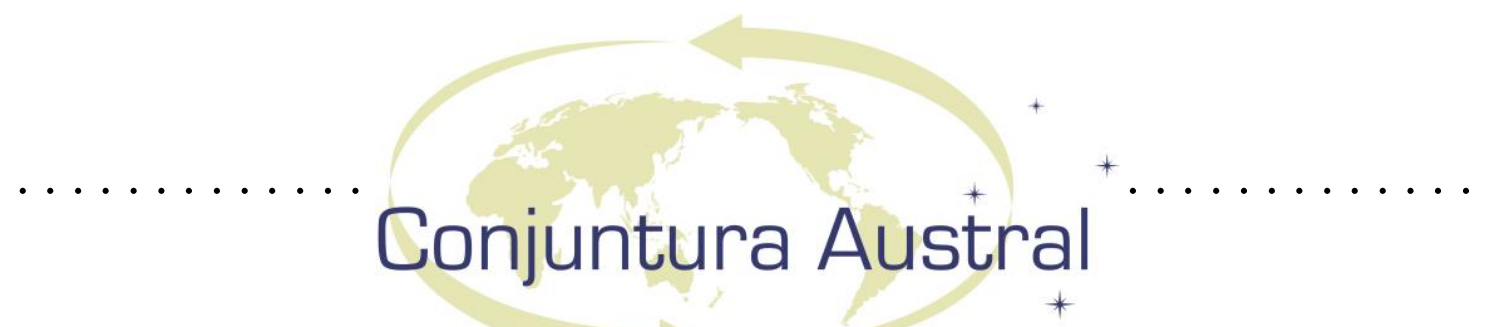

ANÁliSE BRASIL GLOBAL. Anuário 2013. São Paulo. Análise Editorial. 2013. Disponível em: http://www.analise.com/index.php/site/publicacoes/exibe/1/analisebrasil-global Acesso em: 29 jun. 2014.

ANYUL, Martín Puchet; ARAÚJO, Leandro Rocha; DUTRÉNIT, Gabriela; SANZ-

MENENDEZ, Luis; TEUBAL, Morris; CELLI JR., Umberto; MERCADANTE, Araminta de Azevedo. Blocos econômicos e integração na América Latina. 1. ed., 2007, Curitiba: Juruá, 2011.

ARBIX, Glauco. Brasil, México, Africa do Sul, India e China: diálogo entre os que chegaram depois. São Paulo: Editora UNESP: Editora da Universidade de São Paulo, 2002 .

ÁVILA, Carlos Federido Domínguez. El jaguay y el águila: un estudio de las relaciones bilaterales brasileño-mexicanas en los primeros años del siglo XXI. Revista de Relaciones Internacionales de la UNAM, n. 103. Ciudad de México: Ed. UNAM, 2009.

BARRETO, Fernando de Mello. A política externa após a redemocratização. Brasília: FUNAG, 2012.

CHAGAS BASTOS, Fabrício. H.; HARPER, Nicolas. D.; ROCHMAN, Alexandre R. Economia Política da Energia e Encruzilhadas da Integração na América Latina. Monções, Revista de Relações Internacionais da UFGD, v. 2, 2013.

BATISTA, Jorge Chami. Relações comerciais entre o Brasil e o México. Brasília: IPEA, fev. 2000.

CASTAÑEDA, Jorge. Gigante ou anão diplomático. OESP, 27 de setembro de 2009, http://alias.estadao.com.br/noticias/geral,gigante-ou-anao-diplomatico,441726 , acesso em 09 de janeiro de 2014.

CEPALUNI, Gabriel; VIGEVANNI Tullo. A política externa de Lula da Silva: a estratégia da autonomia pela diversificação. Contexto internacional, v. 29, n. 2, jul/dez. Rio de Janeiro: Ed. PUC-RJ, 2007.

CRUZ, María Gabriela Gildo; MILANI, Carlos R. S. A política mundial contemporânea: atores e agendas na perspectiva do Brasil e do México. Salvador:

DÚRAN, Clemente Ruiz. Brasil-México: trayectorias estructurales diferenciadas. Revista de Estudos e Pesquisas sobre as Américas, p. 54-81, v. 6, n. 2/2012. Cidade do México, México: Ed. Universidad Nacional Autónoma de México (UNAM). 


\section{Conjuntura Austral}

DUROSELLE, Jean-Baptiste; RENOUVIN, Pierre. Introduction à l'histoire des relations intenacionales. Paris: A. Colin, 1964.

FAUSTO, Sérgio; HERNANDEZ, José Traslosheros. DEBATES GACINT. Grupo de Análise da Conjuntura Internacional - Instituto de Relações Internacionais. Informativo n. 13. São Paulo: EDUSP, 2012. Disponível em: http://www.iri.usp.br/documentos/DebatesGacint11.pdf. Acesso em: 08 jun. 2014.

FIORI, José L. Estados e moedas no desenvolvimento das nações. 2. ed. Petrópolis, RJ, 1999.

FLORES, Fidel Irving Pérez. Ideologia e política externa do Brasil e do México frente às opções de integração regional (1990-2006). Rio de Janeiro: UFRJ/IFCS, 2007.

FONDEVILA, Gustavo Javier. Educação e pobreza na América Latina. Cadernos Adenauer VII (2006), n. 2. Rio de Janeiro: Fundação Konrad Adenauer, Jun. 2006.

FRANCHINI, Matías. A inserção das potências climáticas latino-americanas na governança global de clima. Um estudo comparado: Argentina, Brasil, México e Venezuela. In: $4^{\mathrm{o}}$ Encontro Nacional da Associação Brasileira de Relações Internacionais, 2013, Belo Horizonte, MG.

GARCIA, Marco Aurélio. Paraguai, Brasil e o Mercosul. Revista Política Externa, v. 21, n. 3, jan-mar. 2013. São Paulo: Ed. Paz e Terra.

GUIMARÃES, Samuel Pinheiro. Entrevista com Samuel Pinheiro Guimarães. RARI, Revista Acadêmica de Relações Internacionais, 3. ed., n. 3, v.1, jul. 2013. Florianópolis: Ed. UFSC, 2013.

GUIMARÃES, Samuel Pinheiro. Desafios brasileiros na era dos gigantes. Rio de Janeiro: Contraponto, 2006.

GUIMARÃES, Samuel. O mundo multipolar e a integração sul-americana. Revista Comunicação \& Política, v. 25, n. 3, 2008.

HOFMEISTER, Wilhelm; ROJAS, Francisco; SOLÍS, Luis Guillermo. La percepción de Brasil en el contexto internacional: perspectivas y desafíos, tomo 2: África, Asia y Europa. Rio de Janeiro: Konrad-Adenauer-Stiftung, 2007.

KEOHANE, Robert O. Lilliputians' Dilemmas: Small States in International Politics, International Organization, N. ${ }^{\circ}$ 23, Madison: Estados Unidos. 1969.

MILZA, Pierre. Política interna e política externa. In: REMOND, René. Por uma historia política. Rio de Janeiro: UFRJ/FGV, 1996. 


\section{Conjuntura Austral}

MORALES, Esther; MEJÍA, Pablo; GUTIÉRREZ, Raul de Jesus; DÍAZ, Miguel Angel; VERGARA, Reyna. Interacciones econômico-financeiras Brasil-México: ? cúal es su grado de integración? In: Perfiles Latinoamericanos, v. 20, n. 39. México, enero/junio 2012. Disponível em: http://www.scielo.org.mx/scielo.php?pid=S01886532012000100005\&script=sci_arttext Acesso em: 29 jun. 2014.

PUTNAM, Robert D.. Diplomacia e política doméstica: a lógica dos jogos de dois níveis. Rev. Sociol. Polit. [online]. 2010, vol.18, n.36. p. 147-174.

RAMOS, Leonardo César Souza. Contra-hegemonia e política externa? A política externa brasileira no governo Lula. Carta Internacional (USP), v. 7, p. 69-86, 2012.

RICUPERO, Rubens. A política externa do governo Luiz Inácio Lula da Silva (20032010). Novos estudos, n. 87, jul. 2010. São Paulo: CEBRAP, 2010.

RIOS, Sandra. Relações comerciais entre o Brasil e o México: oportunidades para a expansão das exportações brasileiras. Brasília: Confederação Nacional da Indústria (CNI), dez. 2004.

ROCHA V., Alberto. México y Brasil en el proceso de integración regional de América Latina y el Caribe:¿Rol de los subhegemones? Liminar. Estudios Sociales y Humanísticos, v. I, n. 1, junio-sin mes, 2003, pp. 26-44. Tuxla Gutiérrez, México: Universidad de Ciencias y Artes de Chiapas.

ROSAS, Maria Cristina. México y Brasil: ¿Buenos enemigos o amigos mortales? Revista Mosaico, v.1, n.1, p.87-105, jan/jun. 2008.

VEIGA, Pedro da Motta e RIOS, Sandra. O Regionalismo Pós -Liberal na América do Sul: origens, iniciativas e dilemas. Santiago, Chile, CEPAL, Divisão de Comércio Internacional e Integración, Série Comércio Internacional, 2007.

VELLOSO, João Paulo dos Reis. A crise global e o novo papel mundial dos BRICS. Rio de Janeiro: José Olympio, 2009.

VIGEVANI, Tullo; RAMANZINI JÚNIOR, H. Autonomia, Integração Regional e Política Externa Brasileira: Mercosul e Unasul. Dados v. 57. (Rio de Janeiro,), 2014.

VIGEVANI, Tullo ; CEPALUNI, Gabriel . A política externa brasileira: a busca da autonomia, de Sarney a Lula. 1. ed. São Paulo: Editora Unesp, 2012.

RODRIGUES, Romário de Avilla. A análise das relações entre Brasil e México através da observação de casos: a reforma do Conselho de Segurança da ONU e o ACE 55. Núcleo Prisma. Santa Maria. UFSM, 2014. Disponível em: 


\title{
Conjuntura Austral
}

http://www.nucleoprisma.org/wp-content/uploads/2014/08/TCC-Brasil-Mexico-v.Final-Rom\%C3\%A1rio-Rodrigues.pdf Acesso em: 29 jun. 2014.

SARAIVA, Miriam Gomes; VALENÇA, Marcelo M. A política externa brasileira e sua projeção internacional: um projeto caracterizado pela continuidade. Rio de Janeiro. Centro Brasileiro de Relações Internacionais. Ano VII, v.1, 2012. Disponível em: http://www.cebri.org/midia/documentos/a_politica_externa_brasileira_final.pdf Acesso em: 29 jun. 2014.

SPEKTOR, Matias. O Regionalismo do Brasil. In: Bernardo Sorj; Sergio Fausto. (Orgs.). Brasil e América do Sul: Olhares Cruzados. Rio de Janeiro: Centro Edelstein de Pesquisas Sociais, 2011, p.141-172.

\section{Resumo}

O presente trabalho objetiva descrever as relações Brasil-México entre 2003 e 2013. Com isso, espera-se compreender os possíveis determinantes que impedem um maior adensamento das relações bilaterais, apesar das similitudes políticas, econômicas e sociais.

\section{Palavras-Chave}

Política Externa Brasileira; Relações Brasil-México; Política Externa Mexicana

\begin{abstract}
The present study aims to describe Brazil-Mexico relations in the period comprising 2003 and 2013. It seeks to understand the possible determinants that prevent a strong bilateral relations, despite political, economic and social similarities.
\end{abstract}

Keywords

Brazilian Foreign Policy; Brazil-Mexico relations; Mexican Foreign Policy

Artigo recebido em 12 de outubro de 2014. Aprovado em 20 de fevereiro de 2015. 
RESENHA

Bookreview

\title{
TRANSFORMING MILITARY POWER SINCE THE COLD WAR: BRITAIN, FRANCE, AND THE UNITED STATES, 1991-2012
}

\author{
Marcus Vinícius Pinheiro Dutra Piffer ${ }^{2}$
}

O livro explora os processos de transformação dos exércitos dos Estados Unidos, do Reino Unido e da França ocorridos entre 1991 e 2012. Embora o título do livro cite a transformação do poder militar, os autores optaram por um recorte que abordasse apenas os exércitos por entenderem que o poder aéreo e naval foram apenas coadjuvantes em relação ao poder militar terrestre nos conflitos que ocorreram durante o período estudado.

Em sua Introdução, o livro explora a crise pela qual as forças militares dos paísesmembros da OTAN mergulharam após a queda do Muro de Berlim e o esfacelamento da União Soviética. Suas forças armadas, preparadas e equipadas para um combate de alta intensidade contra o Pacto de Varsóvia se encontraram repentinamente com um grande excesso de material, sem uma ameaça concreta e sem uma clara ideia de qual seriam as suas missões dali em diante. Dessa forma, se colocaram novos desafios a esses exércitos: para os Estados Unidos, o exército tinha como objetivo se manter à frente dos demais estados que se apresentassem como concorrentes e também fazer frente a oponentes não-

\footnotetext{
${ }^{1}$ FARRELL, T.; RYNNING, S.; TERRIFF, T. Transforming Military Power since the Cold War: Britain, France, and the United States, 1991-2012. Cambridge, UK: Cambridge University Press, 2013. ISBN: 9781107621442

${ }^{2}$ Major do Exército Brasileiro e mestre em Ciências Miltares pelo Instituto Meira Mattos da Escola de Comando e Estado-Maior do Exército. Email: pifferm@gmail.com
} 


\section{Conjuntura Austral}

estatais. Os países europeus visavam manter seus exércitos com capacidades próximas das norte-americanas e atender aos seus compromissos regionais e globais.

Os três exércitos estudados seguiram linhas mestras semelhantes em seus processos de transformação: a mudança de uma estrutura dedicada à guerra continental para uma estrutura expedicionária. Isso resultou na substituição de tropas blindadas por tropas mecanizadas mais leves e da organização em divisões de exército por forças modulares organizadas em escalões menores, como brigadas ou batalhões. Além disso, houve uma intensa "digitização" do campo de batalha e o aumento do emprego dos conceitos de guerra centrada em redes.

O primeiro capítulo trata das transformações ocorridas no Exército dos Estados Unidos. Uma característica desse período foi a restrição dos orçamentos. O processo de encolhimento do Exército americano, que já ocorria desde a década de 1980, se acentuou. O exército passou de uma estrutura com dezoito divisões para a atual, com dez divisões.

O alto-comando do exército americano se preocupou em realizar uma "evolução e não uma revolução", de modo a que os comandos subordinados aceitassem melhor as inovações. Uma questão recorrente nos Estados Unidos é o uso da tecnologia para melhorar a consciência situacional ou mesmo criar a "omnisciência" situacional. Dessa maneira se eliminaria o fog da guerra e a superioridade de informações substituiria a necessidade de grandes efetivos. Notou-se ao longo dos anos foi que a grande quantidade de informações era muito difícil de ser analisada e o que realmente interessava - as reais intenções do inimigo - permanecia desconhecido (MURRAY, 2009). O emprego massivo da tecnologia da informação se mostrou um salto muito grande e, talvez por isso, não atingiu as metas a que se propunha. A reorganização das unidades, teoricamente mais simples, foi efetivamente a indutora das transformações, tornando o exército mais ágil e modular.

O capítulo seguinte trata do Reino Unido. Todo o processo de transformação desse exército é regido por uma premissa básica: a "relação especial" entre Reino Unido e Estados Unidos. Dessa maneira, qualquer que fosse a transformação que fosse realizada, o seu resultado teria que ser um elevado grau de interoperabilidade com o exército americano. Porém, essa interoperabilidade apresenta dois grandes óbices culturais: o 


\section{Conjuntura Austral}

primeiro é o forte tradicionalismo do exército britânico, com uma cultura centrada na autoridade e no homem. Essa atitude não vê com bons olhos a estrutura menos hierarquizada e a troca de informações no sentido horizontal que ocorre na guerra centrada em redes. O outro é o natural ceticismo dos militares britânicos quanto à tecnologia.

A transformação do exército foi planejada sobre grandes projetos. Nenhum deles efetivamente atingiu seus objetivos. Durante todo o período, o ministério da defesa centralizou bastante as mudanças. Esse fato, aliado às grandes limitações orçamentárias, limitou o sucesso dos projetos. Mais recentemente, os comandantes das forças armadas foram colocados num patamar de autoridade equivalente ao do chefe do Estado-Maior Conjunto ${ }^{3}$ e estão com uma maior liberdade para gerir seus projetos e orçamentos.

O último capítulo trata do exército francês. Assim como ocorreu com os britânicos, a transformação francesa teve um resultado bastante diferente do que havia sido visualizado inicialmente. O catalisador para o início da transformação foi a Guerra do Golfo, em 1991. O governo determinou, nessa ocasião, que o contingente francês deveria ser composto exclusivamente por efetivos profissionais. Essa decisão expôs o despreparo francês para a campanha. O serviço militar obrigatório, um aspecto muito caro ao exército francês e que lhe conferiu vantagens em campanhas históricas, se mostrou inadequado, ao menos da maneira que estava sendo conduzido. O planejamento para a transformação foi fortemente baseado na tecnologia, mas dúvidas e controvérsias internas causaram um baixo comprometimento com esse processo. Os franceses se orgulham de sua capacidade de combater "no meio do povo". David Galula é um expoente nesse tipo de ambiente e sua obra ${ }^{4}$ inspirou a atual doutrina americana de contra-insurgência.

O exército francês foi efetivamente moldado pelas operações das quais participou nesse período - com óbvio destaque para o Afeganistão - e não pelos projetos que deveriam realizar essa transformação. Como a participação nessas campanhas foi relativamente modesta, a transformação não foi tão extensa como se planejara inicialmente.

\footnotetext{
${ }^{3}$ Este é um arranjo semelhante ao adotado no Brasil (N. do A.).

${ }^{4}$ Galula (1966)
} 


\section{Conjuntura Austral}

Ao concluir, os autores tratam principalmente da emulação realizada pelos britânicos e franceses para poder combater ao lado dos americanos. Este é um dos aspectos mais interessantes do livro, pois Farrell e Terriff, em estudo realizado uma década antes (FARRELL; TERRIFF, 2002), argumentavam que a emulação era um assunto pouco estudado por ser realizada quase que exclusivamente por países em desenvolvimento. Apesar de citarem os poderes aéreo e naval como coadjuvantes durante esse período, os autores citam, em diversas ocasiões, que as campanhas do Kosovo e da Líbia contribuíram para as transformações citadas. Ambas as campanhas, porém, foram conduzidas quase que exclusivamente por meios aéreos e navais. Durante o caso específico da campanha na Líbia, em 2011, a participação dos exércitos se resumiu quase que exclusivamente aos helicópteros de ataque empregados e ainda assim houve uma enorme diferença entre os procedimentos empregados por britânicos e franceses, refletindo assim os diferentes rumos tomados durante os processos de transformação ${ }^{5}$.

Os três exércitos estudados se tornaram menores, mais leves, tecnológicos e expedicionários. Apesar dessas linhas gerais comuns, nenhum dos programas de transformação implantados foi realizado da maneira que estava inicialmente previsto. Também se viu um processo de emulação conduzido por potências médias, de considerável poder militar, e que não foi bem sucedido por impeditivos culturais: o tradicionalismo britânico e a "crise de consciência" francesa em abandonar aspectos historicamente consolidados em seu exército.

Os autores demonstram claramente que cada processo de transformação é conduzido pelos imperativos culturais da nação e que quando os projetos tendem a fugir desse padrão, dificilmente lograrão o êxito desejado. O Exército Brasileiro atualmente conduz um processo de transformação baseado em projetos indutores, que guarda uma grande semelhança conceitual com os casos citados no livro, notadamente os dos exércitos britânico e francês. Essa característica torna a obra de Farrell, Rynning e Terriff de grande relevância para militares e estudiosos desse processo.

\footnotetext{
${ }^{5}$ Para as operações da aviação do exército francês, v. Ciolette (2012). Para a contrapartida britânica, v. Hoyle (2011) e Ripley (2012).
} 


\section{Conjuntura Austral}

\section{Referências}

CIOLETTE, M. R. Harmattan: A maioridade da ALAT. Pégasus, n. 18, jul. 2012.

FARRELL, T.; TERRIFF, T. (EDS.). The Sources of Military Change: Culture, Politics, Technology. Boulder, CO: Lynne Rienner Publishers, 2002.

GALULA, D. Teoria e prática da contra-rebelião. Rio de Janeiro: Edições GRD, 1966.

HOYLE, C. Libya: British Army details Apache's success. Disponível em: <http://www.flightglobal.com/news/articles/libya-british-army-details-apache39ssuccess-359298/>. Acesso em: 23 out. 2014.

MURRAY, W. Military Adaptation in War. Alexandria, VA: Institute for Warfighting Program, 2009.

RIPLEY, T. British Army Aviation in Action. South Yorkshire: Casemate Publishers, 2012.

Resenha recebida em 03 de novembro de 2014. Aprovada em $1^{\circ}$ de fevereiro de 2014. 


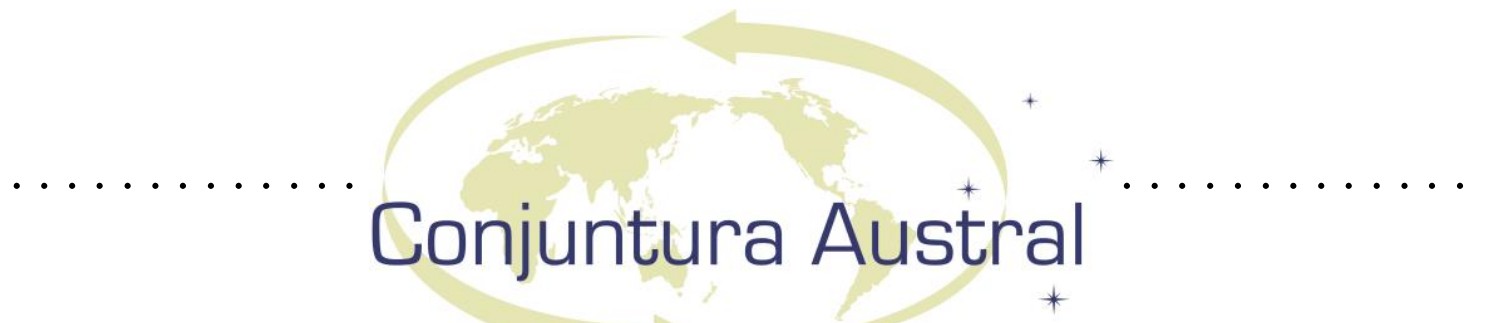

NORMAS DE SUBMISSÃO / Submission Standards

\section{Diretrizes para Autores}

1. A revista CONJUNTURA AUSTRAL publica artigos científicos e resenhas bibliográficas;

2. A revista está dividida em três seções: Conjuntura; Pesquisa e Leitura (resenhas)

3. Os artigos de análise de conjuntura devem conter entre 8 mil e 20 mil caracteres (incluindo espaços) e os artigos de pesquisa devem conter cerca de 35 mil caracteres, as resenhas bibliográficas devem conter cerca de 5 mil caracteres (espaços inclusive);

4. As notas de rodapé restringem-se a esclarecimentos adicionais ao texto;

5. A bibliografia deve ser citada de acordo com o sistema Chicago (Autor, data), referenciando a literatura citada ao final do texto;

6. As contribuições devem ser inéditas e podem ser submetidas em português, inglês ou espanhol;

7. As contribuições devem conter o nome completo do autor, sua titulação e filiação institucional;

8. Admite-se a publicação de estudantes de graduação, desde que em parceria com um professor orientador titulado, que constará como autor principal do trabalho.

9. No caso de resenhas bibliográficas, devem ser informados os dados completos e o ISBN da obra analisada;

10. As contribuições devem vir acompanhadas de: 3 palavras-chave em português e 3 key words em inglês; Título em inglês; Resumo em português e Abstract em inglês, ambos com até 50 palavras.

11. Todas as submissões devem ser feitas através do site da revista : www.seer.ufrgs.br/ConjunturaAustral.

\section{Condições para submissão}

Como parte do processo de submissão, os autores são obrigados a verificar a conformidade da submissão em relação a todos os itens listados a seguir. As submissões que não estiverem de acordo com as normas serão devolvidas aos autores.

1. A contribuição é original e inédita, e não está sendo avaliada para publicação por outra revista; caso contrário, deve-se justificar em "Comentários ao Editor".

2. Os arquivos para submissão estão em formato Microsoft Word, OpenOffice ou RTF (desde que não ultrapassem 2MB)

3. URLs para as referências foram informadas quando necessário.

4. O texto está em espaço simples; usa uma fonte Times New Roman de 12-pontos; emprega itálico em vez de sublinhado (exceto em endereços URL); as figuras e tabelas estão inseridas no texto, não no final do documento, como anexos.

5. O texto segue os padrões de estilo e requisitos bibliográficos descritos em Diretrizes para Autores, na seção Sobre a Revista, no site www.seer.ufrgs.br/ConjunturaAustral.

6. A identificação de autoria do trabalho foi removida do arquivo e da opção Propriedades no Word, garantindo desta forma o critério de sigilo da revista, caso submetido para avaliação por pares (ex.: artigos), conforme instruções disponíveis em Assegurando a Avaliação Cega por Pares.

\section{Author Guidelines}

1. The journal CONJUNTURA AUSTRAL publishes articles and book reviews;

2. The journal is divided in three sections: Conjuncture (Conjuntura), Research (Pesquisa) and Review (Leitura);

3. The conjuncture analysis articles must contain a minimum of 8 thousand and a maximum of 20 thousand characters (spaces included) and the research articles must contain around 35 thousand characters; the book reviews must contain around 5 thousand characters (spaces included);

4. The footnotes should be strictly of a substantive and complementary nature;

5. The bibliography must follow the rules of the Chicago system (Author, date), specifying the used literature at the end of the text;

6. Contributions must be original and can be submitted in Portuguese, English or Spanish;

7. Contributions must contain the full name of the author, their titles and institutional affiliation

8. Publications of undergraduate students are accepted, as long as in partnership with an advisor professor, which will appear as the main author of the work;

9. Book reviews must contain the complete data and the ISBN of the analyzed work;

10. Contributions must be accompanied of: 3 key-words in Portuguese and 3 key-words in English; Title in English; Abstract in Portuguese, Abstract in English, both with up to 50 words.

11. All the submissions should be made through the website: www.seer.ufrgs.br/ConjunturaAustral.

\section{Submission Preparation Checklist}

As part of the submission process, authors are required to check off their submission's compliance with all of the following items, and submissions may be returned to authors that do not adhere to these guidelines.

1. Contributions must be original, and shall not have been submitted for publication in another journal; otherwise, it must be justified in "Comments to the Editor".

2. Submitted files must be in Microsoft Word, OpenOffice or RTF (as long as their size is up to 2MB) format.

3. URLs must be informed in the references when necessary.

4. The text must be single-spaced; Times New Roman typeface 12 pt must be used for the body of the text; italic is to be used instead of underline (except in URL addresses); Figures and Tables must be embedded in the text.

5. The text must follow patterns of style and bibliographical requirements described in Authors Guidelines Author Guidelines, in the section "About the Journal", on the website: www.seer.ufrgs.br/ConjunturaAustral.

The identification of authorship of the work must be removed from the file and the Properties option in Word, thus ensuring the confidentiality criteria of the journal, if it is to be subjected to peer review (i.e. articles), accordingly with available instructions in "Ensuring Blind Peer Review". 


\section{Conjuntura Austral}

\section{INDEXADORES}

Os artigos publicados na Revista Conjuntura Austral estão sumarizados e indexados nos seguintes serviços internacionais (Articles appearing in this journal are abstracted and indexed in the following international services):

- Latindex

- Google Scholar

- Portal de Periódicos UFRGS

- Citas Latinoamericanas en Ciencias Sociales y Humanidades (CLASE)

- Mundorama

- Ulrich's Web Global Serials Directory 